\title{
Stimulus-secretion coupling in pancreatic $\beta$-cells of healthy and diabetic rats in tissue slice preparation
}

\author{
Dissertation \\ zur Erlangung des Doktorgrades der \\ Mathematisch-Naturwissenschaftlichen Fakultäten der \\ Georg-August-Universität zu Göttingen
}

vorgelegt von

Tobias Rose

aus Warburg

Göttingen, 2005 
D7

Referent

Prof. Dr. Erwin Neher

Korreferent

Prof. Dr. Michael Hörner

Tag der mündlichen Prüfung 18.01. 2006 


\section{Contents}

List of Figures iv

List of Tables $\quad$ v

Abbreviations vi

1 Introduction 1

1.1 Physiology of glucose homeostasis . . . . . . . . . . . . . . 1

1.2 The exocrine and endocrine pancreas ............ 2

1.3 Stimulus-secretion coupling in $\beta$-cells .......... 5

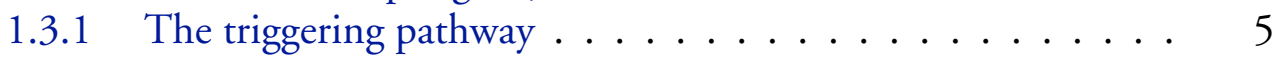

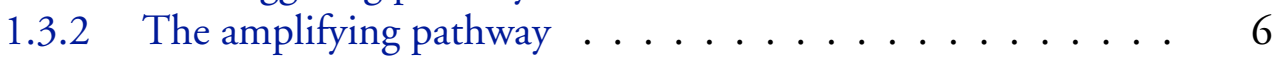

1.3.3 Mechanisms of insulin secretion ........... . 7

1.3.4 Regulation of insulin release by protein phosphorylation . . . 13

1.3.5 Biphasic insulin release .............. 15

1.4 Diabetes mellitus . . . . . . . . . . . . . . . . . 17

1.4 .1 Definition . . . . . . . . . . . . . 17

1.4.2 Etiology of type 2 diabetes . . . . . . . . . . . 18

1.5 Animal models and insulin release . . . . . . . . . . . . . 20

1.5.1 Rodent T2D models . . . . . . . . . . . . . . 21

1.6 Preparations to study insulin release . . . . . . . . . . . . 25

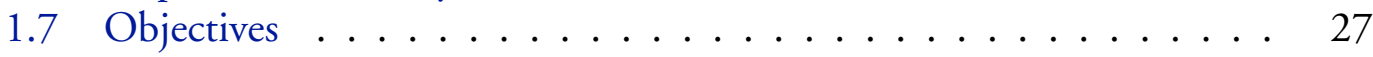

2 Material $\quad 28$

2.1 Animals ............................. 28

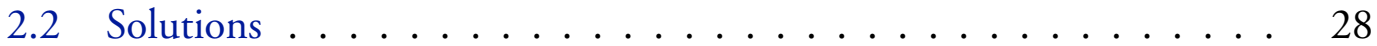

2.3 Preparation of pancreatic tissue slices . . . . . . . . . . . . . . . 29

2.4 Imaging . . . . . . . . . . . . . . . 30

2.4 .1 Immunocytochemistry . . . . . . . . . . . . 30

$2.4 .2 \mathrm{Ca}^{2+}$-imaging $\ldots \ldots \ldots \ldots \ldots \ldots \ldots \ldots$

2.5 Electrophysiology . . . . . . . . . . . . . . 33 
3 Results $\quad 38$

3.1 Characterization of rat pancreatic tissue slices . . . . . . . . . 38

3.1 .1 The rat tissue slice preparation . . . . . . . . . 38

3.1.2 Electrophysiological characterization of rat $\beta$-cells $\ldots \ldots .41$

3.1.3 Exocytotic activity in rat $\beta$-cells ........... 46

$3.2 \mathrm{Ca}^{2+}$-secretion coupling in healthy vs. diabetic rats . . . . . . 50

3.2.1 General characterization of GK rats . . . . . . . . . . 50

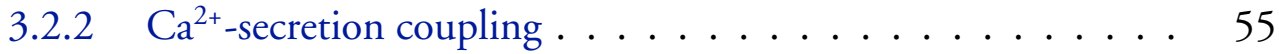

4 Discussion $\quad \mathbf{6 8}$

4.1 The rat pancreatic tissue slice preparation . . . . . . . . . . . 68

4.1.1 Electrical activity in rat $\beta$-cells in tissue slices . . . . . . 70

4.1.2 Whole-cell measurements of insulin secretion . . . . . . . 71

$4.2 \mathrm{Ca}^{2+}$-secretion coupling in healthy vs. diabetic rats . . . . . . . . 74

4.2.1 Increased basal electrical activity and higher $\mathrm{Ca}^{2+}$ current density in GK rat $\beta$-cells . . . . . . . . . . . . . . . 74

$4.2 .2 \beta$-cell hypertrophy . . . . . . . . . . . . . 76

4.2.3 Impaired $\mathrm{Ca}^{2+}$-secretion coupling . . . . . . . . 77

5 Summary $\quad 83$

$\begin{array}{ll}\text { Bibliography } & 85\end{array}$

$\begin{array}{lr}\text { Curriculum Vitae } & 115\end{array}$

$\begin{array}{lr}\text { Acknowledgements } & 117\end{array}$ 


\section{List of Figures}

1.1 Steps involved in the exocytosis of insulin-containing LDCVs . . . 8

1.2 Biphasic insulin release . . . . . . . . . . . . . 16

1.3 Insulin secretion in GK rats . . . . . . . . . . . . . 22

1.4 Preparations used to study insulin secretion . . . . . . . . . 25

3.1 Pancreatic tissue slices . . . . . . . . . . . . . . . . 39

3.2 Islets of Langerhans . . . . . . . . . . . . . . . . . . . . . . . 40

3.3 Cell identification . . . . . . . . . . . . . . 42

3.4 Electrical activity in rat $\beta$-cells . . . . . . . . . . . . 43

3.5 Electrical coupling between $\beta$-cells . . . . . . . . . . . . . 45

3.6 Whole-cell conductance in $\beta$-cells before and after $\mathrm{K}_{\text {ATP }}$ channel inhibition ........................ 46

3.7 Stimulus-evoked exocytosis and $\mathrm{Ca}^{2+}$ influx during whole-cell recording 47

3.8 Exocytosis during stimulation with repetitive pulses . . . . . . . . 49

3.9 Pancreatic tissue slices of diabetic GK rats . . . . . . . . . . 50

3.10 Increased basal electrical activity in GK rat $\beta$-cells . . . . . . . . 51

3.11 Glucose induces similar $\Delta\left[\mathrm{Ca}^{2+}\right]_{\mathrm{i}}$ in healthy and in diabetic rats . . . . 52

3.12 GK rat $\beta$-cells are hypertrophic . . . . . . . . . . . 54

3.13 GK rat $\beta$-cells in tissue slices display enhanced $\mathrm{Ca}^{2+}$ currents . . . . 55

3.14 Exocytosis during repetitive stimulation is impaired in diabetic $\beta$-cells 56

3.15 Exocytosis elicited by depolarizations of progressively longer duration $\quad 57$

3.16 Sizes of release-ready pools are not changed in $\beta$-cells of diabetic rats. 59

3.17 The time course of RRP recovery is similar in Wistar and GK $\beta$-cells . 61

$3.18 \mathrm{Ca}$ influx during train stimulation $\ldots \ldots \ldots 62$

3.19 The apparent $\mathrm{Ca}^{2+}$ sensitivity in diabetic GK rat $\beta$-cells is decreased in a PKC-dependent manner . . . . . . . . . . . . . . . . . .

3.20 GK rat $\beta$-cells show PKC-mediated activity-dependent facilitation of release ......................... 66

4.1 Electrical activity in a GK rat $\beta$-cell during stimulation with $30 \mathrm{mM}$

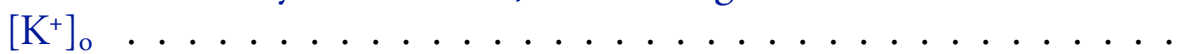




\section{List of Tables}

1.1 Synaptic proteins involved in exocytosis of SVs and LDCVs in neurons and pancreatic $\beta$-cells of healthy and diabetic rats. . . . . . . 24 


\section{Abbreviations}

AC adenylate cyclase

$\mathrm{ACH}$ acetylcholine

AM acetoxymethyl

AMPK adenosin-monophosphate activated protein kinase

ADP adenosin-diphophate

ATP adenosin-triphophate

BSA bovine serum albumin

BIS-1 bisindolylmaleimide I

cAMP adenosin 3', 5'-cyclic monophosphate

$\mathrm{Ca}_{\mathrm{v}} \quad$ voltage-gated $\mathrm{Ca}^{2+}$ channel

CSP cysteine string protein

$\mathrm{C}_{\mathrm{m}} \quad$ membrane capacitance

$\Delta \mathrm{C}_{\mathrm{m}} \quad$ change in membrane capacitance

$\Sigma \Delta \mathrm{C}_{\mathrm{m}} \quad$ cumulative change in membrane capacitance

Cx36 connexin protein of $36 \mathrm{kDa}$

CAPS $\mathrm{Ca}^{2+}$-dependent activator protein for secretion

CNS central nervous system

DAG diacylglycerol

DMSO dimethyl sulfoxide

$E \quad$ exocytotic efficacy $\left(\Sigma \Delta \mathrm{C}_{\mathrm{m}} / \Sigma \mathrm{Q}_{\mathrm{Ca}^{2+}}\right)$

$\mathrm{EC}_{50} \quad$ half maximal effective concentration

$\mathrm{E}_{\mathrm{K}^{+}} \quad \mathrm{K}^{+}$equilibrium potential

EGTA ethylene glycol-bis( $\beta$-amnoethyl ether)-N,N,N',N'-tetraacetic acid

ELISA enzyme-linked immunosorbent assay

G-protein guanine nucleotide-binding protein

GABA $\gamma$-aminobutyric-acid

Glc glucose

GIP glucose-dependent insulinotropic polypeptide

GLP-1 glucagon-like peptide 1

GK Goto Kakizaki

GSIS glucose-stimulated insulin secretion

HCSP highly $\mathrm{Ca}^{2+}$-sensitive pool 
HEPES 4-(2-hydroxyethyl)-1-piperazineethanesulfonic acid

HVA high-voltage activated

IAPP islet amyloid precursor protein

IRP immediately releasable pool

IS intracellular solution

IV Current-voltage

$\mathrm{K}_{\text {ATP }} \quad$ adenosin-triphosphate sensitive $\mathrm{K}^{+}$(channel)

$\mathrm{K}_{\mathrm{d}} \quad$ dissociation constant

LDCV large dense core vesicle

LVA low-voltage activated

MODY maturity-onset diabetes of the young

Munc13-1 mammalian homologue of $C$. elegans unc13-1

Munc18-1 mammalian homologue of $C$. elegans unc18-1 (aka nSec1)

NSF $\quad N$-ethylmaleimide-sensitive factor

PACAP pituitary adenylate cyclase-activating polypeptide

PBS phosphate buffered saline

PDK1 phosphoinositide-dependent kinase 1

$\mathrm{PIP}_{2} \quad$ phosphatidylinositol 4,5-bisphosphate

PKA protein kinase $\mathrm{A}$

$\mathrm{PKC} \quad$ protein kinase $\mathrm{C}$

$\mathrm{PKC}_{\mathrm{c}} \quad$ conventional PKC isoforms $\alpha, \beta \mathrm{I}, \beta \mathrm{II}$ and $\gamma$

$\mathrm{PKC}_{\mathrm{n}} \quad$ novel PKC isoforms $\delta, \epsilon, \eta$ and $\theta$

$\mathrm{PKC}_{\mathrm{a}} \quad$ atypical PKC isoforms $\zeta$ and $\lambda$

PLC phospholipase C

PMA phorbol 12-myristate 13-acetate

RRP readily releasable pool

RIA radio immuno assay

ROI region of interest

SLMV synaptic like microvesicle

$\alpha$-SNAP $\quad \alpha$-soluble $N$-ethylmaleimide-sensitive factor attachment protein

SNAP-25 synaptosomal-associated protein of $25 \mathrm{kDa}$

SNARE soluble $N$-ethylmaleimide-sensitive factor attachment protein receptor

SNP single nucleotide polymorphism

SV synaptic vesicle

T2D type 2 diabetes mellitus

VAMP-2 vesicle-associated membrane protein (aka synaptobrevin-2)

$\mathrm{V}_{\mathrm{m}} \quad$ membrane potential

w/v weight per volume

$[\mathrm{X}]_{\mathrm{i} / \mathrm{o}} \quad$ cytosolic (i) and extracellular (o) concentration of substance $\mathrm{X}$ 


\section{Introduction}

"Insulin is not a cure for diabetes, it is a treatment. It enables the diabetic to burn sufficient carbohydrates [...] to provide energy for the economic burdens of life."

Dr. Frederick G. Banting, Nobel lecture, 1925 (Nobel-Foundation, 1965)

With the discovery of insulin in 1922, Dr. Frederick Banting and his colleagues achieved a major breakthrough in the treatment of a disease that was formerly considered to be an inevitably fatal condition. By injection of insulin they were able to dramatically improve the clinical situation of patients acutely suffering from diabetes mellitus (Banting et al., 1922). The major symptoms of this disease-increased thirst (polydipsia), frequent urination (polyuria) and rapid weight loss-have already been known for more than 2000 years but until then no feasible treatment was possible. However, major steps in understanding the etiology of diabetes have already been made before. Around 400 в.с. an Indian physiologist described the sweet taste of urine of diabetic patients, thus giving the first hint of a defect in carbohydrate metabolism being involved in the disease. Together with the later finding in the closing years of the $18^{\text {th }}$ century that also the serum of diabetic patients tastes sweet this laid the groundwork for today's understanding of the disease: Diabetes mellitus is characterized by an abnormal high level of circulating sugar in the blood. In the beginning of the $19^{\text {th }}$ century this sugar was identified to be the monosaccharide hexose glucose.

\subsection{Physiology of glucose homeostasis}

Glucose is the main energy source for almost all tissues in the body. Especially for the central nervous system (CNS), which consumes $\sim 60 \%$ of the metabolized glucose at 
rest, it is the obligatory energy substrate (Magistretti et al., 1995). Considering this, it is evident that maintaining blood glucose homeostasis is one of the most important tasks of the human body. The concentration of circulating blood glucose in healthy (normoglycaemic) individuals is tightly controlled and ranges between $3.9 \mathrm{mM}$ and $5 \mathrm{mM}$ in the fasting state. Even directly after meals (postprandial state) it rarely exceeds 6.7-7.8 mM (Herman and Engelgau, 2001). The plasma glucose concentration is regulated by two processes: (i) the uptake of sugar from the blood into peripheral tissues and (ii) the release from glucose-producing or -resorbing organs. The most important substance that regulates these processes is the peptide insulin - the only human hormone that is able to decrease the blood glucose concentration. Insulin exerts its hypoglycaemic effect mainly by binding to receptors on its target tissues. In the liver it decreases the glucose output both by inhibiting the de novo synthesis of glucose (gluconeogenesis) and by suppressing the glucose generation from glycogen stores (glycogenolysis). In peripheral tissues insulin mainly increases the glucose-permeability: In skeletal muscle but also in adipose tissue it prominently enhances the recruitment of GLUT- 4 glucose transporters to the plasma membrane. By that insulin facilitates the diffusion of the sugar into the cytoplasm. Whereas there is only one hypoglycaemic hormone, several hyperglycaemic hormones are able to counteract the action of insulin and increase the plasma glucose concentration. Glucagon, catecholamines or growth hormones increase hepatic glucose output by stimulating both gluconeogenesis and glycogenolysis during physiological stress situations like hypoglycaemia (Pickup and Williams, 2003).

\subsection{The exocrine and endocrine pancreas}

In 1889 Von Mering and Minkowski (1890) performed the crucial experiment that inspired the later discovery of the hypoglycaemic effect of insulin: By surgically removing the pancreas (pancreatectomy) of a dog they found that the animal showed clear signs of diabetic polyuria after the operation. By that they clearly demonstrated that the pancreas is involved in the endocrine regulation of carbohydrate homeostasis.

The pancreas is a retroperitoneal organ located posterior to the stomach on the posterior abdominal wall. The adult human organ presents itself as a well defined and 
compact structure with an elongated, tapering gross morphology. In mice and rats, however, the pancreas is more diffusely organized and consists of a body and two lobes: The pancreatic body is located along the cranial part of the duodenum and the right lobe extends into the duodenal ligament, whereas the left lobe extends toward the spleen (Miyaki et al., 1994). Because of its soft structure it is difficult to distinguish rodent pancreas from the mesenteric adipose tissue to which it is tightly associated.

The pancreas is a mixed exocrine and endocrine gland of endodermal origin (Slack, 1995). Its primary exocrine function is to secrete digestive enzymes and enzyme precursors like trypsinogen, chymotrypsinogen, pancreatic lipase and amylase. These proteins are secreted from pancreatic acinar cells which are the most abundant cell type of the organ. The cells that constitute the widely ramified ductal system of the pancreas produce and secrete bicarbonate ions to neutralize the acidic gastric juice at the entrance of the duodenum.

In 1893, endocrine secretion was first suggested to originate from the discrete cellclusters scattered throughout the exocrine tissue of the pancreas, called the islets of Langerhans. Today it is known that insulin indeed is secreted together with other hormones (glucagon, somatostatin, pancreatic polypeptide) from these complex microorgans. In spite of the fact that the endocrine pancreas makes up only $2-3 \%$ of the total mass of the gland, it receives $\sim 20 \%$ of the pancreatic blood flow (Lifson et al., 1985). Furthermore, the islet blood circulation can be prominently enhanced during hyperglycaemic conditions by a mechanism which is under control of the autonomic nervous system (Jansson and Hellerstrom, 1983, 1986; Jansson, 1994).

The adult human pancreas contains about 1 million islets that generally consist of at least four cell types. The insulin-secreting $\beta$-cells comprise $65-80 \%$ of the total islet cell population in humans. The rest is comprised of the glucagon-releasing $\alpha$-cells (15-20\%), the somatostatin-producing $\delta$-cells $(3-10 \%)$ and the smallest group, the pancreatic polypeptide-containing PP-cells ( 1\%) (Rahier et al., 1981). The size of the pancreatic islets is highly variable but the morphology of single islets is relatively uniform. A central core of $\beta$-cells is surrounded by a cortex composed of all four cell types.

The different cell types of the islets of Langerhans are regulated by complex paraand autocrine interactions that are yet not fully understood in their characteristics 
and function. Insulin or other secretory products of $\beta$-cells like $\gamma$-aminobutyric-acid (GABA) or zinc inhibit $\alpha$ - (Rorsman et al., 1989; Ishihara et al., 2003; Ravier and Rutter, 2005; Franklin et al., 2005) and $\delta$-cells (Rouiller et al., 1981), whereas glucagon release from $\alpha$-cells stimulates both insulin (Samols et al., 1966) and somatostatin (Patton et al., 1977) secretion. The latter, in turn, prominently inhibits both $\beta$ - and $\alpha$-cells (Strowski et al., 2000). However, since the microvasculature of the islets directs the blood flow from the afferent arterioles in the $\beta$-cell rich islet medulla to the collecting venules in the mantle region of $\alpha-, \delta$-, and PP-cells, the secretory products of the latter have to pass the systemic circulation to act on the preceding $\beta$-cells (Stagner et al., 1992). Still, it is possible that interstitial paracrine regulation bypasses the microvascular $\beta \rightarrow \alpha \rightarrow \delta$ perfusion direction (Samols and Stagner, 1988). Accordingly, it is not known to which extent many of the reported putative paracrine effects studied by exogenous application of the respective islet cell secretions are able to significantly regulate cellular functions in vivo. For instance, the role of glucagon in the paracrine regulation of insulin release has recently been questioned (Moens et al., 2002). A further local effect of secreted islet cell products is the autocrine inhibition of $\beta$-cells by islet amyloid precursor peptide (IAPP) which is cosecreted with insulin (Tokuyama et al., 1997). In a similar way $\alpha$-cells are positively regulated by endogenously released glucagon acting back on $\alpha$-cell glucagon receptors (Ma et al., 2005).

In addition to the complex chemical cell interactions, the $\beta$-cells of an islet are also able to electrically communicate with each other (Meissner, 1976). Human as well as rodent $\beta$-cells express connexin36 (Cx36) proteins (Serre-Beinier et al., 2000; Theis et al., 2004) that form low conducting, weak voltage dependent gap junctions between neighboring cells (Srinivas et al., 1999). The resulting electrical coupling is believed to synchronize the secretory activity of $\beta$-cells, decrease cell-to-cell heterogeneity and by that generate a "secretory syncytium" (Santos et al., 1991).

The cells of the pancreatic islets are not only regulated by local para- and autocrine mechanisms but are also subjected to intense innervation by the autonomic nervous system (for review see: Ahren, 2000). Postganglionic parasympathetic release of acetylcholine $(\mathrm{ACH})$ onto $\beta$-cells is believed to underly the phenomenon of the pre-absorptive release of insulin: In rodent model animals as well as in humans the sensory stimulus of food ingestion alone leads to a rapid onset of insulin secretion even before any increase 
in the blood sugar concentration can be measured (cephalic phase of insulin release) and this response is abolished by vagotomy (Strubbe and Steffens, 1975; Berthoud et al., 1980).

\subsection{Stimulus-secretion coupling in $\beta$-cells}

\subsubsection{The triggering pathway}

It has been known for more than 30 years that $\beta$-cells are electrically excitable (Dean and Matthews, 1968) and it is established that the same is true for the $\alpha$ - (Rorsman, 1988; Rorsman and Hellman, 1988) and $\delta$-cells (Göpel et al., 2000). Using intracellular microelectrode recordings from $\beta$-cells of isolated islets it could be shown that in mice these cells react to stimulating glucose concentrations $(>7 \mathrm{mM})$ with a depolarization from their resting membrane potential $\left(\mathrm{V}_{\mathrm{m}}\right)$ usually from about $-70 \mathrm{mV}$ to up to $-40 \mathrm{mV}$. In this depolarized state the cells exhibit slow oscillatory changes of $V_{m}$ which are overlayed with a repetitive spiking pattern consisting of bursts of high frequency, non-overshooting action potential firing (Henquin and Meissner, 1984). However, the mechanism how the glucose stimulus is coupled to these changes in membrane potential and how - and if - on the other hand this is coupled to the secretion of insulin remained unclear until the advent of the patch-clamp technique. Using this method Ashcroft et al. (1984) showed that in isolated mouse $\beta$-cells glucose modulates electrical activity via metabolically induced changes in the activity of ATP-sensitive, inwardly rectifying $\mathrm{K}^{+}$channels ( $\mathrm{K}_{\mathrm{ATP}}$ channels). The proposed stimulus-secretion model is based on the observation that $\mathrm{K}_{\text {ATP }}$ channels are inhibited by an increase in the cytosolic ATP concentration $\left([\mathrm{ATP}]_{\mathrm{i}}\right)$ : At non stimulatory glucose concentrations these channels have a high opening probability leading to a net outflow of $\mathrm{K}^{+}$ions which in turn determines the hyperpolarized $V_{m}$ of the cells. An increase in the level of blood plasma glucose evokes the diffusion of the sugar into the cytoplasm of the $\beta$-cells by means of a high affinity Glut-2 glucose transporter ( $\mathrm{K}_{\mathrm{M}}: 50-80 \mathrm{mM}$, Kruszynska, 1997). Glucose is then metabolized which leads to an increase in $[\mathrm{ATP}]_{\mathrm{i}}$ as a result of glycolysis and the subsequent oxidative phosphorylation in the mitochondria. This in turn reduces the $\mathrm{K}^{+}$ conductance by closing of $\mathrm{K}_{\mathrm{ATP}}$ channels which allows a background conductance of yet 
unknown nature to depolarize the membrane. When the cell reaches threshold potential voltage gated $\mathrm{Ca}^{2+}$ channels $\left(\mathrm{Ca}_{v}\right)$ get activated and $\mathrm{Ca}^{2+}$-dependent action potential firing is initiated. In all insulin secreting cells from different species tested so far the $\mathrm{Ca}^{2+}$ influx is mainly mediated by high voltage activated (HVA) L-type $\mathrm{Ca}^{2+}$ currents through $\mathrm{Ca}_{\mathrm{v}} 1.2$ or $\mathrm{Ca}_{\mathrm{v}} 1.3$ channels. Apart from that, $\beta$-cell $\mathrm{Ca}_{\mathrm{v}}$ channels are very heterogenous and display obvious species differences (see chapter 1.5) (Yang and Berggren, 2005). The influx of $\mathrm{Ca}^{2+}$ increases $\left[\mathrm{Ca}^{2+}\right]_{\mathrm{i}}$ which in turn activates the exocytotic machinery (see chapter 1.3.3) and thereby initiates insulin secretion (for review see: Ashcroft and Rorsman, 1989). This general model of glucose stimulated insulin secretion (GSIS) is widely accepted today, especially because it explains the action of commonly used antidiabetic drugs that elicit insulin secretion from islets of individuals suffering from type 2 diabetes: Sulphonylureas like tolbutamide or glibenclamide specifically bind to the sulphonylurea sensitive subunits (SUR1) of the octameric $\mathrm{K}_{\mathrm{ATP}}$ channel whose pore is constituted by Kir6.2 subunits and thus close the channel and lead to insulin secretion uncoupled from the action of nutrient secretagogues like glucose (Inagaki et al., 1995).

\subsubsection{The amplifying pathway}

Insulin release in response to nutrient stimulation is regulated by means beyond the control of ionic mechanisms. GSIS still persist under experimental conditions in which changes in the $\mathrm{K}_{\text {ATP }}$ channel open probability are uncoupled from the metabolic state of the $\beta$-cell. Using the pharmacological $K_{\text {ATP }}$ channel activator diazoxide, to render the channel insensitive to ATP, and high $\left[\mathrm{K}^{+}\right]_{0}$, to depolarize the cells and thus increase $\left[\mathrm{Ca}^{2+}\right]_{\mathrm{i}}$, Gembal et al. (1992) and Sato et al. (1992) could show that glucose is still able to evoke an increase in insulin secretion above the already raised basal level. Additionally, it could be shown that this phenomenon requires glucose metabolism because non-metabolizable agents are not able to trigger the same response (Sato et al., 1992).

It is now being widely accepted, that stimulus-secretion coupling in $\beta$-cells is achieved by at least two interconnected pathways for which the two terms ' $\mathrm{K}_{\text {ATP }}$ channel dependent' or 'triggering' pathway and ' $K_{\text {ATP }}$ channel-independent' or 'amplifying' pathway are in common use today. The existence of the latter is further backed up by clinical 
data: Persistent hyperinsulinaemic hypoglycaemia of infancy (PHHI) is a severe congenital defect in the regulated release of insulin which is caused by SUR1 and/or Kir6.2 gene defects. Individuals suffering from PHHI are consequently lacking functional $\mathrm{K}_{\mathrm{ATP}}$ channels. Despite of this fact and the total unresponsiveness of the subjects to sulphonylureas and diazoxide glucose still readily promotes insulin release which is therefore most likely to be due to the action of the amplifying pathway (Straub et al., 2001).

\subsubsection{Mechanisms of insulin secretion}

\section{Secretory granule maturation}

It is well established that both neurotransmitter release at synapses of the CNS as well as the release of peptides from endocrine cells is mediated and regulated by very similar mechanisms. One of the main differences is, that in contrast to neuronal transmitters that are released from small $(\varnothing<50 \mathrm{~nm}$; Jahn and Südhof, 1994) synaptic vesicles (SVs), hormones are packaged into much bigger secretory compartments—e.g. insulincontaining granules of rat pancreatic $\beta$-cells have an average diameter of $350 \mathrm{~nm}$ (Straub et al., 2004). These granules appear electron dense in transmission electron microscopy and are therefore termed 'large dense-core vesicles' (LDCVs). SVs are able to undergo rapid local cycles of exocytosis, endocytosis and subsequent neurotransmitter refilling at the synaptic release sites. In contrast, LDCVs containing peptide hormones have to undergo several maturation and translocation steps until they are ready for release at the plasma membrane.

Insulin is a protein that consists of two polypeptide chains (A- and B-peptide) of 21 and 30 amino-acid residues, respectively, that are linked by two disulfide bridges (Brown et al., 1955). In mature LDCVs insulin is stored in crystalline form. However, to reach this state it has to undergo several transformations. The principle gene product of $\beta$-cells is preproinsulin which is converted to proinsulin in the lumen of the rough endoplasmic reticulum and during the trafficking to the $c i s$-Golgi network. Proinsulin is very similar to insulin except that both polypeptide chains of the final product are still linked by a $30-35 \mathrm{kDa}$ sequence (C-peptide). Starting at the trans-Golgi complex and continuing in the early secretory granules, the C-peptide is cleaved off by endopeptidases. The 


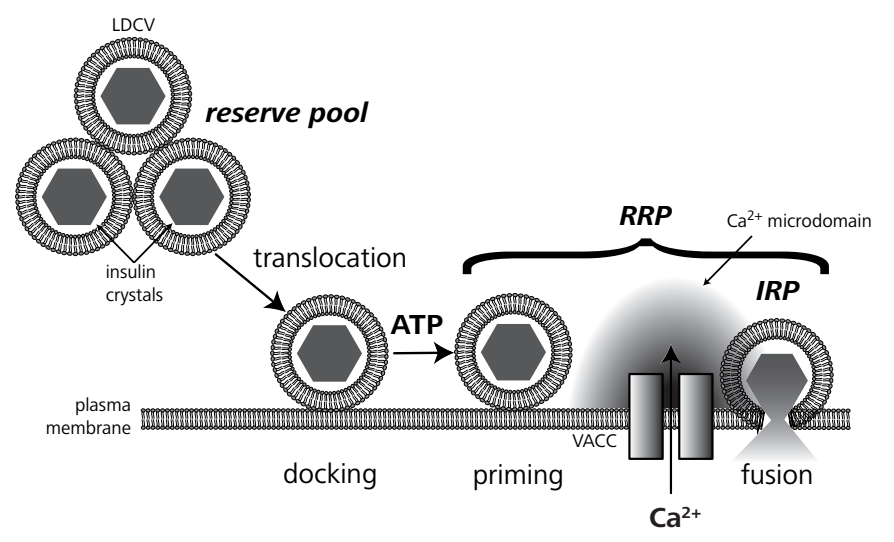

Figure 1.1: Steps involved in the exocytosis of insulin-containing LDCVs

mature state of insulin is reached after six insulin monomers conjugate with 2 zinc ions to form the hexamers that constitute the insulin crystal (Adams et al., 1969). Finally, after shedding their protein complements, the mature LDCVs disperse in the cytosol to form the so called reserve pool that comprises the majority $(\sim 95 \%)$ of all insulin containing granules in $\beta$-cells.

\section{The secretory process}

The steps involved in the secretion of mature insulin-containing LDCVs are very similar to the sequence of events involved in SV exocytosis. The process of regulated LDCV secretion can be subdivided into 4 phases (translocation, docking/tethering, priming and $\mathrm{Ca}^{2+}$-dependent fusion; see fig. 1.1).

First, the mature secretory granules from the reserve pool have to be translocated to the respective release sites at the plasma membrane. In $\beta$-cells and other cell types this involves ATP-dependent myosin-actin interactions (Lang, 1999) as well as the local disassembly of the actin cytoskeleton (Orci et al., 1972; Li et al., 1994). Subsequently, the membranes of the LDCVs and the plasma membrane have to come into physical contact. For SV and LDCVs the morphology of this docking or tethering process has been intensively studied using the methods of electron microscopy (Heuser and Reese, 1973). In pancreatic $\beta$-cells usually about $5 \%$ of the LDCVs are tightly associated to the plasma membrane: From the total $11000 \mathrm{LDCVs}$ of an average rat $\beta$-cell about 
700 appear to be in the docked state (Straub et al., 2004). Besides of this morphological definition of docking, LDCVs are considered to be chemically docked as soon as there is a proteinaceous connection between the plasma membranes. To gain full release competence, docked LDCVs and SVs have to undergo further steps involving ATP hydrolysis, moderately increased $\mathrm{Ca}^{2+}$-levels (Heinemann et al., 1993; Smith et al., 1998) modified phospholipid composition (Martin, 1997; Milosevic et al., 2005) and changes in protein conformation (Klenchin and Martin, 2000). The complex sequence of events is referred to as 'priming' and whereas many of the molecular components involved in this reaction are known to date, the full process is not completely understood (see below). Release-competent vesicles that are fully primed are generally referred to as the 'readily releasable pool' (RRP). LDCV release from (neuro-)endocrine cells has often been reported to have a very fast and a sustained kinetic component in response to a tonic stimulation. The fast component is commonly attributed to a subset of releasecompetent granules of the RPP that reside in close proximity to the $\mathrm{Ca}^{2+}$ channels. This small 'immediately releasable pool' (IRP) is proposed to be released first upon membrane depolarizations because these granules experience the high $\left[\mathrm{Ca}^{2+}\right]_{\mathrm{i}}$ in the immediate vicinity of the $\mathrm{Ca}^{2+}$ channel mouth (see fig. 1.1) (Horrigan and Bookman, 1994; Voets et al., 1999; Barg et al., 2001).

The final step- $\mathrm{Ca}^{2+}$-triggered membrane fusion-involves several energetically highly unfavorable intermediate steps of non-bilayer formation that finally lead to the generation of an aquatious fusion pore (Jahn et al., 2003). This pore dilates so that first non-crystalline and easy diffusible factors like ATP are released from the LDCVs into the extracellular space. With some delay (Barg et al., 2002) the insulin crystal dissolves and finally also the peptide cargo gets secreted. The fusion event in $\beta$-cells can occur in two ways: (i) As complete merger of the vesicle with the plasma membrane followed by membrane-retrieval (endocytosis) at a different site. (ii) As only partial and transient fusion without membrane intermixing. In this case the vesicle content is released through a fusion pore. The latter mechanism is referred to as 'kiss and run' or 'cavicapture' (Ales et al., 1999; Tsuboi and Rutter, 2003; Tsuboi et al., 2004). 


\section{Molecular determinants of insulin exocytosis}

In the last decade a unifying hypothesis of the molecular determinants involved in docking, priming and fusion of SVs and LDCVs has emerged that involves the interaction of highly conserved vesicular, plasma membrane and cytosolic factors (see also table 1.1, p. 24). Current evidence suggests that in eukaryotes specific proteins, containing the soluble $N$-ethylmaleimide-sensitive factor attachment protein receptor (SNARE) motive of $~ 60-70$ amino acid residues, are always involved in the events leading to the fusion of two lipid bilayers (for reviews see: Jahn et al., 2003; Burgoyne and Morgan, 2003). Regulated membrane fusion is dependent on the formation of a tightly associated and highly stable 4-helical coiled-coil bundle comprised of 4 SNARE motives. According to the characteristic amino acids (arginine, $\mathrm{R}$ and glutamine, Q) that form the central 0-layer of the helical bundle, the participating SNARE motives are classified as Qa, Qb, Qc and R. Exocytosis of both SVs and LDCVs is dependent on the formation of a trans-SNARE complex that stems from the interaction of the vesicular R-SNARE synaptobrevin-2 (vesicle associated membrane protein 2, VAMP-2) with the plasma membrane SNARE proteins SNAP-25-contributing a Qb as well as Qc motive-and the Qa motive-containing syntaxin-1. The free energy from the formation of the core complex is thought to be sufficient to overcome the energetical barriers of membrane fusion. Evidence from isolated bilayers suggests, that these proteins indeed are both sufficient and necessary for membrane fusion and are therefore considered to be the minimal fusion machinery (Weber et al., 1998).

The formation of the trans-SNARE complex is preceded by a selective docking/tethering step that is believed to ensure target specificity of the vesicle-plasma membrane contact and to bring both membranes close enough to initiate the 'zippering up' of the SNARE coiled-coils (Matos et al., 2003; Jahn et al., 2003). The process involves the specific interaction of vesicle-associated small GTPases with effector complexes on the plasma membrane (Novick and Guo, 2002). This effector complex-termed 'exocyst' - is best characterized in yeast (TerBush et al., 1996) but is also found in mammals (Kee et al., 1997). Recently it has been shown that in $\beta$-cells the mammalian exocyst complex plays an important role in insulin secretion (Tsuboi et al., 2005). 
After a full fusion event the whole SNARE complex resides on the same plasma membrane. It was shown that this cis-SNAREs needs to be dissociated to allow recycling of the individual SNARE components for subsequent fusion reactions (Sollner et al., 1993a). The energy-consuming process is thought to be mediated by two further highly conserved cytosolic proteins that have a high binding affinity for cis-SNARE complexes: the ATPase $N$-ethylmaleimide-sensitive factor (NSF) and its interaction partner $\alpha$-soluble $N$-ethylmaleimide-sensitive factor attachment protein ( $\alpha$-SNAP) (Banerjee et al., 1996; Sollner et al., 1993b). Other lines of evidence suggest, that the NSF/ $\alpha$-SNAP complex is also involved in ATP-depending steps preceding SNARE complex formation and might thus be partly responsible for the ATP-dependence of the priming process (Xu et al., 1999; Littleton et al., 2001). Since the ATP-dependent generation of phosphatidylinositol-4,5-bisphosphate ( $\mathrm{PIP}_{2}$ ) has repeatedly been shown to be of great importance for the priming step in general (Martin, 1997; Milosevic et al., 2005; Gong et al., 2005) and insulin secretion in particular (Olsen et al., 2003; Waselle et al., 2005), this might also account for the ATP dependence of priming. $\mathrm{Ca}^{2+}$ dependent activator protein for secretion 1 (CAPS-1) is one of the few secretory proteins that is exclusively expressed in cells containing LDCVs (Hay and Martin, 1992). As has been shown by Olsen et al. (2003), CAPS is involved in insulin secretion. Preceding membrane-fusion, CAPS interacts with $\mathrm{PIP}_{2}$ in a $\mathrm{Ca}^{2+}$-dependent manner (Loyet et al., 1998). This might explain the $\mathrm{Ca}^{2+}$-dependence of LDCV priming (Grishanin et al., 2004). However, recent evidence suggests that CAPS might not be directly involved in regulated secretion at all and might act in the filling of LDCV instead (Speidel et al., 2005).

The mammalian homologue of the C. elegans unc-18 protein (MUNC-18/nSec1) (Brenner, 1974) —also discovered in a yeast screen as secretion deficient mutant sec1 (Novick and Schekman, 1979)—is a further essential exocytotic protein that is thought to be involved in the priming event. It potently binds the free form of syntaxin-1 (Pevsner et al., 1994) and thus has to dissociate from the Qa-SNARE to enable fusion. According to a current model, this dissociation is mediated by another $C$. elegans homologue, Munc-13. This protein has a diacyglycerol (DAG) binding C1-domain and has repeatedly been shown to enhance priming in many preparations including $\beta$-cells (Sheu et al., 2003). Its putative role is to promote a conformational change in 
syntaxin- 1 to free it from the Munc-18 interaction and thus enable SNARE complex formation. However, the precise role of Munc- 18 as well as Munc-13 is far from being completely elucidated since especially Munc- 18 has pleiotropic effects including post-priming functions (Fisher et al., 2001; Ciufo et al., 2005).

\section{$\mathrm{Ca}^{2+}$-dependent fusion}

Regulated exocytosis differs from constitutive release by being dependent on a triggering signal. In $\mathrm{SV}$ as well as LDCV exocytosis this signal in most cases is an increase in $\left[\mathrm{Ca}^{2+}\right]_{i}$ caused either by $\mathrm{Ca}^{2+}$-influx through $\mathrm{Ca}^{2+}$ channels or by release from internal stores. In $\mathrm{SV}$ and secretory granule exocytosis of neuronal tissues solid evidence identifies the isoforms I and II of synaptotagmin as the molecular $\mathrm{Ca}^{2+}$ sensor. This protein contains two $\mathrm{Ca}^{2+}$-binding regions $\left(\mathrm{C}_{2} \mathrm{~A}\right.$ and $\left.\mathrm{C}_{2} \mathrm{~B}\right)$ and resides in the vesicular membrane (Fernandez-Chacon et al., 2001; Tucker and Chapman, 2002). Pancreatic $\beta$-cells, however, lack this specific synaptotagmin isoforms (Lang et al., 1997; Gut et al., 2001) but express the isoforms III, V, VII and IX, all of which have been implicated in insulin secretion (Gao et al., 2000; Iezzi et al., 2004; Brown et al., 2000). The various synaptotagmins have different $\mathrm{Ca}^{2+}$-sensitivities with synaptotagmin$\mathrm{I} / \mathrm{II}$ showing the lowest in vitro $\mathrm{Ca}^{2+}$ affinity $\left(\mathrm{EC}_{50} \approx 10-200 \mu \mathrm{M}\right.$ depending on experimental conditions) and synaptotagmin-III and IV exhibiting high $\mathrm{Ca}^{2+}$ binding affinities $\left(\mathrm{EC}_{50} \approx 1 \mu \mathrm{M}\right)$ (Sugita et al., 2002). The distinct $\mathrm{Ca}^{2+}$-sensitivity of the synaptotagmin isoforms is believed to explain the different $\mathrm{Ca}^{2+}$-sensitivities of central nervous SV vs. LDCV release: Retinal bipolar cells show a half maximal release rate at $190 \mu \mathrm{M}\left[\mathrm{Ca}^{2+}\right]_{\mathrm{i}}$ (Heidelberger et al., 1994) whereas exocytotic speed of insulincontaining LDCVs from pancreatic $\beta$-cell is half maximal at $\mathrm{Ca}^{2+}$-concentrations around $20 \mu \mathrm{M}$ (Takahashi et al., 1997; Barg et al., 2001). The molecular mechanism how synaptotagmin acts as a $\mathrm{Ca}^{2+}$ sensor has not been fully elucidated yet but it might involve $\mathrm{Ca}^{2+}$-dependent phospholipid binding leading to a destabilization of intermediate membrane fusion states after SNARE complex formation (Jahn et al., 2003). In two recent reports it has been shown that $\beta$-cells and insulin-secreting cell lines contain a population of LDCVs that are released at $\left[\mathrm{Ca}^{2+}\right]_{i}$ of less than $1 \mu \mathrm{M}$ (Yang and Gillis, 2004; Wan et al., 2004). The presence of this highly $\mathrm{Ca}^{2+}$-sensitive pool 
(HCSP) that is also present in chromaffin cells (Yang et al., 2002) opens the possibility that several $\mathrm{Ca}^{2+}$-sensors acting in parallel are involved in LDCV exocytosis.

\subsubsection{Regulation of insulin release by protein phosphorylation}

Numerous studies have shown that protein phosphorylation plays an important role in the control of regulated exocytosis. Phosphorylation and dephosphorylation provides means to rapidly change the function of a protein in response to a given stimulus. Activity-dependent short-term changes in synaptic efficacy, for instance, are induced by activation of protein kinases that act on presynaptic molecular targets near the site of SV fusion (Barclay et al., 2005). Especially in $\beta$-cells both nutrient- and receptormediated signalling frequently converges on protein kinases as intracellular effectors of either elevated $\left[\mathrm{Ca}^{2+}\right]_{\mathrm{i}}$ or various second messenger systems to regulate insulin release (Jones and Persaud, 1998). A large variety of protein kinases has been documented in eukaryotes but especially activation of protein kinases $\mathrm{A}$ and C (PKA, PKC) enhances $\mathrm{Ca}^{2+}$-triggered exocytosis in almost any cell type studied to date (Burgoyne and Morgan, 2003). Most of the key proteins involved in regulated exocytosis are subjected to phosphorylation but in most cases the mechanistic basis mediating the actions of protein kinases is unknown.

\section{PKA}

In $\beta$-cells the action of PKA has received much attention. Gastrointestinal incretin hormones as glucagon-like peptide-1 (GLP-1) and glucose-dependent insulinotropic polypeptide (GIP) are important physiological potentiators of GSIS. These peptides exert their stimulatory effect on insulin secretion by attaching to guanine nucleotidebinding protein (G-protein)-coupled receptors in the $\beta$-cell plasma membrane. This activates adenylate cyclase (AC) and subsequently increases the cytosolic adenosine 3', 5'-cyclic monophosphate (cAMP) level which then leads to the activation of PKA and other cAMP effectors. A similar mechanism has also been proposed to underly the insulinotropic action of pituitary adenylate cyclase-activating polypeptide (PACAP) which is a neuropeptide that is released from pancreatic neurons upon vagal stimulation (Filipsson et al., 2001). Exogenous application of cAMP or cAMP raising agents 
like forskolin potentiates $\mathrm{Ca}^{2+}$-triggered secretion in $\beta$-cells severalfold both via PKAdependent but also PKA-independent mechanisms (Ammala et al., 1993; Kashima et al., 2001; Eliasson et al., 2003).

\section{PKC}

Activation of PKC is an important factor in the generation of several forms of synaptic plasticity (Barclay et al., 2005) and it is well documented that the activation of PKC in $\beta$-cells also plays an important—albeit controversial—role in the regulation of insulin release (Jones and Persaud, 1998). The ten isoforms of PKC known to date constitute a family of serin/threonin kinases that can be subdivided into three groups based on structural differences in their regulatory domain: (i) The conventional $\mathrm{PKC}$ isoforms $\alpha, \beta \mathrm{I}, \beta \mathrm{II}$ and $\gamma\left(\mathrm{PKC}_{\mathrm{c}}\right)$ have a $\mathrm{C}_{1}$ and a $\mathrm{C}_{2}$ domain that confer the DAG- and $\mathrm{Ca}^{2+}-$ sensitivity of this subgroup. (ii) The novel isoforms $\delta, \epsilon, \eta$ and $\theta\left(\mathrm{PKC}_{\mathrm{n}}\right)$ are activated by DAG as well but lack the $\mathrm{C}_{2}$ domain and are thus not directly sensitive to $\mathrm{Ca}^{2+}$. (iii) The atypical $\mathrm{PKC}$ isoforms $\zeta$ and $\lambda\left(\mathrm{PKC}_{\mathrm{a}}\right)$ are characterized by the absence of both $\mathrm{C}_{1}$ and $\mathrm{C}_{2}$ domains and are thus neither $\mathrm{Ca}^{2+}$ - nor DAG-sensitive. Instead, phosphoinositidedependent kinase 1 (PDK1) activates $\mathrm{PKC}_{\mathrm{a}}$ in a $\mathrm{Ca}^{2+}$-independent manner. In rat pancreatic islets the presence of PKC- $\alpha, \beta \mathrm{II}, \delta, \epsilon, \eta$ and $\zeta$ has been detected (Knutson and Hoenig, 1994; Ishikawa et al., 2005). The physiological relevance of PKC activation for insulin release is best established for the insulinotropic action of $\mathrm{ACH}$ released from parasympathetic postganglionic neurons onto $\beta$-cells. Upon binding of $\mathrm{ACH}$ or cholinergic agonists like carbachol to G-protein coupled muscarinic ACH-receptors, phospholipase C (PLC) gets activated leading to the hydrolysis of phosphatidylinositol 4,5-bisphosphate ( $\mathrm{PIP}_{2}$ ) and the generation of DAG (Zawalich and Zawalich, 1996a). PKC activation also plays an important role in GSIS but because of the high number of isoforms and the lack of specific inhibitors and activators the precise role of PKC is still controversial (Carpenter et al., 2004). However, most studies agree that nutrient stimulation leads to the activation of conventional and novel PKC isoforms-namely $\alpha$ and $\epsilon$ (Yedovitzky et al., 1997; Mendez et al., 2003; Zhang et al., 2004). Whereas in general a exclusively stimulatory role of PKC on insulin secretion has been demonstrated, more recent reports show that conventional PKC isoforms can exert both inhibitory 
and stimulatory actions in a time-dependent manner (Zawalich and Zawalich, 2001; Zhang et al., 2004).

Under some experimental conditions, protein phosphorylation in $\beta$-cells appears to be sufficient as the triggering signal for exocytosis: It has been demonstrated that simultaneous activation of PKA together with PKC by pharmacological agents can elicit insulin secretion even in the complete absence of any increase in $\left[\mathrm{Ca}^{2+}\right]_{\mathrm{i}}$ (Komatsu et al., 1995).

\subsubsection{Biphasic insulin release}

A characteristic feature of GSIS in man as well as in some model organisms (see chapter 1.5 ) is that an abrupt ('square-wave') increase in the plasma glucose concentration by systemic application of the hexose (i.e. by intravenous injection in vivo or pancreas perfusion in vitro) evokes a biphasic insulin release pattern (Grodsky et al., 1967; Curry et al., 1968) (see fig. 1.2). During the initial first few minutes a square-wave glucose stimulus leads to a sharp rise in insulin secretion which is followed by a rapid decline leading to a nadir. After this 'first phase' which lasts about 10 min the persistent nutrient stimulation gives rise to a gradual increasing and much larger insulin output which reaches a plateau after $1-2 \mathrm{~h}$ to which is generally referred to as the 'second phase' (Gerich, 2002).

These macroscopic dynamics of insulin release are not mirrored by electrophysiological data in which a square-wave glucose stimulation causes a fairly constant membrane depolarization and stable spiking pattern (Antunes et al., 2000). Additionally, $\mathrm{Ca}^{2+}$ measurements during glucose stimulation also do not show a comparable biphasic change in $\left[\mathrm{Ca}^{2+}\right]_{\mathrm{i}}$ (Antunes et al., 2000). Furthermore, application of physically depolarizing agents (i.e. sulphonylureas and high $\left[\mathrm{K}^{+}\right]_{0}$ ) only elicit a first phase response of insulin release in secretory assays (Hellman et al., 1992). The second phase of insulin release is thus supposed to be 'non-ionic' and additional nutrient-derived signals are thought to be involved in the initiation and maintenance of this specific GSIS release pattern. Accordingly, the amplifying pathway (see chapter 1.3.2) seems to be exclusively responsible for the generation of second phase insulin release (Taguchi et al., 1995; Straub and Sharp, 2002). 


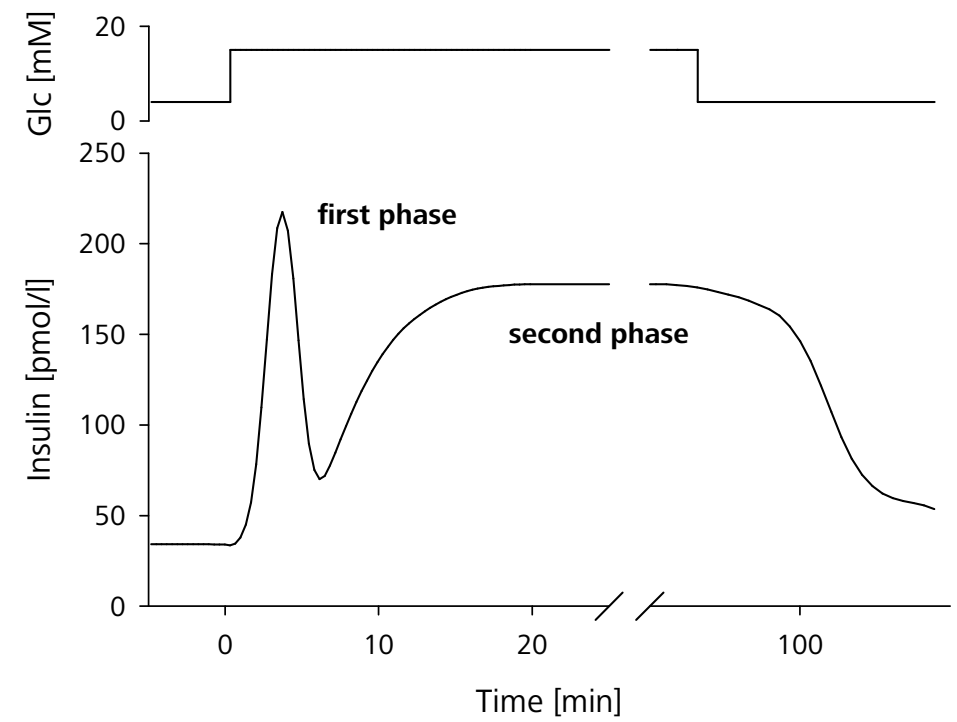

Figure 1.2: Idealized biphasic change of the plasma insulin concentration (lower panel) in response to a square wave increase in blood glucose (glc) (upper panel). Quantitative aspects are loosely based on Caumo and Luzi (2004).

\section{Model hypotheses}

Two models are currently competing to explain the biphasic kinetics of insulin release: (i) a 'storage-limited model' (Grodsky, 1972) and (ii) a 'signal-limited model' (Cerasi et al., 1974). The latter proposes that glucose exerts potentiating and inhibitory signals in a concentration- and time-dependent manner. The signal-limited model is able to faithfully mimic the quantitative aspects of the GSIS pattern under many circumstances (Nesher and Cerasi, 2002). However, since the signals are not further specified it refrains from making any mechanistic cell biological explanation and is therefore not considered further in the current work.

In the case of the storage-limited model it is currently proposed that the observed biphasicity is the result of the dynamic processes of transportation, maturation, activation and release of functional subsets ('pools') of secretory granules in response to nutrient stimulation. In this scenario the first phase corresponds to the fast release and depletion of a small fraction (less than $5 \%$ of the total number) of vesicles. This "labile pool" (Grodsky, 1972) has later been suggested to be identical with the pool of morphologically docked LDCVs (Daniel et al., 1999). More recently, this has been specified 
further by proposing that the functionally defined RRP is released at the beginning of the stimulation (Rorsman et al., 2000). The nadir following the first phase of GSIS is thought to mark the complete RRP depletion. In this model the residual release during the nadir is rate-limited by the speed of the time and ATP-dependent mobilization of granules from the larger reserve pool. The rising second phase is explained by the gradual glucose-dependent potentiation of the mobilization rate (Rorsman et al., 2000; Rorsman and Renstrom, 2003; Straub et al., 2004). The quantitative aspects of GSIS agree reasonably well with the functionally defined pool sizes in animal models (Rorsman and Renstrom, 2003). A major objection to this model, however, is the different time course of depletion and refilling of functional LDCV pools in single $\beta$-cells in comparison to the macroscopic release kinetics. Whereas RRP depletion in response to strong tonic stimulation is reported to take place in the range of milliseconds to seconds (Barg et al., 2001), first-phase insulin release, as mentioned, lasts several minutes. Commonly, this is explained with a certain lack of synchronization between individual $\beta$-cells leading to a broadening of the response pattern (Rorsman and Renstrom, 2003).

\subsection{Diabetes mellitus}

\subsubsection{Definition}

The importance of insulin becomes particularly evident under pathophysiological conditions-namely in diabetes mellitus. The chronic hyperglycaemia of subjects suffering from this disease is the result of a combination of genetically determined and acquired defects leading to secretory deficiency of $\beta$-cells as well as insulin insensitivity of the target tissues. Diabetes mellitus constitutes a heterogenous group of disorders that share the common feature of chronically increased levels of blood glucose. According to the current criteria of the World Health Organization (WHO) diabetes mellitus is diagnosed if the plasma glucose concentration exceeds $11.1 \mathrm{mM} 2 \mathrm{~h}$ after a defined $(75 \mathrm{~g})$ oral glucose load or is higher than $7 \mathrm{mM}$ in the fasting state.

Based on etiological criteria diabetes is classified into type 1, type 2, gestational and 'other types' of diabetes. In the case of type 1 it has been established that this disease originates from an absolute lack of insulin release due to an autoimmune reaction that 
leads to $\beta$-cell lysis and islet destruction. Because of the more or less complete absence of nutrient induced insulin secretion, diseased subjects rely on regular injections of the hormone in order to survive. Type 1 diabetes accounts for $\sim 5 \%$ of all diabetic cases.

Type 2 diabetes (T2D) is very heterogeneous in itself and is characterized by various combinations of defective insulin release and insulin resistance. The chronic hyperglycaemia in T2D causes many secondary complications primarily of the micro- and macrovascular system. This leads to a significantly reduced life expectancy and quality of life due to coronary heart diseases, renal failure, stroke, blindness and lower extremity amputations as a result of vascular and nerve damage. T2D accounts for up to $95 \%$ of all newly diagnosed diabetes cases and approximately $6 \%$ of the European population and more than 170 million people worldwide are afflicted by the disease. Due to its rising prevalence in developed and even more in developing countries it poses an ever greater public health problem (Pickup and Williams, 2003).

\subsubsection{Etiology of type 2 diabetes}

The etiology of T2D is only insufficiently understood but it is considered to be a heterogenous syndrome that usually appears in middle age and is exacerbated by obesity. Both genetic and environmental factors contribute to a variable extent to the development of the disease. The genetic background of some rare monogenetic types of T2D like maturity-onset diabetes of the young (MODY) is known but the vast majority of T2D forms is considered to be polygenic (Rhodes, 2005).

For a long time the view prevailed, that desensitization of insulin target tissues, i.e. mainly liver and musculature, is the predominant cause of diabetes. A lack of insulin responsiveness would decrease the amount of glucose cleared from the blood and thus increase the demand on $\beta$-cells to secrete the peptide hormone. This stress would sooner or later lead to $\beta$-cell failure. However, there is growing evidence that the decreased secretory capacity of $\beta$-cells might be the primary genetic factor leading to T2D. In several studies it has been demonstrated that both first degree relatives and monozygotic twins of T2D patients show impaired insulin secretion but normal insulin sensitivity if matched for obesity. This impairment presents itself as prominent reduction of first but also second phase GSIS (Vaag et al., 1995; van Haeften et al., 1998; Gerich, 2002). 
Furthermore, overt obesity is almost always connected to insulin resistance but only a small fraction of obese individuals develops diabetes (Gerich, 2002). This evidence suggests that in most cases $\beta$-cells are able to cope with the increased secretory demand by increasing their insulin output. T2D only develops when a genetically determined propensity to $\beta$-cell dysfunction is challenged by the increased demand of insulin secretion caused by insulin resistance. This leads to insufficient insulin secretion in relation to the prevailing hyperglycaemia (Cerasi, 1995; Gerich, 1998, 2000; Chiasson and Rabasa-Lhoret, 2004). The reduced capacity to secrete appropriate amounts of insulin is thought to result both from a reduction in $\beta$-cell mass (Rhodes, 2005) and from impaired secretory function of single $\beta$-cells (Kahn, 2001).

In contrast to the notion of inherited $\beta$-cell dysfunction it is frequently stated that the defect is secondary to the toxic effects of the prevailing hyperglycaemia and increased level of circulating fatty acids (byperlipedemia) in T2D (Prentki et al., 2002). However, in an extensive clinical study it has been shown that even aggressive control of plasma glucose levels does not prevent the deterioration of $\beta$-cell function (UKPDS, 1998).

Many possible lesions would decrease or abolish $\beta$-cell responsiveness to glucose but the primary mechanism of stimulus-secretion coupling in these cells remains largely intact: The closing of ATP-dependent $\mathrm{K}^{+}$-channels and the subsequent depolarization leading to influx of $\mathrm{Ca}^{2+}$ via L-type $\mathrm{Ca}^{2+}$-channels seems to be functional in T2D (Ashcroft and Gribble, 1999). Accordingly, the putative impairment is most likely due to $\mathrm{K}_{\mathrm{ATP}}$-channel independent mechanisms-for instance being caused by defective glucose metabolism or being attributable to impaired secretory machinery function. Indeed, a recent finding suggests that the protease calpain-10 (Ma et al., 2001)_ encoded by the only unequivocally identified susceptibility-gene for T2D (Horikawa et al., 2000) - is involved in $\mathrm{Ca}^{2+}$-sensing of the $\beta$-cell secretory apparatus (Marshall et al., 2005). Furthermore, a single nucleotide polymorphism (SNP) in the syntaxin-1 gene has been shown to be frequent in human T2D as well (Tsunoda et al., 2001). This raises the interesting possibility that similarly as has recently been discussed for schizophrenia (Mirnics et al., 2000; Wong et al., 2004) alterations in the expression of genes coding for exocytotic proteins might be also involved in T2D. 


\subsection{Animal models and insulin release}

Since the use of the pancreatectomized dog by Von Mering and Minkowski (1890) animal models have played an ever greater role in the study of the physiology and pathophysiology of glucose homeostasis. Especially laboratory rodents are used extensively because of their short generation time, high reproductive rate, convenient handling and the wealth of information already present. In more recent times the physiology of stimulus-secretion coupling in pancreatic islet cells has almost exclusively been studied using either mice or rats. Therefore, a large part of today's knowledge stems from combining the results from the two murine genera and their subsequent extrapolation to human physiology. For practical reasons a dichotomy between the scientific subjects studied with either rats or mice has developed: Whereas molecular and electrophysiological information on $\beta$-cell physiology has largely been gathered using mice, biochemical measurements of insulin release under more physiological conditions (see section 1.6) in most cases have been performed on rats. However, this approach has been questioned because of pronounced inter-species differences in the pathways involved in GSIS between the murine species. Whereas mice react to a square wave increase in glucose concentration with a monophasic insulin response (Berglund, 1980), rats show a characteristic biphasic release pattern similar to humans (Gerich et al., 1974; Lenzen, 1979; Misler et al., 1992; Elahi, 1996) (see also fig. 1.3). Together with the absence of further non-ionic stimulatory actions of glucose on insulin release (Zawalich and Zawalich, 1996b) this suggests that the amplifying pathway of GSIS is much less pronounced in mice. This coincides with the observation that several metabolic enzymes as well as second messenger systems-e.g. cAMP production (Ma et al., 1995) and phosphoinositide hydrolysis upon glucose stimulation (Zawalich and Zawalich, 1996a)_ can be found to a significantly higher degree in rat pancreatic islets. Also the expression of $\mathrm{Ca}^{2+}$ channels shows obvious species differences. In contrast to mice, both human and rat $\beta$-cells display T-Type $\mathrm{Ca}^{2+}$ currents that are activated at membrane potentials around $-40 \mathrm{mV}$ (Ashcroft et al., 1990; Misler et al., 1992). 


\subsubsection{Rodent T2D models}

Transgenic mouse models helped to understand the principles of glucose homeostasis as well as they were indispensable for the study of the rare monogenic subtypes of T2D like MODY (Bell and Polonsky, 2001; Leroith and Gavrilova, 2005). However, given the largely unknown polygenic background of human T2D, animal models with spontaneously occurring or artificially induced monogenic lesions only have a limited descriptive power for the disease as such. Accordingly, for the identification of new susceptibility genes and environmental risk factors contributing to human T2D especially animals spontaneously displaying T2D-like syndromes on a polygenic background are widely used. Given the phylogenetic difference between humans and the used laboratory animals it is self-evident that no animal model of T2D can mimic the human phenotypes to the last extent. However, in most cases both ethical and practical considerations are prohibitive for studying the pathophysiology of glucose homeostasis in untreated patients suffering from T2D. Furthermore, the analysis of many T2D models showed striking similarities in the diabetic phenotype as well the genetic markup responsible for the disease: Several of the six identified quantitative trait loci (QTL) in the diabetic model that has been used in the present work have been demonstrated to be conserved with diabetes loci on human chromosomes (Gauguier et al., 1996; Galli et al., 1999; Wallace et al., 2004).

\section{The Goto Kakizaki rat}

The Goto Kakizaki (GK) rat is a well established and characterized model for inherited T2D that has been obtained by recurrent selective inbreeding of non-diabetic (Wistar) rats with high plasma levels of glucose (Goto et al., 1976; Östenson, 2000; Portha, 2005). After nine generations $\left(\mathrm{F}_{8}\right)$ of selective breeding, hyperglycaemia and glucose intolerance was established and a stable diabetic phenotype was reached in $\sim \mathrm{F}_{40}$ (Portha, 2005). In contrast to many other spontaneous models of T2D like the Zucker Diabetic Fatty (ZDF) rat, the Otsuka Long-Evans Tokushima Fatty (OLETF) rat and ob/ob as well as $\mathrm{db} / \mathrm{db}$ mice (Chen and Wang, 2005), GK rats are non-obese and display a diabetic phenotype relatively early in life after about 4 weeks (Portha, 2005). Albeit showing some degree of hepatic as well as peripheral insulin resistance, the most charac- 

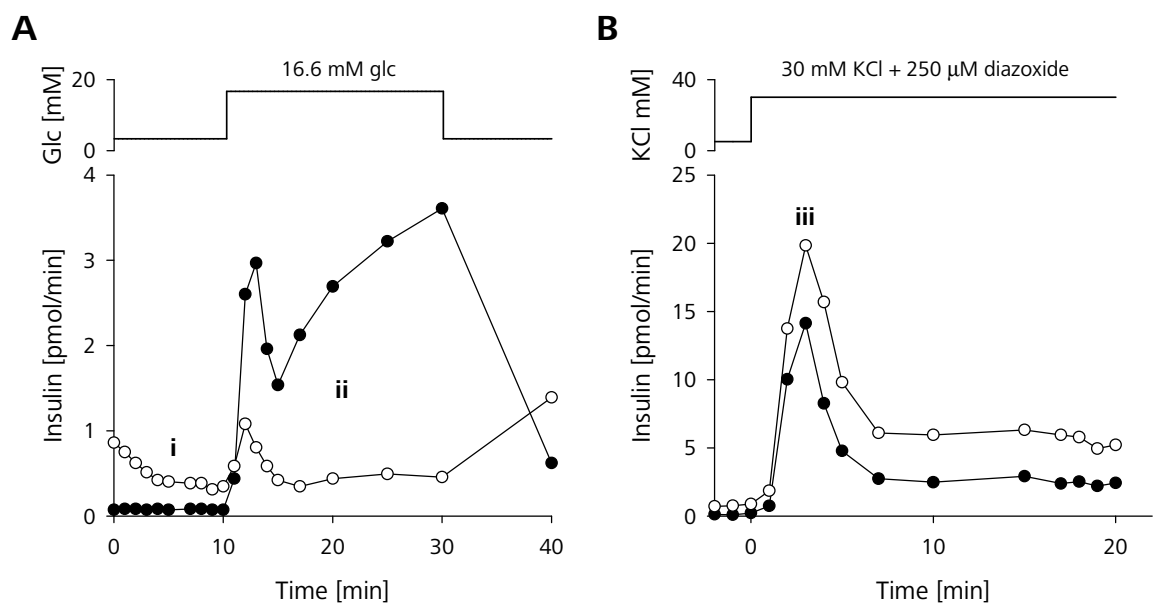

Figure 1.3: (A) Insulin release from healthy Wistar (closed symbols) and diabetic GK rat (open symbols) perfused pancreata (lower panel) in response to a square wave increase in blood glucose (glc) from 3.3 to $16.7 \mathrm{mM}$ glucose (upper panel). (B) Insulin release in control (closed symbols) and diabetic rats (open symbols) depolarized by $30 \mathrm{mM} \mathrm{KCl}$ in the presence of $250 \mu \mathrm{M}$ of the $\mathrm{K}_{\mathrm{ATP}}$ channel opener diazoxide. Note the different scale of the y-axis. Roman numerals in (A) and (B) indicate (i) resting hyperinsulinaemia, (ii) glucose unresponsiveness and (iii) non-nutrient hypersecretion as characteristic features of diabetic GK rats. Figures modified after Abdel-Halim et al. (1996).

teristic features of these lean animals is defective basal and stimulated insulin secretion (Portha et al., 1991) (see fig. 1.3). This impairment presents itself as (i) increased basal secretion of insulin (see fig. 1.3 Ai), (ii) prominently depressed GSIS (fig. 1.3 Aii) and (iii) as increased insulin secretion in response to physically depolarizing non-nutrient stimulation (fig. 1.3 Biii) (Abdel-Halim et al., 1996).

Similar as in human T2D, also in the GK rat many heterogeneous lesion sites putatively leading to defective insulin secretion have been described. Mostly metabolic defects are mentioned that would lead to insufficient ATP generation in response to glucose stimulation (Östenson, 2000; Portha et al., 2001; Portha, 2005). This would prevent the closing of $\mathrm{K}_{\mathrm{ATP}}$ channels and thus prevent both voltage-gated $\mathrm{Ca}^{2+}$ influx and the subsequent $\mathrm{Ca}^{2+}$-triggered LDCV exocytosis. However, ATP production in response to glucose stimulation appears to be normal in diabetic GK rats (Ling et al., 1998; Metz et al., 1999). 
Recently it has been shown that the expression of several highly conserved proteins involved in $\mathrm{SV}$ as well as insulin containing LDCV exocytosis is dysregulated in this animal model: Protein levels of $\alpha$-SNAP, SNAP-25, syntaxin-1, Munc13-1, Munc18-1 (nSec1), NSF and synaptotagmin III are found to be reduced in the GK rat (Nagamatsu et al., 1999a; Sheu et al., 2003; Zhang et al., 2002) (see table 1.1). Furthermore, the number of syntaxin-1A and SNAP-25 clusters and the number of morphologically docked insulin containing granules have been reported to be reduced as well (Ohara-Imaizumi et al., 2004a,b). Normalization of the expression of some of the aforementioned proteins has been shown to improve impaired insulin secretion in these animals (Nagamatsu et al., 1999a; Ohara-Imaizumi et al., 2004b). Nevertheless, earlier studies using isolated and cultured $\beta$-cells could not demonstrate any defects in late steps of stimulus-secretion coupling in GK rats (Hughes et al., 1998). In addition, islets of GK rat $\beta$-cells respond to physically depolarizing non-nutrient stimulation like high $\left[\mathrm{K}^{+}\right]_{\mathrm{o}}$ with an even more pronounced insulin secretion than healthy rats (see fig. 1.3 B). This led to the conclusion of defective glucose metabolism rather than impaired secretory machinery function being the primary lesion site in type 2 diabetic $\beta$-cells (Abdel-Halim et al., 1996).

However, the studies performed so far either lacked the temporal and spatial resolution necessary to reveal kinetic alterations in LDCV secretion of diabetic $\beta$-cells or have been performed in vitro on single $\beta$-cells from primary cell-cultures, an invasive preparation that is known to alter secretory function in many different cell types like adrenal chromaffin cells or pituitary melanotrophs (Moser and Neher, 1997; Sedej et al., 2005). 


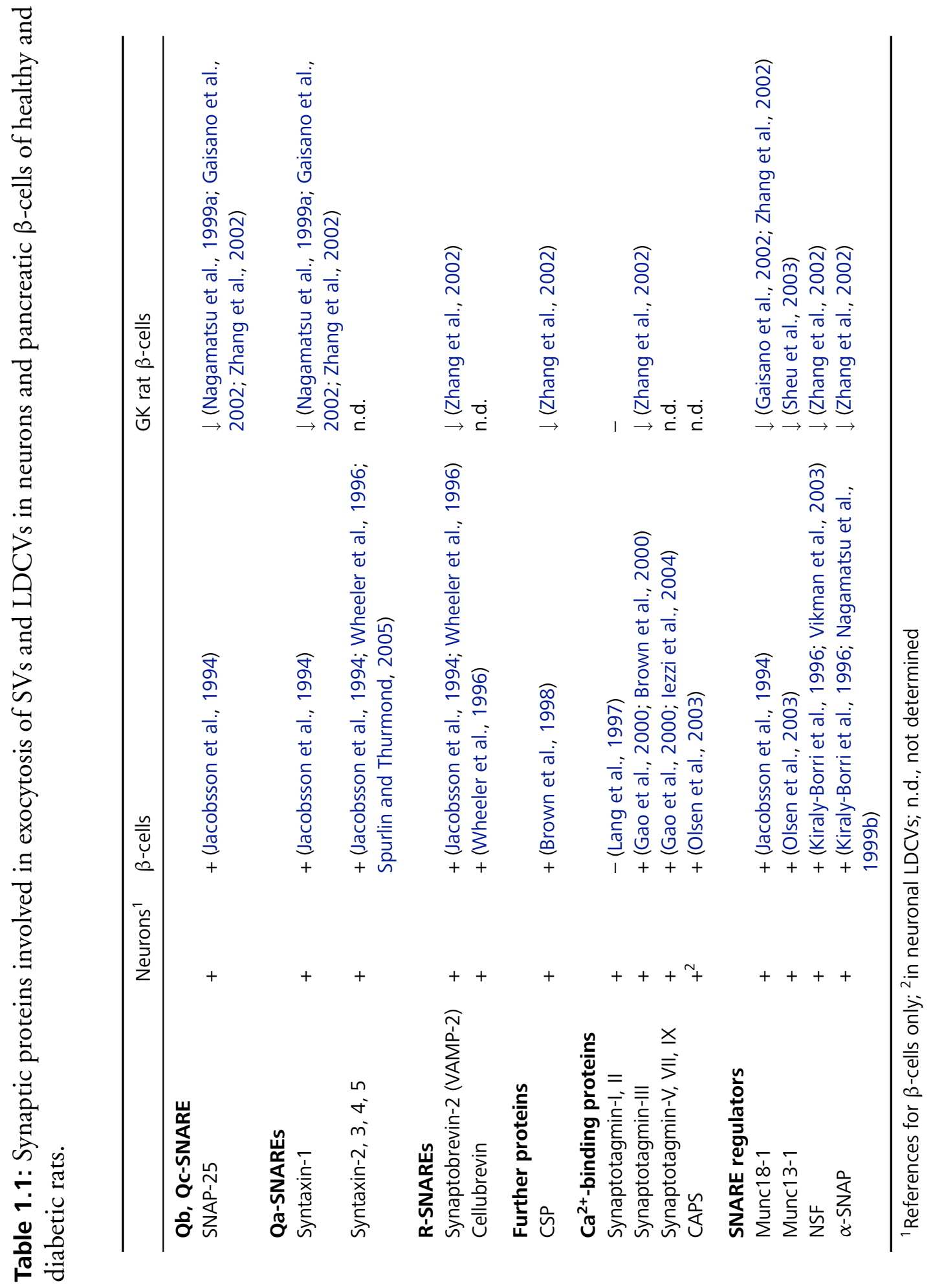




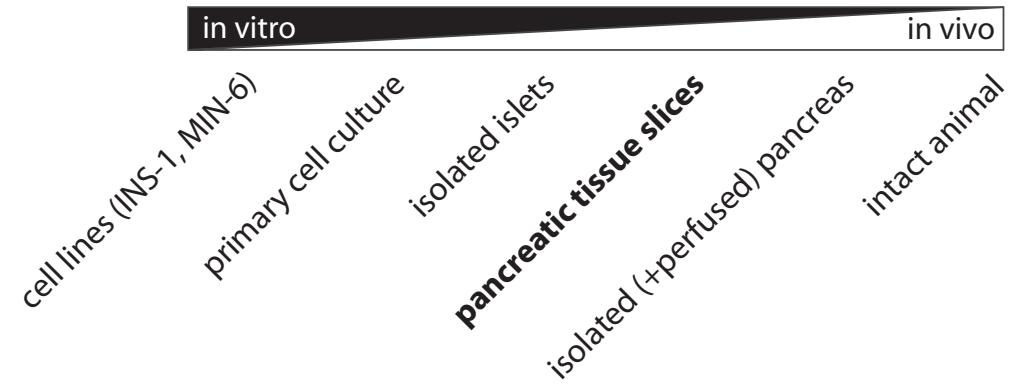

Figure 1.4: Commonly used preparations to study the physiology and pathophysiology of insulin secretion

\subsection{Preparations to study insulin release}

Since the discovery of insulin, quantitative measurements of stimulated insulin secretion have been greatly improved by the development of new preparations as well as by advancements in the temporal fidelity and detection sensitivity of the insulin assays used. Starting from the era of the first radio immuno assays (RIA) for insulin detection (Yalow and Berson, 1959; Hales and Randle, 1963) over the early enzyme-linked immunosorbent assays (Ishikawa, 1973), one is now able to detect quantities of $\sim 100 \mathrm{aM}$ at a temporal resolution of $\sim 10 \mathrm{~s}$ (Westerlund and Bergsten, 2001). The preparations used to study evoked insulin release can be classified according to the degree of preservation of in vivo characteristics (see fig. 1.4).

One of the first methods to study GSIS was the isolated and perfused rat pancreas (Anderson and Long, 1947; Grodsky et al., 1963; Sussman et al., 1966). This method is still widely used today and achieves a well defined stimulation regime while still preserving the full integrity of the endocrine pancreas. An even higher degree of physiological stimulation and measurement was achieved with the development of the hyperglycaemic clamp. By means of a feedback mechanism, the plasma glucose concentration could be increased in an almost ideal square wave, thus enabling the in vivo measurement of GSIS in both model animals and humans (DeFronzo et al., 1979). On the other end of the spectrum of techniques available today are approaches that try to limit the complexity of the investigated system by applying in vitro methods. This has been enabled by the development of protocols for the enzymatic isolation of islets of Langerhans (Lacy and Kostianovsky, 1967) and later on also the setup of cultures of 
dispersed primary islet cells (Lernmark, 1974) as well as the use of immortalized cell lines (Gazdar et al., 1980; Asfari et al., 1992). In spite of the improvement of biochemical insulin assays that enabled the detection of the GSIS pattern of single isolated islets or in the case of the reverse hemolytic plaque assay even from single dispersed $\beta$-cells (Salomon and Meda, 1986; Hiriart and Matteson, 1988), the temporal resolution still is too low to assess the basic questions of regulated LDCV exocytosis from single cells, since these processes are expected to take place in the range of milliseconds to seconds.

Besides of helping to clarify the ionic basics of excitability in pancreatic $\beta$-cells, the patch-clamp technique also provided an assay of secretion with a potentially submillisecond resolution: By taking advantage of the fact that the membrane surface area of a cell is proportional to its electrical capacitance $\left(\mathrm{C}_{\mathrm{m}}\right)$, high resolution measurement of the latter property rendered it possible to detect the small membrane enlargements that occur when a secretory vesicle fuses with the membrane-as it is the case in exocytosis (Neher and Marty, 1982). This technique has successfully been applied to isolated $\beta$ cells (Penner and Neher, 1988; Gillis and Misler, 1992; Ammala et al., 1993; Renstrom et al., 1997; Barg et al., 2001; MacDonald et al., 2005). The single cell preparations provided time-resolved insights in the biophysical properties of $\mathrm{Ca}^{2+}$-secretion coupling, however, lacking autocrine, paracrine and neural interactions as well as input from electrical coupling between the cells_-all these properties being characteristic to more intact preparations. Additionally, dissociated islet cells are suffering from culturing and the deleterious effects of enzymatic digestion and gradient differentiation processes commonly used in the islet and cell isolation procedure. This has been reported to result in reduced secretory capacity (Pipeleers et al., 1982; Zawalich et al., 1998) as well as changed glucose-induced electrical activity and defective nutrient induced changes in $\left[\mathrm{Ca}^{2+}\right]_{\mathrm{i}}$ (Zhang et al., 2003). Other recent efforts to come to a more in situ approach for studying the electrophysiology of these cells, like the 'whole islet patch-clamp method' using isolated islets instead of single cells (Göpel et al., 1999, 2004), still suffer from isolation artifacts and practical difficulties (primarily the limitation of being restricted to surface cells) and, while preserving the paracrine and electrical interplay, also lack the innervation of local pancreatic ganglia.

Tissue slices have been used to study the physiology of a large number of organs, including kidney, lung, intestine, heart, liver and brain. This preparation is commonly 
applied where a higher level of biological organization better reflects the response and function of the organ studied. Especially for the investigation of the electrical properties and cellular interactions of neurons in the CNS the slicing technique has proven to be an invaluable tool. Recently, this method has successfully been adapted to the pancreas of mice, thus providing a new and less invasive preparation to study islet and $\beta$-cell physiology (Speier and Rupnik, 2003) (see fig. 1.4). It has been demonstrated that this preparation does not disrupt the gross morphology of the mouse pancreas, preserves the structural organization of the islet and even retains the innervation by local ganglia associated to the islets (Meneghel-Rozzo et al., 2004).

\subsection{Objectives}

The main goal of this study is to address the question if a possible secretory defect late in $\beta$-cell stimulus-secretion coupling might be partly responsible for the hyperglycemic phenotype of a widely used animal model of type- 2 diabetes. In spite of biochemical data pointing towards an impairment of the secretory machinery, no defect in $\mathrm{Ca}^{2+}$ secretion coupling has yet been demonstrated using isolated and cultured $\beta$-cells. The secretory function of diabetic $\beta$-cells is therefore assessed by taking advantage of a novel and more in situ approach-the tissue slice preparation of murine pancreas. This technique first had to be established for the rat pancreas. The initial part of this study therefore characterizes the general morphological and electrophysiological features of pancreatic islets and $\beta$-cells in tissue slices of rat pancreas. In the light of recently reported species differences between rats and mice, special emphasis is laid on a comparative assessment of $\beta$-cell stimulus-secretion coupling-comparing both the two species as well as the preparations used to collect the data. The second and main part of this work first compares general aspects of stimulus-secretion coupling in healthy and diabetic rats. Subsequently the central question of a putative downstream lesion in insulin containing LDCV release in diabetic $\beta$-cells is addressed by applying highly time-resolved membrane capacitance measurements to study regulated exocytosis from $\beta$-cells in tissue slices of healthy and diabetic rats. 


\section{Material}

\subsection{Animals}

Experiments were performed on $\beta$-cells within intact islets in pancreatic tissue slices of adult male individuals of healthy Wistar and diabetic GK rats (age 8-18 weeks). GK rats and GK rat breeding pairs were obtained from a commercial supplier (Taconic $\mathrm{M} \& \mathrm{~B}$, Eiby, Denmark) and bred up to $\mathrm{F}_{2}$ in our animal facility. The commercially available GK rats originate from the Aarhus University Hospital colony that has been established in 1994 with animals from the original colony at Tohoku University, Sendai, Japan (Goto et al., 1976). All animals were kept under standard housing conditions and were allowed to feed and drink ad libitum. The rats were sacrificed by $\mathrm{CO}_{2}$ asphyxiation followed by cervical dislocation. Immediately afterwards, blood samples were taken from the tail vein and heart for glucose and insulin measurements, respectively. Blood glucose concentration was measured using the glucose oxidase method (OneTouch Ultra, Lifescan, USA) and plasma insulin measurements were performed with an insulin sandwich enzyme-linked immunoassay (Ultrasensitive Mouse Insulin ELISA Kit, Mercodia, Sweden). Experiments were conducted according to the regulations of our institutional and state committees on animal experiments.

\subsection{Solutions}

We used a standard extracellular solution consisting of (in mM): $125 \mathrm{NaCl}, 2.5 \mathrm{KCl}, 26$ $\mathrm{NaHCO}_{3}, 1.25 \mathrm{Na}_{2} \mathrm{HPO}_{4}, 2 \mathrm{Na}$ pyruvate, 0.25 ascorbic acid, 3 myo-inositol, 6 lactic acid, $1 \mathrm{MgCl}_{2}$ and $2 \mathrm{CaCl}_{2}$. All external solutions were adjusted to $\mathrm{pH} 7.3$ by bubbling with carbogen $\left(95 \% \mathrm{O}_{2}, 5 \% \mathrm{CO}_{2}\right)$ for at least $30 \mathrm{~min}$ before use. If not indicated otherwise, the glucose concentration of the extracellular solution was $3 \mathrm{mM}$. 
Experiments were performed with two different pipette filling solutions. The first intracellular solution (IS-1) was used to measure cellular electrical activity in the currentclamp mode and contained (in $\mathrm{mM}$ ): $132 \mathrm{~K}$-gluconate, $28 \mathrm{KCl}, 10$ Hepes (pH 7.2 with $\mathrm{KOH}$ ), $2 \mathrm{MgCl}_{2}, 0.05$ EGTA and 4 ATP-Na 2 . The second intracellular solution (IS-2) was used to measure $\mathrm{Ca}^{2+}$ currents and contained (in mM) 127 Cs-methanesulfonate, 8 $\mathrm{CsCl}, 10$ Hepes ( $\mathrm{pH} 7.2$ with $\mathrm{CsOH}$ ), $2 \mathrm{MgCl}_{2}, 0.05$ EGTA, 20 tetraethylammonium chloride (TEA) and 4 ATP-Na. For both solutions a higher ATP concentration as otherwise used (Barg et al., 2001: $3 \mathrm{mM}$ ) was chosen to comply with empirical data showing a mean islet ATP concentration of $3.9 \mathrm{mM}$ (Ashcroft et al., 1973). Experiments in which the external $\mathrm{CaCl}_{2}$ concentration was elevated to 7 and $10 \mathrm{mM}$ were performed with reduced $\mathrm{NaCl}$ concentration in the extracellular solution $\left(7 \mathrm{mM} \mathrm{Ca}^{2+}, 119 \mathrm{mM}\right.$ $\mathrm{NaCl} ; 10 \mathrm{mM} \mathrm{Ca}^{2+}, 113 \mathrm{mM} \mathrm{NaCl}$ ) to maintain iso-osmolarity (300 $\left.\pm 10 \mathrm{mOsm}\right)$. The liquid junction potential between the extracellular and intracellular solutions was calculated with the JPCalc software (Barry, 1994) to be 13 and $9 \mathrm{mV}$ for IS-1 and IS-2, respectively and was similar for both the standard and $\mathrm{Ca}^{2+}$-elevated solutions. All potentials were adjusted accordingly. Tolbutamide was dissolved in ethanol to prepare stock solutions of $100 \mathrm{mM}$. Phorbol 12-myristate 13-acetate (PMA) and bisindolylmaleimide I (BIS) were obtained from Calbiochem and stock solutions of $1 \mathrm{mM}$ (PMA) and $2.5 \mathrm{mM}$ (BIS) were prepared in dimethyl sulfoxide (DMSO). The final concentration of DMSO in solution was less than $0.02 \%$. All other chemicals used were purchased from Sigma-Aldrich (USA) unless otherwise indicated.

\subsection{Preparation of pancreatic tissue slices}

The abdominal cavity was opened and warm $\left(37^{\circ} \mathrm{C}\right)$ low gelling temperature agarose $(1 \% \mathrm{w} / \mathrm{v}$, Seaplaque GTG agarose, BMA Products, USA) was injected into the distally (duodenal side) clamped bile duct. Prior to the injection a ligature was performed at the height of the hepatic bifurcation of the bile duct to prevent the injected agarose from flowing backwards towards the liver. After injection, the pancreas was cooled down fast with ice-cold extracellular solution. The hardened pancreas was extracted and submerged in ice-cold extracellular solution. To reduce ischemic damage of the 
tissue, care was taken to ensure that less than 10 min elapsed from the stoppage of cardiac activity to cooling down of the preparation. The tissue was inserted into a small dish filled with warm $\left(37^{\circ} \mathrm{C}\right)$ agarose and then immediately cooled down on ice. A small cube was cut out of the agarose-embedded pancreatic tissue and glued (Super Glue $^{\mathrm{TM}}$, ND Industries, USA) onto the probe plate of a vibratome (VT $1000 \mathrm{~S}$, Leica, Germany). The tissue was sliced at a speed of $0.05 \mathrm{~mm} \mathrm{~s}^{-1}$ at $75 \mathrm{~Hz}$ into $200 \mu \mathrm{m}$ thick slices of $\sim 1 \times 1 \mathrm{~cm}$. During slicing and for storage the tissue slices were kept in ice-cold extracellular solution and were continuously bubbled with carbogen. Before starting the experiments slices were incubated for at least $30 \mathrm{~min}$ at $32^{\circ} \mathrm{C}$ in carbogenated extracellular solution. Experiments regularly started within $1 \mathrm{~h}$ after tissue extraction and could be performed for up to $8 \mathrm{~h}$.

\subsection{Imaging}

\subsubsection{Immunocytochemistry}

The immunostaining of insulin- and glucagon-containing islet cells was performed using the following standard protocol: First, fresh slices were permeabilized and fixed by incubation in $4 \%$ paraformaldehyde and $0.3 \%$ Triton X-100 in phosphate buffered saline (PBS) for $30 \mathrm{~min}$ at room temperature. After repeated washing steps $(3 \times 5 \mathrm{~min}$ in PBS) the primary anti-insulin (mouse, monoclonal) and anti-glucagon (rabbit, polyclonal; Dako, USA) antibodies were added at dilutions of 1:1000 and 1:500 in PBS and $3 \%$ bovine serum albumin (BSA). After $2 \mathrm{~h}$ of incubation at $37^{\circ} \mathrm{C}$ (or alternatively overnight at $4^{\circ} \mathrm{C}$ ) and 5 min of washing in PBS the secondary antibodies Alexa 488 (goat anti-mouse, Molecular Probes, USA) and Alexa 647 (goat anti-rabbit, Molecular Probes, USA) at a dilution of 1:500 in PBS were added for $45 \mathrm{~min}$ at $37^{\circ} \mathrm{C}$. After additional washing in PBS the slices were mounted on microscope slides with the SlowFade Light Antifade Kit (Molecular Probes, USA) to prevent bleaching of the specimen.

Images of the stained islet cells were obtained using a confocal microscope (TCS SP2, Leica, Germany). The fluorophores were excited using laser lines of $488 \mathrm{~nm}(\mathrm{Ar})$ and $633 \mathrm{~nm}(\mathrm{He}-\mathrm{Ne})$. Emission was detected at 505-530 nm (green channel), and $656 \mathrm{~nm}$ (red channel). 


\subsection{2 $\mathrm{Ca}^{2+}$-imaging}

\section{Single-cell $\mathrm{Ca}^{2+}$-imaging}

The water soluble $\mathrm{K}^{+}$-salt of Fura-PE3 (TEF Labs, USA, $50 \mu \mathrm{M}$ added to the pipette solution) was used to monitor intracellular $\mathrm{Ca}^{2+}$ concentration changes $\left(\Delta\left[\mathrm{Ca}^{2+}\right]_{\mathrm{i}}\right)$ simultaneously with the patch-clamp recordings. Fura-PE3 was used because it is less prone to compartmentalization and leakage from cells than the commonly used Fura-2 while still showing identical spectral characteristics (Quigley et al., 1995). Monochromatic light (Polychrome IV; TILL Photonics, Germany) alternating between 340 and $380 \mathrm{~nm}$ $(50 \mathrm{~Hz})$ was short-pass filtered (at $410 \mathrm{~nm})$, reflected by a dichroic mirror (centered at $400 \mathrm{~nm}$ ) and directed through a $60 \times$ water immersion objective (CFI Fluor, N.A. = 1) focussed on the vertical midline of the patched and loaded cell. The emitted fluorescence was transmitted by the dichroic mirror and further filtered through a $470 \mathrm{~nm}$ barrier filter. Contrast enhancing elements like the DIC prism were removed from the light path to obtain optimal transmission conditions. Images were obtained using a cooled front-illuminated frame-transfer emCCD camera (Ixon, Andor Technology, Japan) and native Andor software. A subarea of $256 \times 128$ pixels of the CCD chip was illuminated for $6 \mathrm{~ms}$ per wavelength and $2 \times 2$ on-chip binning was performed to reduce image noise and achieve sufficient acquisition speed.

$\left[\mathrm{Ca}^{2+}\right]_{\mathrm{i}}$ was calculated from the background subtracted intensity ratios of the images obtained with 340 and $380 \mathrm{~nm}$ excitation using the equation derived by Grynkiewicz et al. (1985):

$$
[\mathrm{Ca}]_{\text {free }}=K_{d}^{*} \times \frac{R-R_{\text {min }}}{R_{\text {max }}-R}
$$

A 3-point in situ calibration was performed by dialyzing $\beta$-cells with IS-2 of low $(\sim 0 \mu \mathrm{M})$, medium $(0.367 \mu \mathrm{M})$ and high $(\sim 36 \mu \mathrm{M})$ free $\mathrm{Ca}^{2+}$ concentrations to obtain the fluorescence ratios $R_{\min }, R_{\text {def }}$ and $R_{\max }$, respectively. For low $\mathrm{Ca}^{2+} 10 \mathrm{mM}$ of $\mathrm{K}$ EGTA was added and high $\mathrm{Ca}^{2+}$ was obtained using $10 \mathrm{mM}$ of Ca-EGTA. To achieve a sufficiently high $\mathrm{Ca}^{2+}$ concentration, all calibration solutions contained $1 \mathrm{mM}$ ATP instead of $4 \mathrm{mM}$ to reduce the buffering effect of ATP. The defined $\mathrm{Ca}^{2+}$ concentration was achieved by mixing Ca-EGTA and K-EGTA at a ratio of $2 . \overline{3}: 1$. Free $\mathrm{Ca}^{2+}$ was 
calculated using the MaxChelator software (Patton et al., 2004). The apparent $K_{d}$ for the experimental conditions used in this study was calculated according to

$$
\mathrm{K}_{\mathrm{d}}^{*}=[\mathrm{Ca}]_{\mathrm{def}} \times \frac{\mathrm{R}_{\mathrm{max}}-\mathrm{R}_{\mathrm{def}}}{\mathrm{R}_{\mathrm{def}}-\mathrm{R}_{\max }}
$$

The in situ calibration was performed using 2-3 cells for each calibration solution. The resulting apparent $K_{d}$ was $K_{d}^{*}=1.2 \mu M$ and $R_{\min }$ and $R_{\max }$ were determined to be 0.14 and 0.98 , respectively.

All necessary calculations were performed using a custom written Matlab (MathWorks Inc., USA) script and the image acquisition and hardware triggering parameters were calculated and controlled by a custom AndorBasic (Andor Technology, Japan) program.

In addition to monitoring $\left[\mathrm{Ca}^{2+}\right]_{\mathrm{i}}$, images of the dye loaded cells were used for the morphometric analysis of cell size to complement the resting membrane capacitance $\left(C_{m}\right)$ measurements (see below, section 2.5). The $\beta$-cell cross-sectional area $(A)$ of a custom-shaped region of interest (ROI) enclosing the cell perimeter of the midline focus section was determined with the WiseVision software (Wise Technologies, Ljubljana, Slovenia). The total surface area (F) of the cell was approximated by assuming spherical cell shape according to

$$
\begin{aligned}
& A=\pi r^{2} \\
& F=4 A
\end{aligned}
$$

The obtained images were size-calibrated using images of fluorescent microspheres ( $4 \mu \mathrm{m}$, Molecular Probes, USA) excited at $380 \mathrm{~nm}$.

\section{Islet $\mathrm{Ca}^{2+}$-imaging}

To observe glucose-induced $\Delta\left[\mathrm{Ca}^{2+}\right]_{\mathrm{i}}$ in a large number of islet cells, slices were bulk loaded with the acetoxymethyl (AM) ester of Fura-PE3 (Stock: $4 \mathrm{mM}$ in DMSO with 5\% pluronic acid F-127, Molecular Probes, USA). Fresh slices were loaded with $\mathrm{Ca}^{2+}$-indicator by incubation in standard extracellular solution containing a final concentration of $6 \mu \mathrm{M}$ Fura-PE3-AM. After loading for $60 \mathrm{~min}$ on an orbital shaker, the slices were incubated for at least $15 \mathrm{~min}$ in indicator-free extracellular solution at $32^{\circ} \mathrm{C}$ 
to achieve a sufficient degree of deesterification. The final concentrations of DMSO and pluronic acid in the loading solution were $0.15 \%$ and $0.007 \%$.

A similar setup was used for islet imaging as for single cell $\mathrm{Ca}^{2+}$-imaging except that a $20 \times$ water immersion objective (CFI Fluor, N.A. $=0.5$ ) was used and ratio image pairs were obtained at a frequency of $1 \mathrm{~Hz}$ (exposure time: $60 \mathrm{~ms}$ per image). Images were obtained from medium sized islets at a focal plane well below the first layer of cells close to the islet center. The excitation light intensity was reduced by two neutral density filters (ND8, ND4) to minimize phototoxic effects resulting from UV-exposure as much as possible. Furthermore, excitation light was constantly shut off except during periods of CCD exposure. Images were $512 \times 512$ pixels in size and $2 \times 2$ on chip binning was performed to reduce noise and file size. The images taken during 340 and $380 \mathrm{~nm}$ excitation were background corrected by subtracting the average pixel intensity of tissue free areas from the intensity values of all image pixels for each frame of the time-lapse recording separately. The $\mathrm{F}_{340} / \mathrm{F}_{380}$ ratio images presented in this work have been subjected to a Gauss filter (mask size: $5 \times 5$ pixel, $\sigma=2$ ) and noise was further reduced by $4 \times$ temporal binning. Mean pixel values from ROIs of the $\mathrm{F}_{300} / \mathrm{F}_{380}$ images were obtained from the raw data before any image processing was performed. Image analysis and acquisition were done using the Andor software in connection with custom written AndorBasic scripts. Because actual $\left[\mathrm{Ca}^{2+}\right]_{\mathrm{i}}$ levels were of no interest in this particular experiments, no attempt was made to calibrate the fluorescence intensity ratios.

All experiments were performed under constant perfusion of the recording chamber with carbogenated extracellular solution at $37^{\circ} \mathrm{Cat}$ a constant flow rate of $\sim 1.5 \mathrm{ml} \mathrm{min}^{-1}$. The delay time for a solution change to reach the recording chamber ranged form $40-45$ s. All data was adjusted accordingly.

\subsection{Electrophysiology}

Slices were held on the bottom of the recording chamber by a U-shaped platinum wire, the side ends of which were connected with parallel nylon strings. An upright microscope (Eclipse E600FN, Nikon, Japan) with 10× (CFI Fluor, N.A. = 0.3) dry 
objective and $60 \times$ water-immersion objective (CFI Fluor, N.A. = 1) together with a CCD camera (Cohu, San Diego, CA, USA) was used for visualization.

Recordings were performed from cells in the second or third cell-layer of pancreatic islets using the standard whole-cell configuration of the patch-clamp technique. Both the current- and the voltage-clamp mode were used to measure changes in $V_{m}$ and membrane currents $\left(\mathrm{I}_{\mathrm{m}}\right)$, respectively. The voltage-clamp technique was further used to measure changes in membrane capacitance $\left(\Delta \mathrm{C}_{\mathrm{m}}\right)$, a parameter proportional to cell surface area changes due to exocytosis and endocytosis (Neher and Marty, 1982). The experiments were performed under constant perfusion at $31-33^{\circ} \mathrm{C}$.

All experiments were performed on a SWAM II C dual-phase lock-in patch-clamp amplifier (Celica, Ljubljana, Slovenia). Data were filtered at $3 \mathrm{kHz}$ by an $\mathrm{A} / \mathrm{D}$ converter (National Instruments, USA). Recording, stimulation and preliminary analysis was performed using the WinWcp software (v3.52, John Dempster, University of Strathclyde, UK). Patch pipettes were pulled (P-97; Sutter Instruments, USA) from borosilicate glass capillaries (GC150F-15; WPI, USA) to a resistance of 2-4 M $\Omega$ in both K-gluconate and Cs-methanesulfonate based solutions. After the whole-cell configuration has been established and the fast pipette capacitance $\left(\mathrm{C}_{\mathrm{fast}}\right)$ compensation has been carried out, the slow membrane capacitance $\left(\mathrm{C}_{\text {slow }}\right)$ and series conductance $\left(\mathrm{G}_{\mathrm{s}}\right)$ were compensated as well. Only experiments with a series resistance lower than $20 \mathrm{M} \Omega$ were processed. The $\mathrm{C}_{\text {slow }}$ values obtained by the compensation procedure where further used as data for the estimation of the surface area of the patched cells assuming a specific $C_{m}$ of $9 \mathrm{fF} / \mu \mathrm{m}^{2}$ (MacDonald et al., 2005).

If not noted otherwise, all currents were analyzed and presented after $\mathrm{p} / \mathrm{n}$ leak subtraction of passive linear current components resulting from technical leak as well as from other non-voltage-dependent conductances. In most cases, the changes in membrane current $\left(\Delta \mathrm{I}_{\mathrm{m}}\right)$ resulting from two voltage steps that equaled the subsequent test pulses scaled down by -4 were averaged, multiplied by -4 and subtracted from the $\Delta \mathrm{I}_{\mathrm{m}}$ resulting from the actual test pulse. For train stimulations only one $\mathrm{p} / \mathrm{n}$ test pulse was generated to decrease the protocol duration. Leak subtraction was performed off-line using either the WinWcp software or custom Matlab (Mathworks, Novi, MI, USA) scripts that were used for batch processing and analysis of recordings. 
To assess changes in membrane capacitance $\left(\Delta \mathrm{C}_{\mathrm{m}}\right)$ the piecewise linear technique was used. For that purpose, a sine-wave was superimposed on the holding current. The gap-junctional electrical connection between $\beta$-cells possibly decreases the goodness of the achieved voltage-clamp and therefore might introduce a technical artifact into the later $\mathrm{C}_{\mathrm{m}}$ readout. Kanno et al. (2004) showed that this bias can be minimized by using a high-frequency sine-wave stimulation and we therefore chose a frequency of $1.6 \mathrm{kHz}$ and an amplitude of $11 \mathrm{mV}$ RMS. For the duration of depolarizing pulses the sinusoidal current was switched off to enable the measurement of $\mathrm{I}_{\mathrm{m}}$. Since changes in membrane capacitance $\left(\Delta \mathrm{C}_{\mathrm{m}}\right)$ introduce a phase change in the resulting sinusoidal $I_{m}$ that is orthogonal to the change introduced by alterations in the resistive properties of the cell-i.e. membrane and access resistance $\left(R_{m}\right.$ and $\left.R_{a}\right)-\Delta C_{m}$ can be directly measured using a phase-sensitive detector (Gillis, 1995). The phase angle for $\Delta \mathrm{C}_{\mathrm{m}}$ detection was set manually in the beginning of a recording. For that purpose a calibrated signal of $1 \mathrm{pF}$ was repeatedly switched on and off and the resulting output on the $\mathrm{C}_{\mathrm{m}}$ and $\mathrm{G}_{\mathrm{ac}}$ channels was monitored. The phase angle was adjusted in a way that no changes corresponding to the simulated capacitance change could be observed on the $\mathrm{G}_{\mathrm{ac}}$ trace. Additionally, before and after each depolarization protocol the correct setting of the phase angle was tested and readjusted if necessary. The deflection of the $\mathrm{C}_{\mathrm{m}}$ trace in response to the $1 \mathrm{pF}$ test pulse was taken to calibrate the measured $\mathrm{C}_{\mathrm{m}}$ values. To determine $\Delta \mathrm{C}_{\mathrm{m}}$ in response to depolarizing pulses, $\mathrm{C}_{\mathrm{m}}$ was first averaged over the $30 \mathrm{~ms}$ preceding the depolarization to obtain a baseline value which was subtracted from the value estimated after the depolarization averaged over a $40 \mathrm{~ms}$ window. The first $30 \mathrm{~ms}$ after the depolarization were excluded from the $\mathrm{C}_{\mathrm{m}}$ measurement to avoid contamination by non-secretory capacitive transients related to gating charge movement (Horrigan and Bookman, 1994) (see fig. 3.7 A, p. 47, second panel, dotted vertical lines). In most cases no asynchronous release was detected and experiments showing fast endocytosis after stimulus cessation were discarded. Only experiments not displaying crosstalk between the $\mathrm{C}_{\mathrm{m}}$ and $\mathrm{G}_{\mathrm{ac}}$ trace were used for analysis (see fig. 3.7). To calculate the calcium charge entry, the first $2 \mathrm{~ms}$ of the inward current integral were omitted to reduce the contamination with $\mathrm{Na}^{+}$current (see fig. 3.7 A, lower panel, dotted vertical line). No tetrodotoxin was used to enable $\beta$-cell identification (see below) and reduce 
$\mathrm{Na}^{+}$channel gating charge transients that potentially contaminate the $\mathrm{C}_{\mathrm{m}}$ measurements (Horrigan and Bookman, 1994).

$\mathrm{Ca}^{2+}$ current and therefore also $\mathrm{Ca}^{2+}$-triggered $\Delta \mathrm{C}_{\mathrm{m}}$ decreased significantly during recording in the standard whole-cell configuration (see fig. 3.7 A, p. 47). Therefore, special care has been taken to ensure that $\mathrm{C}_{\mathrm{m}}$ measurements in which $\mathrm{I}_{\mathrm{Ca}^{2+}}$ was not monito red in parallel were performed at the same starting time after whole-cell breakthrough. The most measurements therefore were performed after $120 \mathrm{~s}$ of whole-cell dialysis.

In dual-pulse protocols that were used to assess the maximal sizes of releasable pools of LDCVs (see fig. 3.16 and 3.17) no attempt was made to adjust the second pulse for $\mathrm{Ca}^{2+}$-dependent inactivation of $\mathrm{Ca}^{2+}$ current because adjustments of the depolarization amplitude did not reproducible yield comparable charge entry. A slightly smaller inward current for the second depolarization pulse was therefore considered acceptable, because one has to assume that $\mathrm{Ca}^{2+}$ entering during the second depolarization will be added to the already increased cytosolic $\left[\mathrm{Ca}^{2+}\right]$ elicited by the first depolarization (Dinkelacker et al., 2000).

Single $\beta$-cells were primarily identified based on the steady-state inactivation properties of voltage-activated $\mathrm{Na}^{+}$currents (Göpel et al., 1999; Lou et al., 2003; Speier and Rupnik, 2003; Meneghel-Rozzo et al., 2004) (see chapter 3.1.2). The cells were subjected to conditioning prepulses ranging from -159 to $-9 \mathrm{mV}$ to achieve steady state inactivation. Immediately afterwards a test pulse to $-9 \mathrm{mV}$ elicited inward $\mathrm{Na}^{+}$ currents. The resulting currents were normalized to the maximal $\mathrm{Na}^{+}$current amplitude, plotted as a function of the prepulse potential and fitted with the Boltzmann equation:

$$
\mathrm{I} / \mathrm{I}_{\max }=\frac{1}{1+e^{\left[\frac{\mathrm{V}-\mathrm{V}_{1 / 2}}{\mathrm{k}}\right]}}
$$

The distribution of half-maximal inactivation voltages $\left(\mathrm{V}_{1 / 2}\right)$ was described using a Gauss function (see fig. 3.3):

$$
f(x)=a e^{\left[-0.5 \times\left(\frac{x-\bar{x}}{\sigma}\right)^{2}\right]}
$$

To shorten the time needed to identify $\beta$-cells according to their $\mathrm{I}_{\mathrm{Na}^{+}}$inactivation characteristics, the presence of transient inward currents of similar size at a single voltage 
step from $-84 \mathrm{mV}$ to $-24 \mathrm{mV}$ in comparison to a step form $-154 \mathrm{mV}$ to $-24 \mathrm{mV}$ was taken as indicative for non- $\beta$-cells. An additional criterion for $\beta$-cell identification was the occurrence of electrical activity in the presence of stimulatory glucose concentrations. The likelihood of patching $\beta$-cells was increased further by recording from cells in deeper layers of the islets.

Additional voltage protocols used in the current study are described with the particular data sets. For data analysis and figure preparation we used Matlab, Matview (Matlab WinWCP extension, Wise Technologies, Ljubljana, Slovenia), Sigmaplot and Sigmastat (SPSS, Chicago, IL, USA). Statistics are given as means \pm s.E.M. and statistical significance was tested by paired and unpaired Student's t-tests as indicated. 


\section{Results}

\subsection{Characterization of rat pancreatic tissue slices}

\subsubsection{The rat tissue slice preparation}

After minor modifications were applied to the original protocol (Speier and Rupnik, 2003), the tissue slice preparation of mouse pancreas could be successfully transferred to the rat. The modifications of the preparation procedure primarily were concessions to the different dimensions of mice and rats: Because of the much bigger common bile duct in rats it turned out to be mandatory to prevent the injected agarose from flowing backwards into the liver by performing a ligature posterior to the injection site (see section 2.3). Because of the bigger size of the pancreas itself, spatial considerations also played a more important role for choosing the tissue-part to be extracted. The duodenal body part and right lobe of the pancreas (Miyaki et al., 1994) were generally discarded because the injected tissue in this regions was not dense enough to yield a sufficient number of islets per slice. Furthermore, the abundance of big and rigid pancreatic ducts made it difficult to obtain tissue slices from this region. Therefore, almost exclusively injected tissue from the left pancreatic lobe proximal to the spleen was extracted and used because of the homogenous fabric of the tissue and the high density of islets (Svensson et al., 2005) in this region. On average, typical slices from the size of $\sim 1 \mathrm{~cm}^{2}$ contained $4 \pm 0.3$ ( $n=20$ slices and 73 islets) islets (see fig. 3.1). Because rat islets turned out to be sensitive to the mechanical stress introduced by the slicing procedure, the thickness of the slices was increased as compared to the mouse preparation $(200 \mu \mathrm{m}$ vs. $150 \mu \mathrm{m})$. This greatly improved the yield of intact islets as judged by their cell-density (see below).

The morphology of both the exocrine and endocrine pancreas in rat tissue slices was well preserved (see fig. 3.1 C, D). In transmitted light, islets of Langerhans could be 


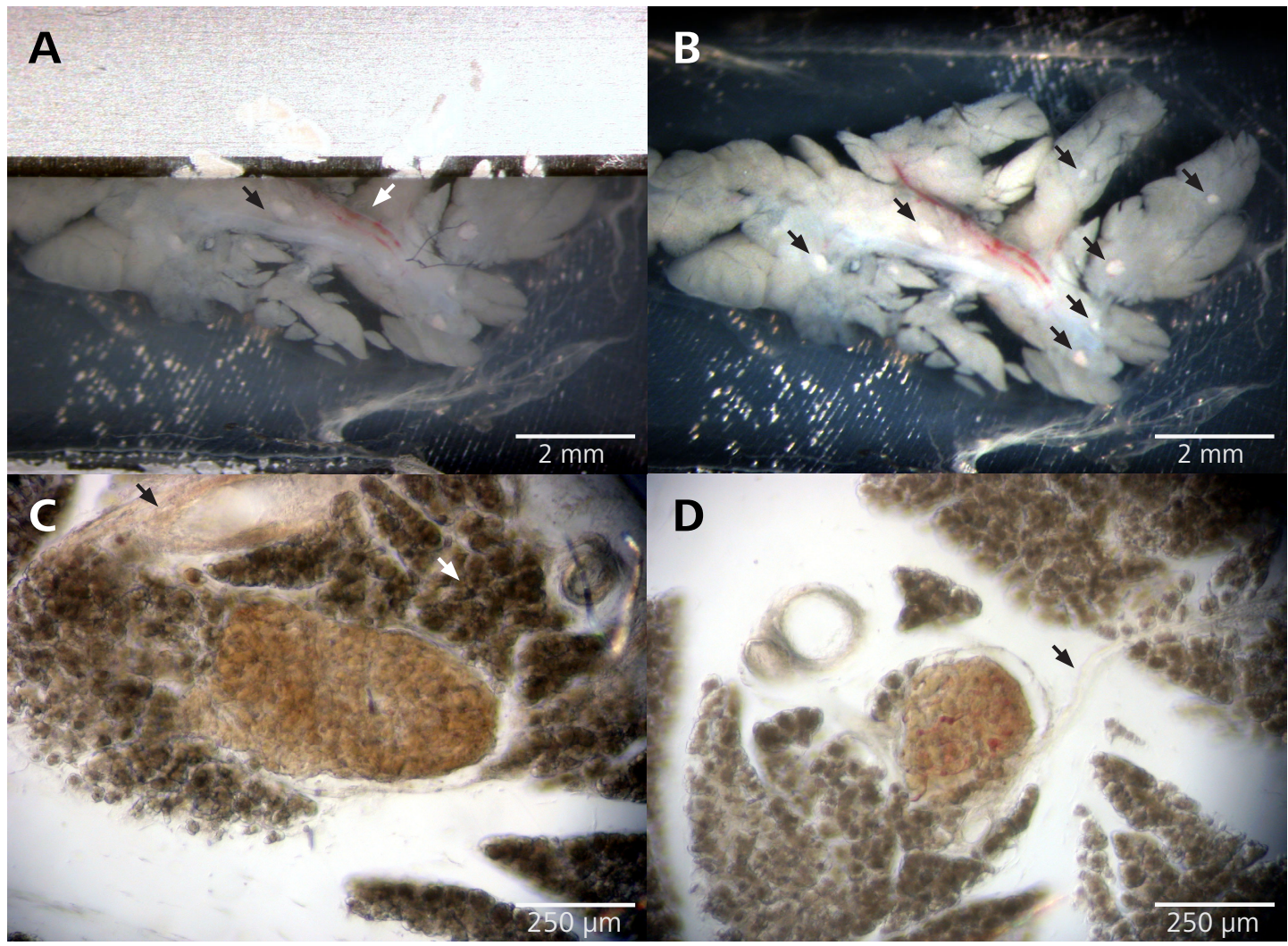

Figure 3.1: Pancreatic tissue slices. (A) Agarose-embedded pancreatic tissue of Wistar rats during the slicing procedure. Blood vessel (white arrow), pancreatic duct (black arrow). (B) Same as in (A) with retracted blade. Note the clearly visible islets (arrows). (C, D) Transmitted light images of Wistar rat tissue slices. Central islets are surrounded by exocrine tissue. Further visible structures are a pancreatic duct (C, black arrow), exocrine tissue (C, white arrow) and an afferent or efferent blood vessel (D, black arrow).

clearly distinguished from the surrounding exocrine tissue because of their orange-brown color. Pancreatic structures like the dark acinar cells that constitute the exocrine pancreas as well as pancreatic ducts and afferent or efferent blood vessels were clearly visible.

The isolation procedures commonly used to study islet physiology tend to be selective for islets of a certain size and shape. In rat pancreatic tissue slices, however, islet morphology was highly variable. Islets of simple round shapes were as frequent as elongated structures and the sizes ranged from small cell clusters of $\sim 50 \mu \mathrm{m}$ to big islets of up to $\sim 1 \mathrm{~mm}$. The four representative islets of fig. 3.2 have been immunostained 


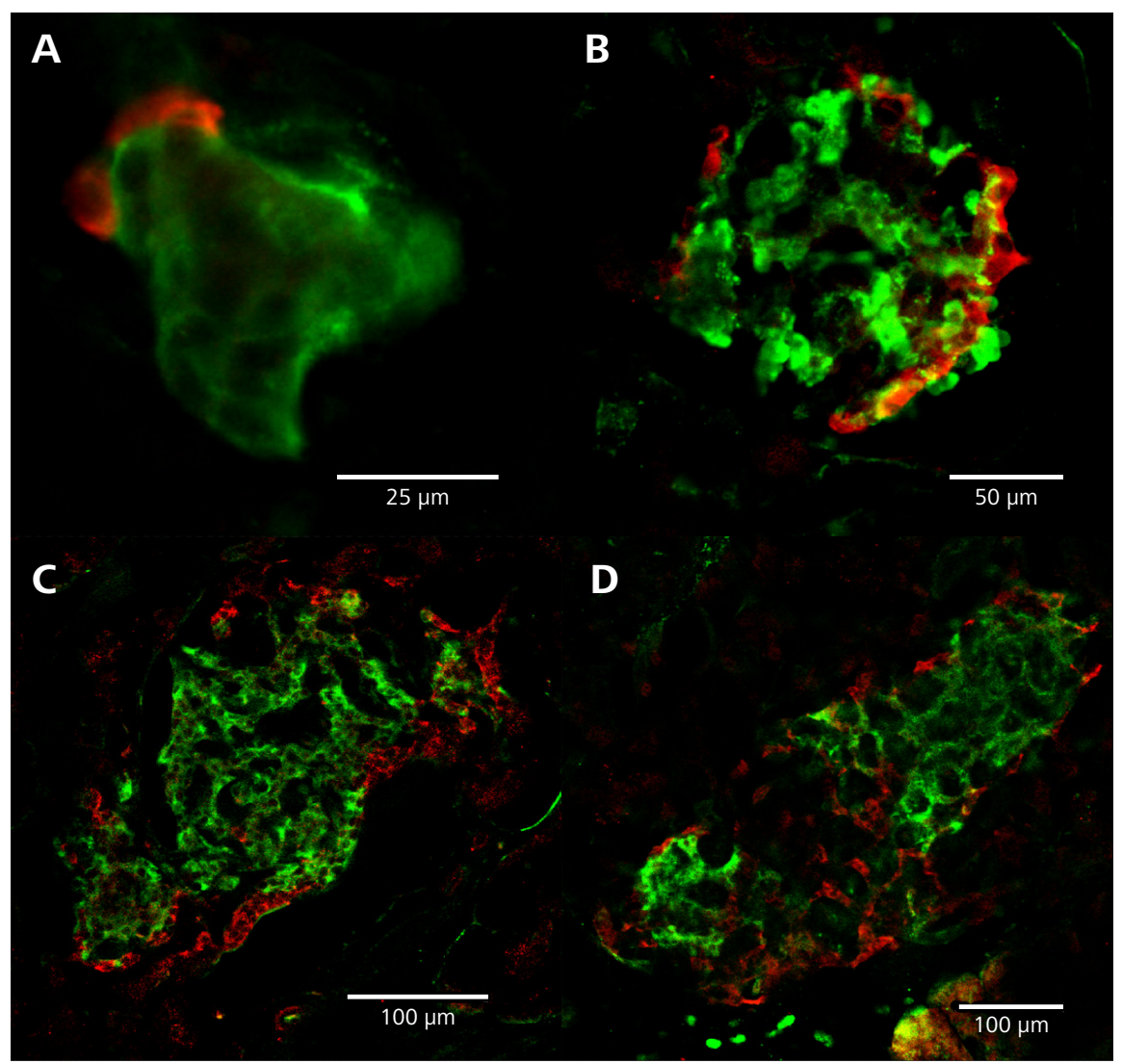

Figure 3.2: Islets of Langerhans. (A-D) Confocal images of 4 different rat islets of Langerhans stained with anti-insulin (green) and anti-glucagon (red) antibodies. Note the mantle/core organization of the islets and the variety of islet shapes and sizes in pancreatic tissue slice preparation. The structure of islet $\mathrm{D}$ has been disrupted by the slicing procedure.

against insulin and glucagon and whereas the long axis of the islet shown in fig. 3.2 A has a diameter of $50 \mu \mathrm{m}$, the long axis diameter of islet $\mathrm{D}$ is $600 \mu \mathrm{m}$. It is also evident from this pictures that rat islets in tissue slices retain their characteristic organization: The center of the islets is almost exclusively comprised of insulin-containing $\beta$-cells that constitute the biggest part of the islet cell mass and the outer cell layer predominantly contains glucagon-positive $\alpha$-cells.

In general, the cells of rat islets in tissue slices appeared to be less densely packed than in mice. Especially islets that where cut during the slicing procedure showed a 
disrupted morphology with strands of cells enclosing apparently cell-free spaces (see fig. 3.2 D). However, also islets of undisturbed integrity—as judged by an intact connective tissue capsule surrounding the respective islets on all sides—frequently showed a similar, albeit less pronounced morphology. In many cases erythrocytes were visible in these cell-free regions, thus suggesting that these spaces are occupied by islet microvessels. Electrophysiological experiments were predominantly performed in deeper cell-layers of intact islets in which the connective tissue capsule could either be penetrated by movements of the patch pipette or in which the capsule already was slightly cut, thus providing unhindered access to the cells.

\subsubsection{Electrophysiological characterization of rat $\beta$-cells}

\section{Cell identification}

Functional identification of pancreatic $\beta$-cells by electrophysiological means is commonly performed by elevating the external glucose concentration. Spiking electrical activity elicited in cells by this stimulation regime is generally regarded as a $\beta$-cellexclusive hallmark (Dean and Matthews, 1968). Cells that have been functionally identified in this way exhibit a sizable inward $\mathrm{Na}^{+}$current (Plant, 1988). In contrast to cells not showing electrical activity in high glucose, this current is already fully inactivated at the normal $\beta$-cell resting membrane potential of -70 to $-90 \mathrm{mV}$ (Ashcroft and Rorsman, 1989; Göpel et al., 1999) in mouse but also in rat $\beta$-cells (Plant, 1988; Hiriart and Matteson, 1988). Accordingly, the steady-state inactivation properties of $I_{\mathrm{Na}^{+}}$have repeatedly been used as a quick way to identify $\beta$-cells in primary cell cultures (Yang et al., 2004; Speier et al., 2005) as well as in more intact preparations (Göpel et al., 1999; Speier and Rupnik, 2003).

Using a standard protocol of conditioning prepulses ranging from very negative to more positive membrane potentials $(-159$ to $-9 \mathrm{mV}$ ) followed by a test pulse to $-9 \mathrm{mV}$ the inactivation properties of rat islet cells in tissue slice preparation were assessed (see fig. 3.3). The average leak corrected peak inward $\mathrm{Na}^{+}$current in these cells was $1102 \pm 95.3 \mathrm{pA},(n=31)$. Of 78 cells tested in total, only 8 cells showed half-maximal inactivation at conditioning potentials $\left(\mathrm{V}_{1 / 2}\right)$ more positive than $-60 \mathrm{mV}$. The remaining cells had an average $V_{1 / 2}$ of $-98 \pm 1.4 \mathrm{mV}$. This value lies between the 
A
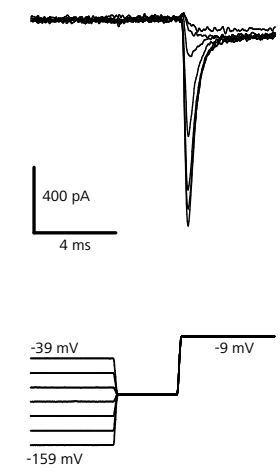

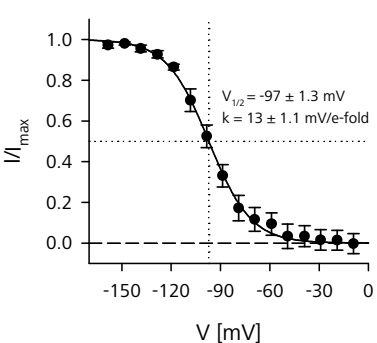

B
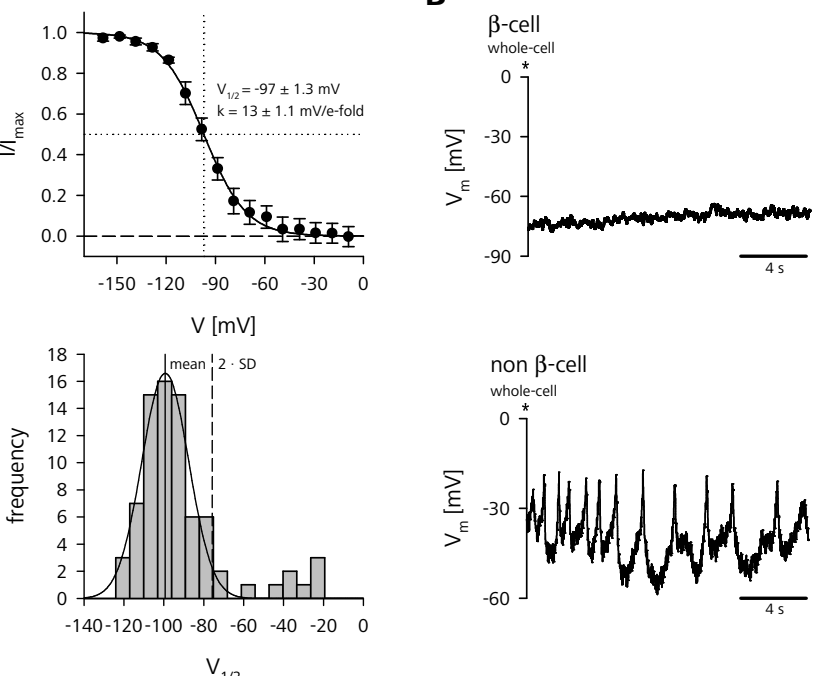

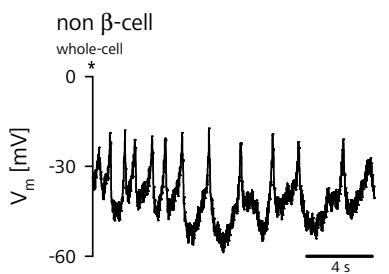

Figure 3.3: Identification of rat $\beta$-cells based on the steady-state inactivation characteristics of voltage-gated $\mathrm{Na}^{+}$currents. (A) The cells were subjected to conditioning prepulses $(50 \mathrm{~ms})$ ranging from -159 to $-9 \mathrm{mV}$ to achieve steady state inactivation. After a delay of $3 \mathrm{~ms}$ at a holding potential of $-89 \mathrm{mV}$ a test pulse to $-9 \mathrm{mV}$ of $5 \mathrm{~ms}$ duration elicited inward $\mathrm{Na}^{+}$currents (left panels). If plotted against the prepulse potential and fitted with the Boltzmann equation (eqn. 2.5 ), normalized $\mathrm{Na}^{+}$currents $\left(\mathrm{I} / \mathrm{I}_{\max }\right)$ of 31 cells (intracellular solution: IS-2) show half-maximal inactivation $\left(\mathrm{V}_{1 / 2}\right)$ at a potential of $-97 \pm 1.3 \mathrm{mV}$ (upper right panel, dotted lines). The histogram of $\mathrm{V}_{1 / 2}$ values of 78 cells (including cells measured without leak correction and cells patched with IS-1) shows normal distribution for $V_{1 / 2}$ centered at $\bar{x}=-98 \mathrm{mV}$ (eqn. 2.6). (B) $\beta$ - and non- $\beta$-cells identified by $V_{1 / 2}$ being more negative $(\beta)$ or more positive (non- $\beta$ ) than the mean $\mathrm{V}_{1 / 2}$ plus double standard deviation (i.e. $-75 \mathrm{mV}$ ).

frequently reported $-110 \mathrm{mV}$ for mouse $\beta$-cells (Plant, 1988; Göpel et al., 1999) and the $-90 \mathrm{mV}$ recently demonstrated for isolated rat $\beta$-cells (Lou et al., 2003). All cells showing a $V_{1 / 2}$ more positive than $-75 \mathrm{mV}$-i.e. double standard deviation $(11.5 \mathrm{mV})$ of the average $V_{1 / 2}$-were considered to be non- $\beta$-cells. Upon establishment of the whole-cell configuration, Wistar rat $\beta$-cells identified accordingly did not show any electrical activity in the absence of stimulatory glucose concentrations. Non- $\beta$-cells, however, occasionally fired single action potentials in $3 \mathrm{mM}$ external glucose (see fig. 3.3). 
A
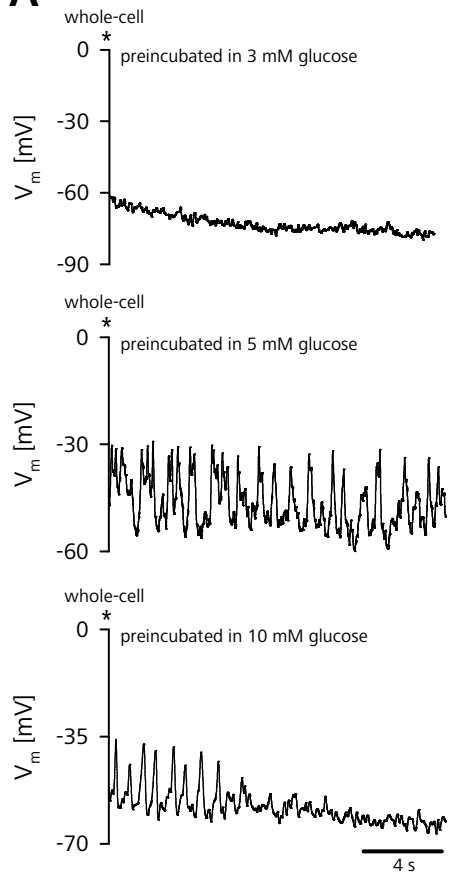

B

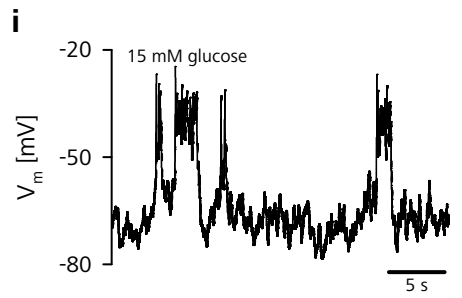

ii

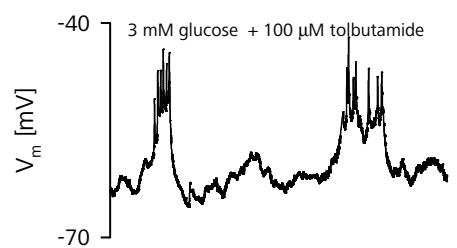

$\sum_{-70}^{\sum_{-E}}$

Figure 3.4: Electrical activity in rat $\beta$-cells. (A) Spiking activity of three different $\beta$-cells preincubated at different glucose concentrations and monitored immediately after establishment of the whole-cell configuration $\left(^{*}\right)$. (B) Electrical activity of two cells after prolonged periods of whole-cell dialysis. (i) Bursting electrical activity after a recording duration of $6 \mathrm{~min}$ and $1.5 \mathrm{~min}$ perifusion with $15 \mathrm{mM}$ glucose. (ii, upper panel) Bursting measured after 25 min of whole-cell dialysis and 10 min with $100 \mu \mathrm{M}$ tolbutamide. (ii, lower panel) High frequent bursting in the same cell 35 min after the beginning of the recording and $8 \mathrm{~min}$ after the glucose concentration was increased to $15 \mathrm{mM}$ in the continued presence of $100 \mu \mathrm{M}$ tolbutamide.

\section{Electrical activity in rat $\beta$-cells}

As stated above, Wistar rat $\beta$-cells were electrically silent at an external glucose concentration of $3 \mathrm{mM}$. The resting $\mathrm{V}_{\mathrm{m}}$ of $\beta$-cells is primarily dependent on the $\mathrm{K}^{+}$conductance of the $\mathrm{K}_{\mathrm{ATP}}$ channels (see section 1.3.1). Therefore, both the intracellular ATP concentration as well as the $\mathrm{K}^{+}$equilibrium potential $\left(\mathrm{E}_{\mathrm{K}^{+}}\right)$govern the resting $\mathrm{V}_{\mathrm{m}}$ of these cells. Because during prolonged whole-cell recording the intracellular ATP- as well as $\mathrm{K}^{+}$concentrations are determined by the composition of the pipette solution, undisturbed measurements of $\mathrm{V}_{\mathrm{m}}$ can only be obtained right in the beginning of a current-clamp 
recording before whole-cell dialysis is complete (Pusch and Neher, 1988). Measured accordingly, rat $\beta$-cells showed a resting $\mathrm{V}_{\mathrm{m}}$ of $-77 \pm 2.5 \mathrm{mV}(n=80)$. This value is in reasonable agreement with the previously reported resting $V_{m}$ of $-50 \mathrm{mV}$ measured with intracellular microelectrodes in isolated rat islet $\beta$-cells (Antunes et al., 2000), considering that different external $\mathrm{K}^{+}$-concentrations have been used $\left(5 \mathrm{mM}\left[\mathrm{K}^{+}\right]_{\mathrm{o}}\right.$ vs. current study: $2.5 \mathrm{mM}\left[\mathrm{K}^{+}\right]_{\mathrm{o}}$ ). This would account for a $18 \mathrm{mV}$ more positive $\mathrm{E}_{\mathrm{K}^{+}}$in the microelectrode recordings if similar cytosolic $\mathrm{K}^{+}$concentrations are assumed.

Further microelectrode measurements have shown that rat $\beta$-cells in intact islets depolarize upon glucose stimulation and exhibit single $\mathrm{Ca}^{2+}$-dependent action potentials (Antunes et al., 2000). In the current study, rat $\beta$-cells in tissue slices rarely showed spiking activity after prolonged periods of whole-cell dialysis. However, if preincubated in glucose concentrations higher than $3 \mathrm{mM}(5-20 \mathrm{mM}$ glucose) for $\sim 10 \mathrm{~min}, 14$ out of $20 \beta$-cells fired action potentials at the start of a recording (see fig. $3.4 \mathrm{~A}$ ). This activity usually presented itself as single spikes of an amplitude of $\sim 20 \mathrm{mV}$. In contrast to previous reports, however, short bursts of $\sim 2-20$ action potentials could also be observed. Usually, the spiking activity ceased in the first minute of whole-cell recording (see fig. $3.4 \mathrm{~A}$, lower trace). Nevertheless, in some cases $\beta$-cells showed electrical activity even after prolonged recording durations (see fig. 3.4 B). In the cell shown in fig. 3.4 Bii, closing of $K_{\text {ATP }}$ channels by extracellular application of the $K_{\text {ATP }}$ channel antagonist tolbutamide $(100 \mu \mathrm{M})$ led to clear oscillatory bursting electrical activity. An increase in the extracellular glucose concentration further depolarized the cell and decreased the inter-burst duration and the number of spikes per burst.

\section{Electrical coupling}

Action potential firing and oscillatory changes in $\mathrm{V}_{\mathrm{m}}$ observed after prolonged cell dialysis usually coincided with fluctuations of the holding current. After switching from the current- to the voltage-clamp mode during periods of oscillatory activity, $\mathrm{I}_{\mathrm{m}}$ frequently showed oscillations as well. These $I_{m}$ changes were in phase with the $V_{m}$ oscillations but were of opposing sign (see fig. 3.5). The activity patterns shown in the $\beta$-cells of fig. $3.4 \mathrm{~B}$ are therefore most likely secondary to electrical activity generated in one ore more neighboring $\beta$-cells. A depolarization in an adjacent cell would result 
A

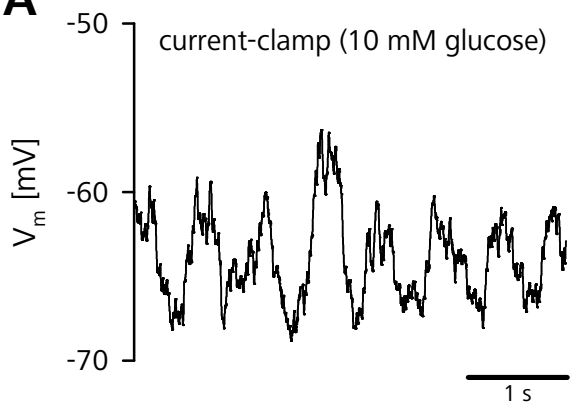

B

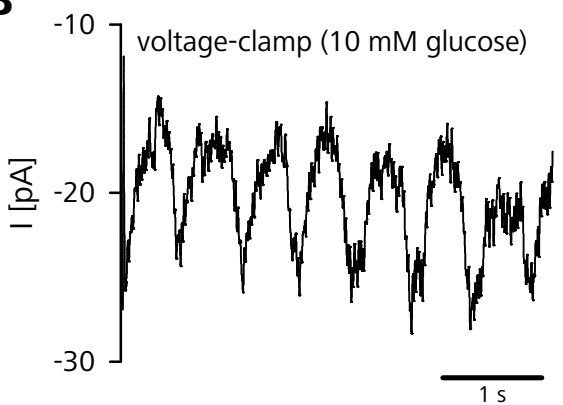

Figure 3.5: Electrical coupling between $\beta$-cells. (A) Whole-cell current-clamp recording of glucose-induced $(10 \mathrm{mM}) \mathrm{V}_{\mathrm{m}}$ oscillations of a $\beta$-cell. Immediately afterwards, recording was continued in the voltage-clamp mode (B). Note the oscillations of identical period but opposing sign in the holding current.

in an injection of current into the patched $\beta$-cell via gap junctions. These changes in $\mathrm{I}_{\mathrm{m}}$ and the corresponding $\mathrm{V}_{\mathrm{m}}$ can be used to estimate the gap junctional conductance (Mears et al., 1995; Göpel et al., 1999). The peak-to-trough amplitudes of $\mathrm{V}_{\mathrm{m}}$ - and $\mathrm{I}_{\mathrm{m}}$-changes $\left(\Delta \mathrm{V}_{\mathrm{m}}, \Delta \mathrm{I}_{\mathrm{m}}\right)$ in the cell shown in fig. 3.5 range from $\sim 5-10 \mathrm{mV}$ and $\sim 5-$ $10 \mathrm{pA}$, respectively. According to Ohm's law $\left(\mathrm{G}_{\mathrm{j}}=\Delta \mathrm{I}_{\mathrm{m}} / \Delta \mathrm{V}_{\mathrm{m}}\right)$ this corresponds to a gap junctional conductance $\left(\mathrm{G}_{\mathrm{j}}\right)$ of $\sim 1 \mathrm{nS}$.

To further quantify electrical coupling of rat $\beta$-cells in our preparation we took advantage of a feature innate to more intact islet preparations. Upon inhibition of $\mathrm{K}_{\text {ATP }}$ channels by sulphonylureas like tolbutamide, single cultured $\beta$-cells show a very small remaining membrane conductance (Speier et al., 2005). Contrariwise, in $\beta$-cells of isolated mouse islets and even more in tissue slice preparation a high residual conductance of $1-1.7 \mathrm{nS}$ remains even if $\mathrm{K}_{\mathrm{ATP}}$ channels are fully blocked. This conductance is commonly attributed to gap junctional coupling (Göpel et al., 1999; Speier et al., 2005). We measured $I_{m}$ in rat $\beta$-cells in response to ramp depolarizations $(-110$ to $60 \mathrm{mV}$, $100 \mathrm{~ms}$ duration: $1.7 \mathrm{mV} \mathrm{s}^{-1}$, see fig. 3.6). At potentials of up to $-50 \mathrm{mV}, \mathrm{I}_{\mathrm{m}}$ was a linear function of $\mathrm{V}_{\mathrm{m}}$. Then voltage-dependent outward currents activated, most likely attributable to the activation of voltage-gated $\mathrm{K}^{+}$channels (Gillis et al., 1989; Ashcroft and Rorsman, 1989). Therefore, the resting membrane conductance was determined from the slope of the IV curves between -100 and $-60 \mathrm{mV}$. The cell shown in fig. $3.6 \mathrm{~A}$ had an initial conductance of $3.6 \mathrm{nS}$ immediately after the whole-cell configuration was 
A

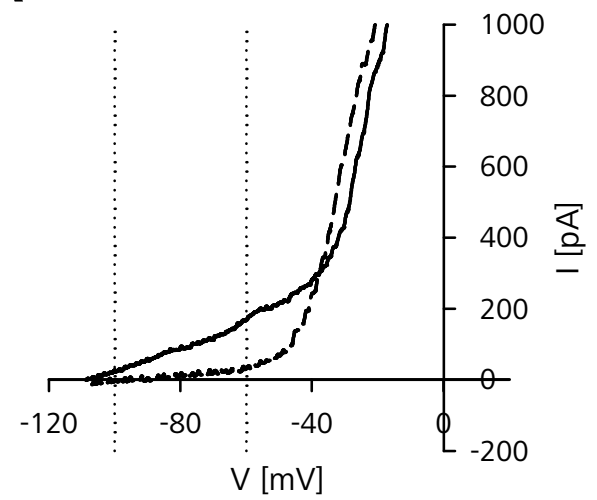

B

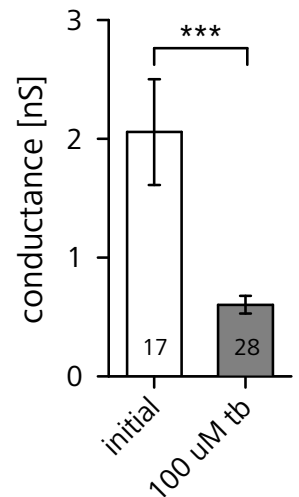

Figure 3.6: Whole cell conductance in $\beta$-cells before and after $K_{\text {ATP }}$ channel inhibition. (A) Current-voltage (IV) relations right after recording begin (solid trace) and after inhibition of $\mathrm{K}_{\mathrm{ATP}}$ channels by extracellular application of $100 \mu \mathrm{M}$ tolbutamide (dashed trace). Current was measured in response to ramp depolarizations from -110 to $60 \mathrm{mV}$ of $100 \mathrm{~ms}$ duration $\left(1.7 \mathrm{mV} \mathrm{s}^{-1}\right)$. No leak subtraction was performed since the $\mathrm{K}_{\text {ATP }}$ as well as gap junction current amplitudes depend effectively linearly on the applied voltage and accordingly would be subtracted as well. (B) Comparison of initial (open bar) and residual conductance after $\mathrm{K}_{\mathrm{ATP}}$ channel inhibition (gray bar) as determined from the slopes of IV curves between -100 and $-60 \mathrm{mV}$ (dotted lines in A). ***, $p \leqslant 0.001$, unpaired t-test. Here and in the following figures error bars represent s.E.M. and numbers on bars indicate the number of cells tested.

established. After application of tolbutamide $0.9 \mathrm{nS}$ residual conductance remained. As expected, membrane conductance was prominently decreased by tolbutamide application in all cells tested (see fig. 3.6). The residual conductance of $0.6 \pm 0.07 \mathrm{nS}(n=28)$, however, was about $50 \%$ lower than the values observed in mouse $\beta$-cells (Göpel et al., 1999; Speier et al., 2005), suggesting that rat $\beta$-cells are significantly less coupled than mice.

\subsubsection{Exocytotic activity in rat $\beta$-cells}

\section{Membrane capacitance measurements as secretory assay}

$\mathrm{C}_{\mathrm{m}}$ measurements have repeatedly been used as a high-resolution assay for insulincontaining LDCV exocytosis of cultured murine $\beta$-cells (Penner and Neher, 1988; Gillis and Misler, 1992; Ammala et al., 1993; Renstrom et al., 1997; Barg et al., 2001; 
A

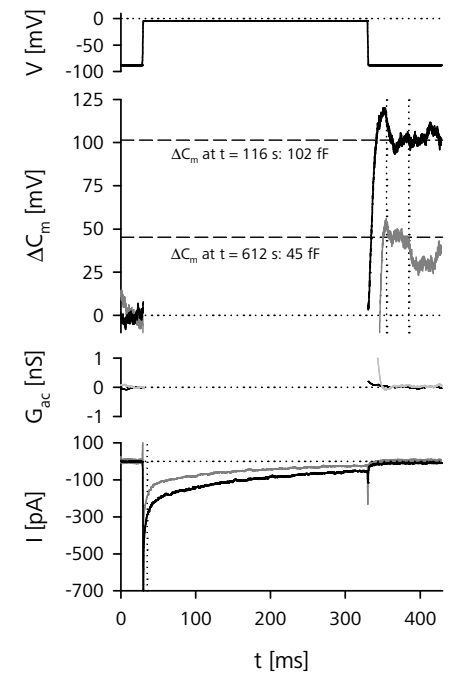

B
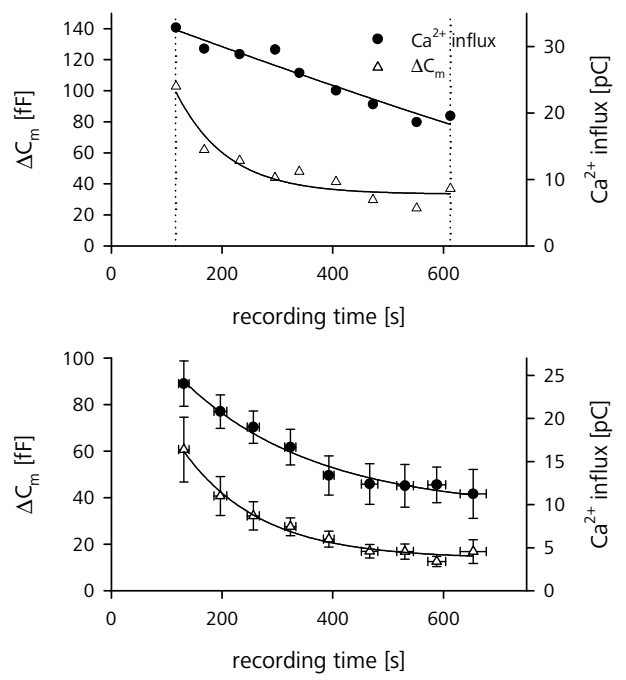

Figure 3.7: Membrane depolarization evokes exocytotic $C_{m}$ changes $\left(\Delta C_{m}\right)$ that decay during whole-cell recording. (A) Every $\sim 60 \mathrm{~s}$ secretion was evoked by depolarizations from -89 to $-4 \mathrm{mV}$ of $300 \mathrm{~ms}$ duration (upper panel) and monitored as $\Delta \mathrm{C}_{\mathrm{m}}$ (second panel). The amount of $\mathrm{Ca}^{2+}$ influx (lower panel) was estimated as integrated $\mathrm{Ca}^{2+}$ current $\left(\mathrm{Q}_{\mathrm{Ca}^{2+}}\right)$. (B) $\Delta \mathrm{C}_{\mathrm{m}}$ (open triangles) and $\mathrm{Ca}^{2+}$ influx (filled circles) evoked at different times after whole-cell breakthrough. The upper panel shows the same cell as in (A) and solid lines represent single exponential fits with time constants $(\tau)$ of $93 \mathrm{~s}$ for $\Delta \mathrm{C}_{\mathrm{m}} \cdot \mathrm{Q}_{\mathrm{Ca}^{2+}}$ approached linearity $(\tau>3000 \mathrm{~s})\left(\Delta \mathrm{C}_{\mathrm{m}}(\mathrm{t})=\Delta \mathrm{C}_{\mathrm{m}}(\infty)+\mathrm{a} e^{(-\mathrm{t} / \tau)}\right.$ and $\left.\mathrm{Q}_{\mathrm{Ca}^{2+}}(\mathrm{t})=\mathrm{Q}_{\mathrm{Ca}^{2+}}(\infty)+\mathrm{a} e^{(-\mathrm{t} / \tau)}\right)$. Dashed vertical lines indicate the time points shown in (A) as black and gray traces. The lower panel displays the same experiment for 18 different $\beta$-cells with $\tau=139$ and $238 \mathrm{~s}$ for $\Delta \mathrm{C}_{\mathrm{m}}$ and $\mathrm{Q}_{\mathrm{Ca}^{2+}}$. $\left[\mathrm{Ca}^{2+}\right]_{\mathrm{o}}$ was $10 \mathrm{mM}$ to maximize $\Delta \mathrm{C}_{\mathrm{m}}$.

MacDonald et al., 2005). However, $C_{m}$ measurements in more intact preparations have only been performed in two studies using mouse $\beta$-cells (Göpel et al., 1999; Speier and Rupnik, 2003).Fig. 3.7 shows that $C_{m}$ measurements can also readily be applied to $\beta$-cells in the rat tissue slice preparation. About $2 \mathrm{~min}$ after whole-cell breakthrough, a single depolarization ( -89 to $-4 \mathrm{mV} ; 300 \mathrm{~ms}$ ) led to a $\mathrm{Ca}^{2+}$ influx of $33 \mathrm{pC}$ which in turn triggered an exocytotic $\mathrm{C}_{\mathrm{m}}$ change $\left(\Delta \mathrm{C}_{\mathrm{m}}\right)$ of $102 \mathrm{fF}$. This corresponds to the release of 30-34 LDCVs if a unitary $\mathrm{C}_{\mathrm{m}}$ of 3-3.4 fF for rat $\beta$-cell LDCVs is assumed according

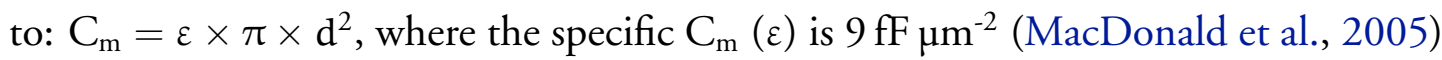
and the mean rat $\beta$-cell LDCV diameter (d) is 327-348 nm (Braun et al., 2004; Straub 
et al., 2004). The amount of LDCV release decreased with prolonged recording in the standard whole-cell configuration. After $10 \mathrm{~min}$ of whole-cell dialysis, $\Delta \mathrm{C}_{\mathrm{m}}$ was reduced by more than $50 \%$ to $45 \mathrm{fF}$ (13-15 LDCVs). Likewise, $\mathrm{Ca}^{2+}$ charge entry was reduced from $33 \mathrm{pC}$ to $20 \mathrm{pC}$. The secretory capacity of 18 rat $\beta$-cells measured upon repetitive identical stimulation (every 60 s) decayed with a single exponential time constant of $138 \mathrm{~s}$ and approached a stable value of $14 \mathrm{fF}$. Very similar time courses of exocytotic 'run-down' during whole-cell dialysis have been measured in adrenal chromaffin cells (Burgoyne, 1995; Smith and Neher, 1997). $\mathrm{Ca}^{2+}$ charge rundown in the exemplary cell shown in fig. 3.7 was almost linear but in general also followed a single exponential decay approaching a value of $9 \mathrm{pC}$ with a time constant of $238 \mathrm{~s}$ (see fig. $3.7 \mathrm{~B}$, lower panel). The resulting non-linear $\mathrm{Ca}^{2+}$-secretion relation could be well described by a low power dependency of exocytosis on $\mathrm{Ca}^{2+}$ influx $\left(\mathrm{C}_{\mathrm{m}} \propto \mathrm{Q}_{\mathrm{Ca}^{2+}}{ }^{\mathrm{k}}\right)$ with a power (k) of 1.7. This value is in good agreement with other reports in which this power relationship of depolarization-evoked LDCV exocytosis has been measured to be 1.8 (Engisch and Nowycky, 1996). Therefore, in contrast to data derived from chromaffin cells where $\mathrm{k}$ is 7.8 during whole-cell experiments (Smith and Neher, 1997), 'run-down' of exocytosis in rat $\beta$-cell seems to solely depend on the decrease in $\mathrm{Ca}^{2+}$-influx during whole-cell dialysis.

\section{Potentiation of secretion by CAMP}

A further hallmark of $\beta$-cell stimulus-secretion coupling is the potentiation of insulin release by cAMP (Jones et al., 1986; Ammala et al., 1993; Renstrom et al., 1997). Therefore, we included $100 \mu \mathrm{M}$ cAMP in the pipette filling solution to assess if $\mathrm{C}_{\mathrm{m}}$ measurements of rat $\beta$-cells in tissue slice preparation indeed report secretion. $\Delta \mathrm{C}_{\mathrm{m}}$ was evoked by trains of depolarizing pulses ( -93 to $-3 \mathrm{mV}, 40 \mathrm{~ms}$ duration, 50 pulses at $10 \mathrm{~Hz}$ ). This stimulation represents a tradeoff between mimicking physiological spiking behavior - which did not exceed $5 \mathrm{~Hz}$ in our current-clamp experiments-and a stimulus intensity strong enough to lead to sufficient LDCV exocytosis. The latter was necessary to be able to unequivocally tell $\beta$-cells responding with secretory $\Delta C_{m}$ from unresponsive cells while still keeping the stimulation short enough to prevent slow endocytosis from affecting the secretion readout. Fig. 3.8 A shows the typical cumulative 
A

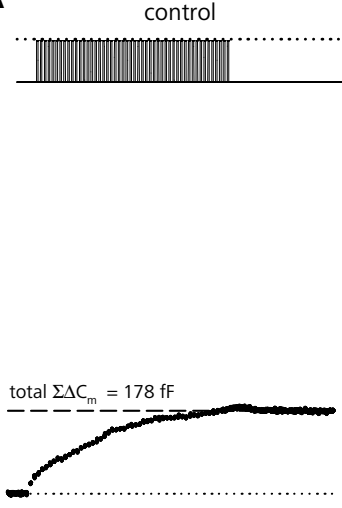

+ CAMP
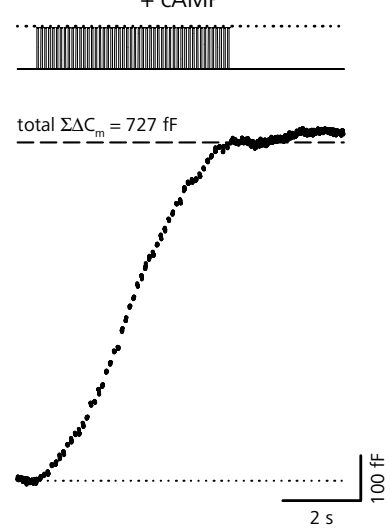

B

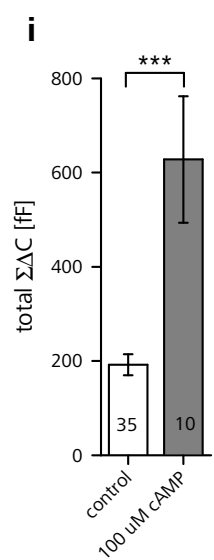

ii

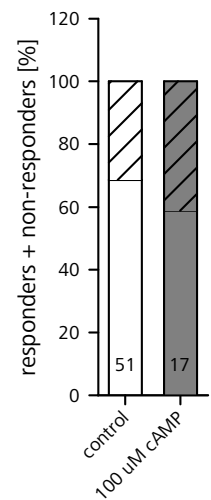

Figure 3.8: Exocytosis during stimulation with repetitive pulses. (A) Cumulative increase in $C_{m}\left(\Sigma \Delta C_{m}\right)$ in response to a train of 50 depolarizing pulses of $40 \mathrm{~ms}$ duration from -93 to $-3 \mathrm{mV}$ at a frequency of $10 \mathrm{~Hz}$. $\Sigma \Delta \mathrm{C}_{\mathrm{m}}$ is shown in a $\beta$-cell dialyzed with standard intracellular solution (IS-1)(left panel) and in a different cell in which $100 \mu \mathrm{M}$ cAMP was added to IS-1 (right panel). Note the absence of fast endocytosis after cessation of train stimulation. (B) Quantification of (i) the total $\Sigma \Delta \mathrm{C}_{\mathrm{m}}$ reached after the $50^{\text {th }}$ pulse in the train with (open bars) and without (gray bars) added cAMP and (ii) the percentage of cells responding (open bars) and not responding (hatched bars) to the train stimulation. Quantification of $\Delta \mathrm{C}_{\mathrm{m}}$ here and in the following figures is only performed on responsive cells. Stimulations were always performed with $\left[\mathrm{Ca}^{2+}\right]_{\mathrm{o}}=2 \mathrm{mM} .{ }^{* * *}, \mathrm{p} \leqslant 0.001$, unpaired $\mathrm{t}$-test.

increase in $C_{m}\left(\Sigma \Delta C_{m}\right)$ of two rat $\beta$-cells in response to train stimulation with and without cAMP added to the intracellular solution. The lack of a pronounced decrease in $\mathrm{C}_{\mathrm{m}}$ after the end of the train stimulation suggests that evoked endocytosis is not fast enough to exert any significant influence on the estimates of secretion. Quantification of the $\mathrm{C}_{\mathrm{m}}$ responses showed that after the $50^{\text {th }}$ pulse in the train, the total $\Sigma \Delta \mathrm{C}_{\mathrm{m}}$ in cAMP treated cells is $3.3 \times$ bigger than in control $(627 \pm 134.2 \mathrm{fF} n=10$ vs. $192 \pm 22.2 \mathrm{fF}, n$ $=35 \mathrm{p} \leqslant 0.001)$ which is similar to the $4 \times$ potentiation measured in isolated mouse $\beta$-cells (Renstrom et al., 1997). Of 51 technically acceptable $\beta$-cells tested under identical conditions only $69 \%$ showed a $C_{m}$ increase bigger than $40 \mathrm{fF}$ at the end of the stimulation and were therefore categorized as responsive. The percentage of responsive cells was not increased by adding cAMP to the pipette solution (59\% of 17 


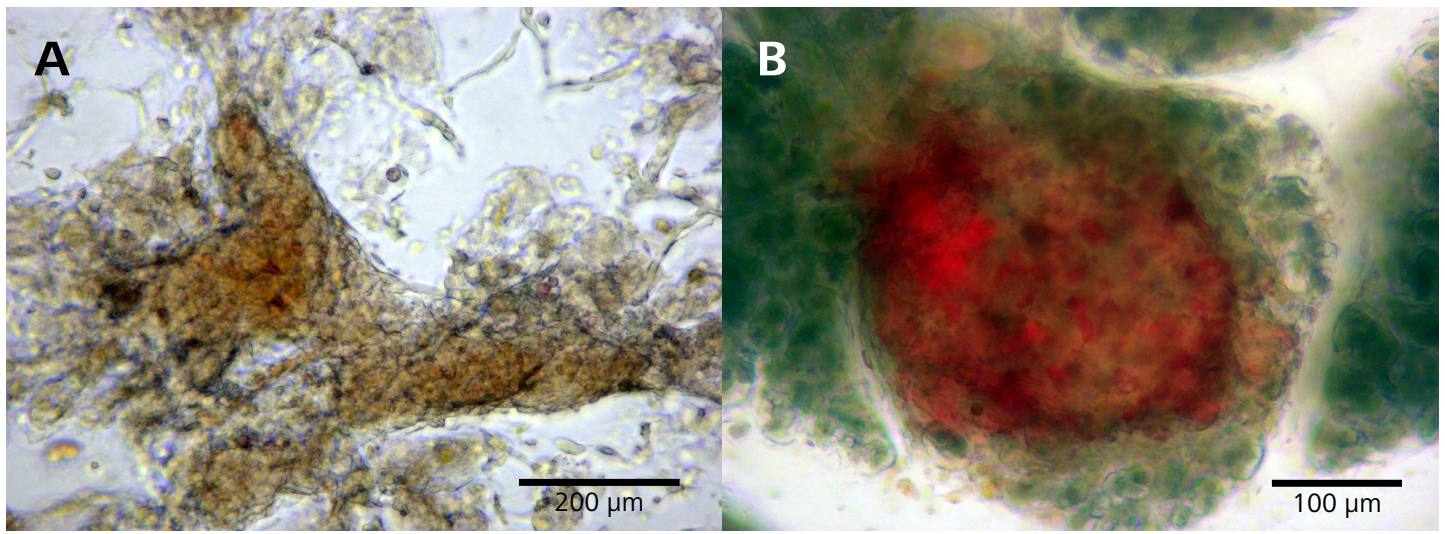

Figure 3.9: Pancreatic tissue slices of diabetic GK rats. (A) Transmitted light image of a 'starfish-shaped' GK rat islet. (B) Image of a red, erythrocyte-filled GK rat islet.

cells), therefore suggesting that a sizable fraction of $\beta$-cells endogenously lacks secretory capacity.

\section{$3.2 \mathrm{Ca}^{2+}$-secretion coupling in healthy vs. diabetic rats}

\subsubsection{General characterization of GK rats}

\section{Diabetic phenotype and islet morphology}

All GK rats of our colony showed a stable non-fasting hyperglycaemia $(16.9 \pm 1.3 \mathrm{mM}$, $n=22$ vs. $6.7 \pm 0.1 \mathrm{mM}, n=38, \mathrm{p} \leqslant 0.001)$ and had increased plasma insulin levels $\left(927.2 \pm 147.4 \mathrm{pMl}^{-1}, n=12\right.$ vs. $\left.342.8 \pm 49.9 \mathrm{pMl}^{-1}, n=13 ; \mathrm{p} \leqslant 0.001\right)$ compared to Wistar rat control at the start of the preparation (usually commencing $\sim 10$ a.m.)

Fig. 3.9 shows the morphology of pancreatic islets in slices of diabetic GK rats in transmitted light microscopy. In some cases GK rat islets showed changes in morphology similar as depicted in fig. 3.9 A. This phenotype is characterized by islets of irregular shape similar to the previously described 'starfish shaped' GK rat islets caused by fibrosis, i.e. an increased invagination of islets by connective tissue (Goto et al., 1988; Guenifi et al., 1995). The gross morphology of most islets, however, was indistinguishable from controls - except that GK rat islets could frequently be distinguished from their Wistar rat counterparts by being of bright red color (see fig. 3.9 B). Closer examination 
A

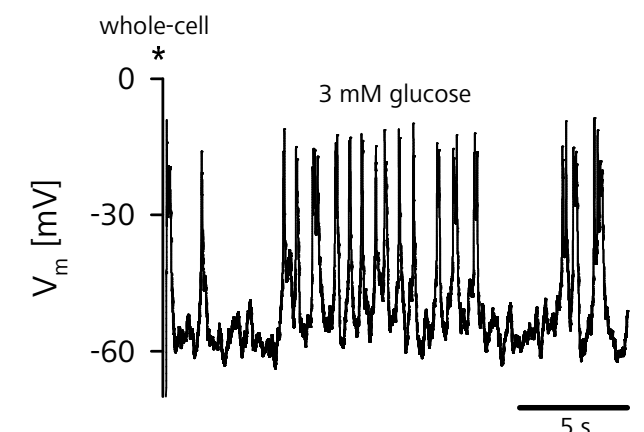

B

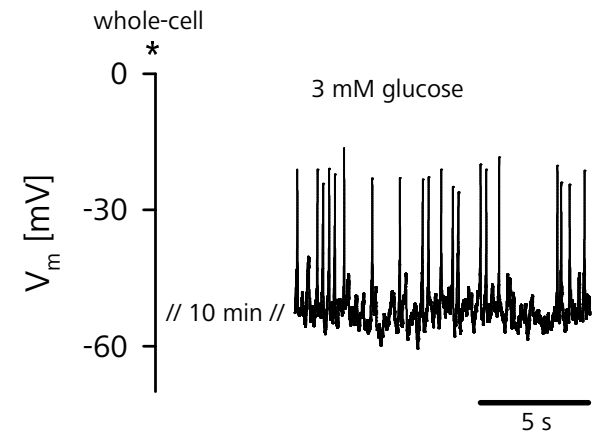

Figure 3.10: GK rat $\beta$-cells show spiking electrical activity at low glucose concentrations. (A) Bursting electrical activity in a GK rat $\beta$-cell at $3 \mathrm{mM}$ glucose right after the wholecell configuration was established. (B) Spiking electrical activity in another GK $\beta$-cell after prolonged whole-cell dialysis ( $\sim 10 \mathrm{~min}$, see also fig. 4.1).

revealed that this was the result of a high number of erythrocytes trapped in the extensive microvasculature of the islets. This is in good agreement with the previously reported increased islet blood flow under hyperglycemic conditions (Svensson et al., 2000) and a further indication for the in situ character of the pancreatic tissue slice preparation.

\section{Electrical activity in GK rat $\beta$-cells}

Standard whole-cell experiments in the current clamp mode showed that GK rat $\beta$ cells exhibit a significantly higher resting $\mathrm{V}_{\mathrm{m}}$ upon establishment of the whole-cell configuration than healthy Wistar rat controls $\left(\mathrm{V}_{\mathrm{m}}=-60 \pm 3.5 \mathrm{mV}, n=20\right.$ vs. $\mathrm{V}_{\mathrm{m}}=$ $-77 \pm 2.5 \mathrm{mV}, n=80 ; \mathrm{p} \leqslant 0.01)$. Furthermore, whereas from 80 tested Wistar rat $\beta$-cells no cell showed spiking electrical activity in low $(3 \mathrm{mM}$ ) glucose, $45 \%$ (9 out of 20) GK rat $\beta$-cells identified based on $\mathrm{I}_{\mathrm{Na}^{+}}$inactivation showed both bursting as well as spiking activity at $3 \mathrm{mM}$ glucose (see fig. 3.10).

\section{Glucose-induced $\left[\mathrm{Ca}^{2+}\right]_{i}$ changes in Wistar and GK rat islets}

In normal $\beta$-cells glucose induces electrical activity which leads to an increase in $\left[\mathrm{Ca}^{2+}\right]_{\mathrm{i}}$ that in turn triggers insulin secretion. We therefore monitored resting $\left[\mathrm{Ca}^{2+}\right]_{i}$ as well as glucose-induced changes in $\left[\mathrm{Ca}^{2+}\right]_{\mathrm{i}}$ by ratiometric imaging of Fura-PE3 loaded islets in tissue slices of Wistar and GK rats (see 3.11). In islets of both healthy and diabetic 
A.

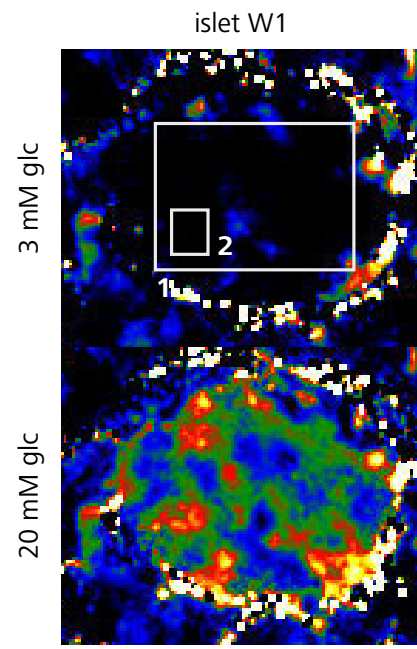

B

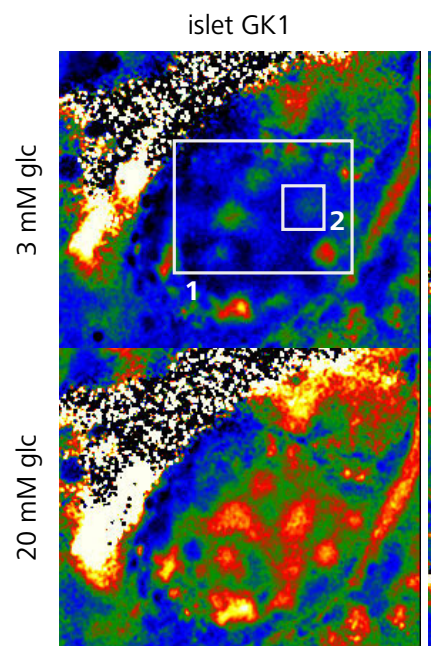

islet W2

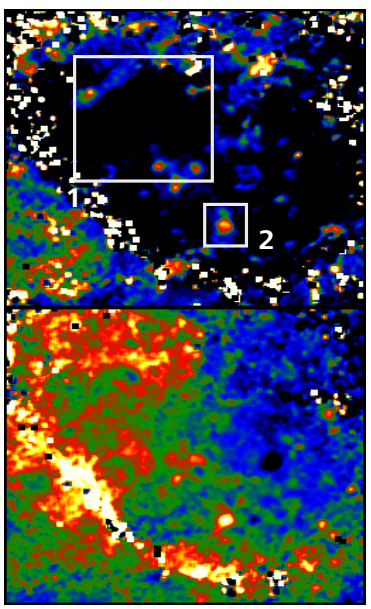

$\mathrm{F}_{340} / \mathrm{F}_{380}$

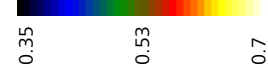

islet GK2

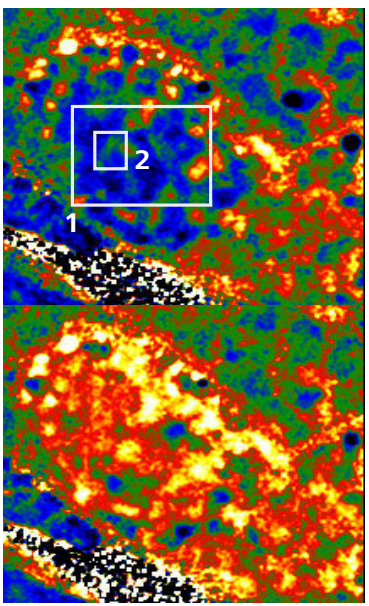

ii
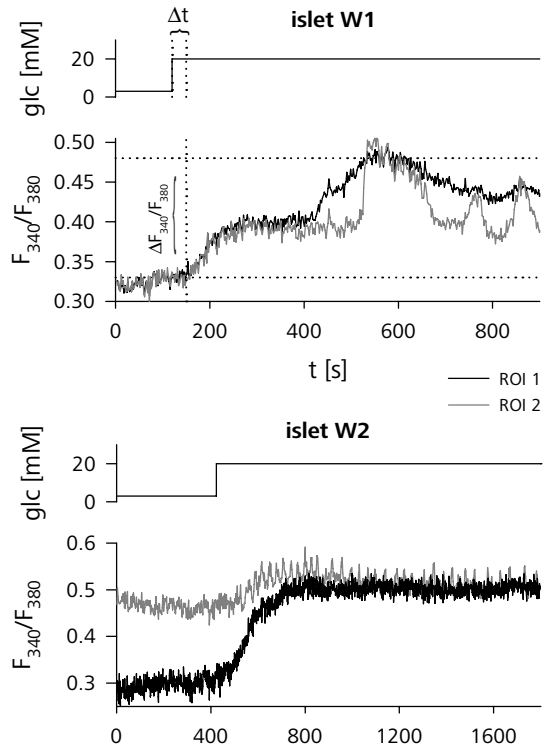

ii
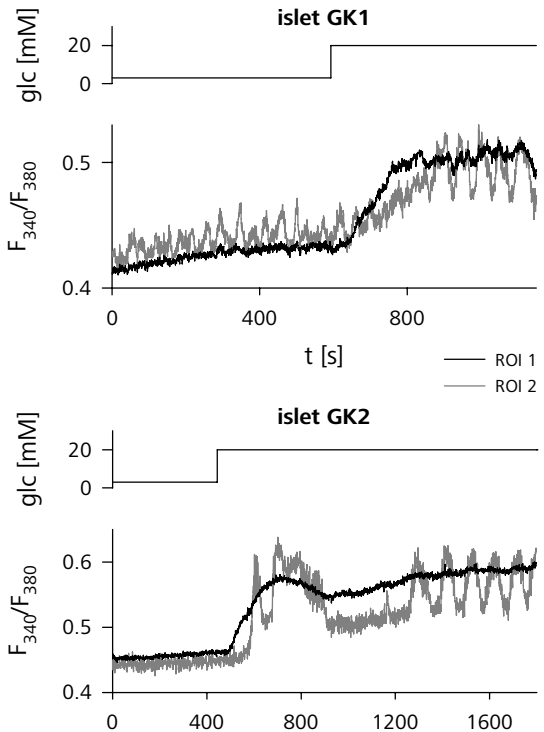

Figure 3.11: Glucose elicits similar changes in the cytosolic $\mathrm{Ca}^{2+}$ concentration in healthy and diabetic rats. (A, i) $\mathrm{F}_{340} / \mathrm{F}_{380}$ images of two Fura-PE3-AM loaded Wistar rat islets (W1, left and W2, right) before (upper images, $\mathrm{t}_{1}=0 \mathrm{~s}$ ) and after (lower images, $\mathrm{W} 1: \mathrm{t}_{2}=1000 \mathrm{~s} ; \mathrm{W} 2: \mathrm{t}_{2}=1800 \mathrm{~s}$ ) application of $20 \mathrm{mM}$ glucose (glc). (ii) Mean pixel intensity data of the ROIs shown in (i). Dotted lines indicate the response latency $(\Delta t)$ and response amplitude $\left(\Delta \mathrm{F}_{340} / \mathrm{F}_{380}\right)$. (B) Same as in (A) but in this case diabetic GK rat islets were subjected to glucose stimulation as indicated $\left(t_{1}=0 \mathrm{~s} ; \mathrm{GK} 1: \mathrm{t}_{2}=1150 \mathrm{~s}\right.$; GK2: $\left.t_{2}=1800 \mathrm{~s}\right)$. Note differences in the scaling of the time axis. 
rats elevation of glucose from $3 \mathrm{mM}$ to $20 \mathrm{mM}$ led to a very similar increase in $\left[\mathrm{Ca}^{2+}\right]_{\mathrm{i}}$ that was monitored as change in the mean fluorescence intensity ratio $\left(\Delta^{F_{340}} / F_{380}\right)$ of an image area enclosing large parts of the respective islets (see fig. 3.11 Ai, Bi, ROI 1). In the two Wistar rat islets shown in fig. $3.11 \mathrm{~A}$ glucose led to a rise in $\left[\mathrm{Ca}^{2+}\right]_{\mathrm{i}}$ that in both cases reached a maximum after $\sim 6 \mathrm{~min}$. In one islet this maximum was preceded by an intermediate plateau level (see fig. 3.11 islet W1) but in general $\mathrm{F}_{340} / \mathrm{F}_{380}$ increased steadily as shown for the second islet (islet W2). Glucose stimulation evoked a very similar change in $\left[\mathrm{Ca}^{2+}\right]_{\mathrm{i}}$ in GK rat islets. Different from previously published reports (Zaitsev et al., 1997; Marie et al., 2001), neither the response latency between glucose stimulation and the onset of a change in $\left[\mathrm{Ca}^{2+}\right]_{\mathrm{i}}(\Delta \mathrm{t}$ ) (Wistar: $50 \pm 8 \mathrm{~s} n=5$ vs. GK: $37 \pm 7 \mathrm{~s} n=4$; n.s.) nor the absolute amplitude of the change in the fluorescence ratio $\left(\Delta^{F_{340}} / F_{380}\right)$ (Wistar: $0.1 \pm 0.03, n=5$ vs. GK: $0.1 \pm 0.01, n=4$; n.s.) showed any significant difference.

In contrast to other reports (Martin et al., 1995; Antunes et al., 2000) but similar as Ahmed and Grapengiesser (2002) we observed oscillatory changes of $\left[\mathrm{Ca}^{2+}\right]_{\mathrm{i}}$ upon glucose stimulation in rat islets. However, these oscillations were limited to small cell clusters within the islets (see fig. $3.11 \mathrm{Ai}, \mathrm{Bi}$, ROI 2; gray traces in Aii and Bii) but could be found in Wistar as well as GK rat islets. The oscillations had a variable frequency and amplitude and ranged from slow but large $\left[\mathrm{Ca}^{2+}\right]_{\mathrm{i}}$ changes with a period of $\sim 1.5 \mathrm{~min}$ (islet W1 and GK2) to small and fast oscillations occurring every $\sim 20 s$ as in islet W2.

Notably, the average resting $\left[\mathrm{Ca}^{2+}\right]_{\mathrm{i}}$ determined from ROIs enclosing large parts of the respective islets was significantly higher in diabetic rats $\left(\mathrm{F}_{340} \mathrm{~F}_{380}: 0.36 \pm 0.03, n=5 \mathrm{vs}\right.$. $0.49 \pm 0.03, n=5 ; \mathrm{p} \leqslant 0.05)$. Furthermore, a cluster of cells in one GK rat islet showed clear oscillations even in $3 \mathrm{mM}$ glucose. Upon a higher glucose challenge $(20 \mathrm{mM})$ this oscillations increased in amplitude (see fig $3.11 \mathrm{~B}$ islet GK1, ROI2).

\section{$\beta$-cell morphology and $\mathrm{Ca}^{2+}$ currents in $\mathrm{GK}$ rats}

We found that $\beta$-cells in diabetic GK rat islets were significantly hypertrophic. In reasonable agreement with previously published data (Lou et al., 2003), rat $\beta$-cells in tissue slices had an average resting $\mathrm{C}_{\mathrm{m}}$ at recording begin of $6.4 \pm 0.15 \mathrm{fF}(n=271)$. Using this value as a measure of cell size (Pusch and Neher, 1988; Zorec et al., 1991) 
A

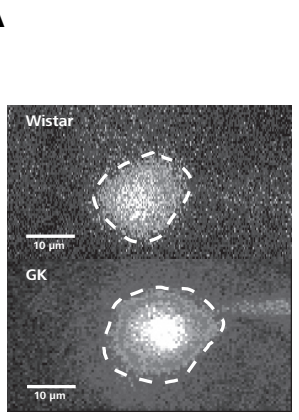

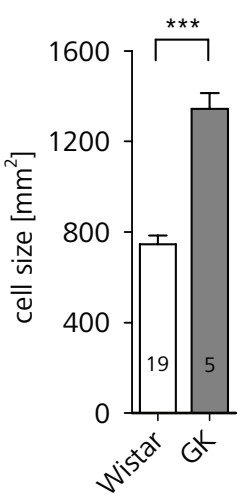

B

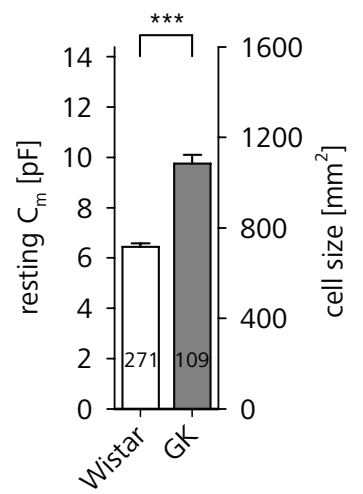

Figure 3.12: GK rat $\beta$-cells are hypertrophic. (A) Cell surface area estimated from images of dye loaded cells and (B) derived from the resting $\mathrm{C}_{\mathrm{m}} .{ }^{* *} \mathrm{p} \leqslant 0.001$ (unpaired t-test).

we found that GK rat $\beta$-cells were significantly larger $\left(\mathrm{C}_{\mathrm{m}}=9.8 \pm 0.36 \mathrm{fF}, n=109\right.$; $\mathrm{p} \leqslant 0.001$ ). Assuming a specific membrane capacitance of $9 \mathrm{fF} \mu \mathrm{m}^{-2}$ (MacDonald et al., $2005)$ this corresponds to a difference in cell surface area of $\sim 367 \mu^{-2}\left(716 \pm 16.2 \mu \mathrm{m}^{-2}\right.$, $n=271$ vs. $\left.1083 \pm 39.6 \mu \mathrm{m}^{-2}, n=109 ; \mathrm{p} \leqslant 0.001\right)$. Similar, albeit slightly bigger cell sizes were determined by estimating the surface area from the circumference of dye-loaded cells (see fig. 3.12 A) $\left(746 \pm 39.1 \mu \mathrm{m}^{-2}, n=19\right.$ vs. $1341 \pm 70.6 \mu \mathrm{m}^{-2}, n=5$; $\mathrm{p} \leqslant 0.001)$.

In agreement with previously published data (Kato et al., 1996), but in contradiction to a more recent report (Hughes et al., 1998), we further found that $\beta$-cells of diabetic rats display prominently enhanced voltage-activated $\mathrm{Ca}^{2+}$ currents (VACCs). Similar as has been demonstrated in pituitary melanotrophs (Kocmur and Zorec, 1993; Sedej et al., 2004), chromaffin cells (Liu and Misler, 1998) and invertebrate muscle cells (Yeoman et al., 1999) we used ramp depolarizations ( -89 to $51 \mathrm{mV}, 0.47 \mathrm{mV} \mathrm{ms}^{-1}$ ) to quickly assess the amplitude and voltage dependence of VACCs. The application of this protocol resulted in the separation of two inward current components, showing peaks around -45 and $-5 \mathrm{mV}$. These peaks most likely correspond to low (LVA) and high (HVA) voltage-activated $\mathrm{Ca}^{2+}$ currents (Kocmur and Zorec, 1993; Sedej et al., 2004). The LVA component in the ramp-evoked current is unlikely to be a blunted $\mathrm{I}_{\mathrm{Na}^{+}}$ because Lou et al. (2003) demonstrated that Wistar rat $\beta$-cell $\mathrm{Na}^{+}$channel inactivation 
A

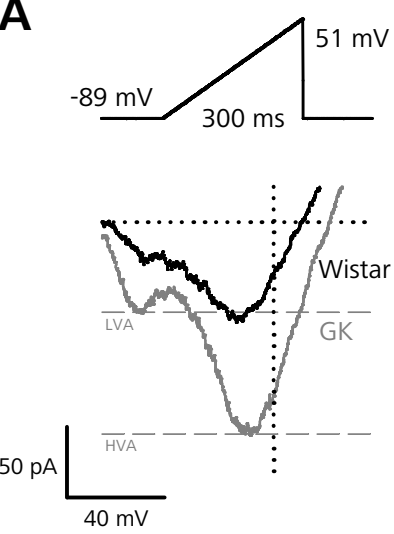

B

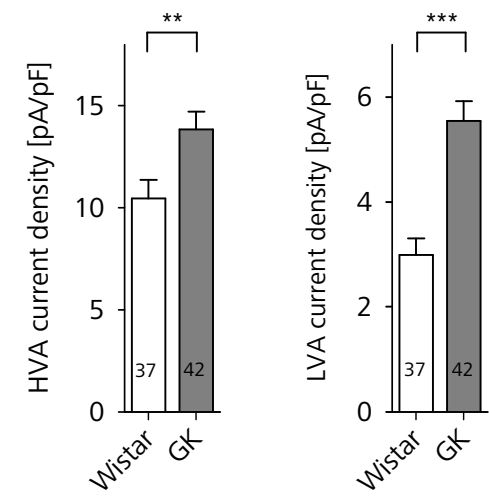

Figure 3.13: $\mathrm{GK}$ rat $\beta$-cells in tissue slices display enhanced $\mathrm{Ca}^{2+}$ currents. (A) Wholecell $\mathrm{Ca}^{2+}$ currents of a Wistar (black trace) and GK (gray trace) rat $\beta$-cell evoked by voltage ramps ranging from -89 to $51 \mathrm{mV}$ with a duration of $300 \mathrm{~ms}\left(0.47 \mathrm{mV} \mathrm{ms}^{-1}\right)$. Peak HVA and LVA currents in the GK rat $\beta$-cell are indicated by dashed gray lines. (B) Peak LVA and HVA current densities of ramp-evoked $\mathrm{Ca}^{2+}$ influx in Wistar and GK rat $\beta$-cells. ${ }^{* * *} \mathrm{p} \leqslant 0.001,{ }^{* *} \mathrm{p} \leqslant 0.01$ (unpaired t-test).

is fast enough to lead to complete disappearance of $\mathrm{I}_{\mathrm{Na}^{+}}$in similar ramp depolarizations $(-150 \mathrm{mV}$ to $60 \mathrm{mV})$ if the voltage slope is $1.5 \mathrm{mV} \mathrm{ms}^{-1}$ or slower. Furthermore the LVA current 'shoulder' on the rising phase of the IV plot was also visible in cells not exhibiting $\mathrm{I}_{\mathrm{Na}^{+}}$(not shown).

We found that peak HVA Ca ${ }^{2+}$ influx was almost doubled in GK rat $\beta$-cells $(141 \pm$ $12.5 \mathrm{pA}, n=41$ vs. $74 \pm 6.8 \mathrm{pA}, n=37, \mathrm{p} \leqslant 0.001$ ). Low-voltage activated (LVA) $\mathrm{Ca}^{2+}$ currents were also prominently increased $(55 \pm 4.7 \mathrm{pA}, n=41$ vs. $21 \pm 2.4 \mathrm{pA}, n=37$, $p \leqslant 0.001$ ) thus confirming previous observations (Kato et al., 1996). Considering the increased size of GK rat $\beta$-cells we normalized the peak VACC amplitudes to the resting $\mathrm{C}_{\mathrm{m}}$ (see fig. $3.13 \mathrm{~B}$ ). Both HVA and LVA current densities still were significantly increased in diabetic GK rat $\beta$-cells.

\subsection{2 $\mathrm{Ca}^{2+}$-secretion coupling}

\section{Exocytosis during repetitive stimulation is impaired diabetic GK rats $\beta$-cells}

The central question of the current work is whether $\mathrm{Ca}^{2+}$-secretion coupling is impaired in $\beta$-cells of diabetic rats. We therefore applied trains of depolarizing pulses $(50$ 

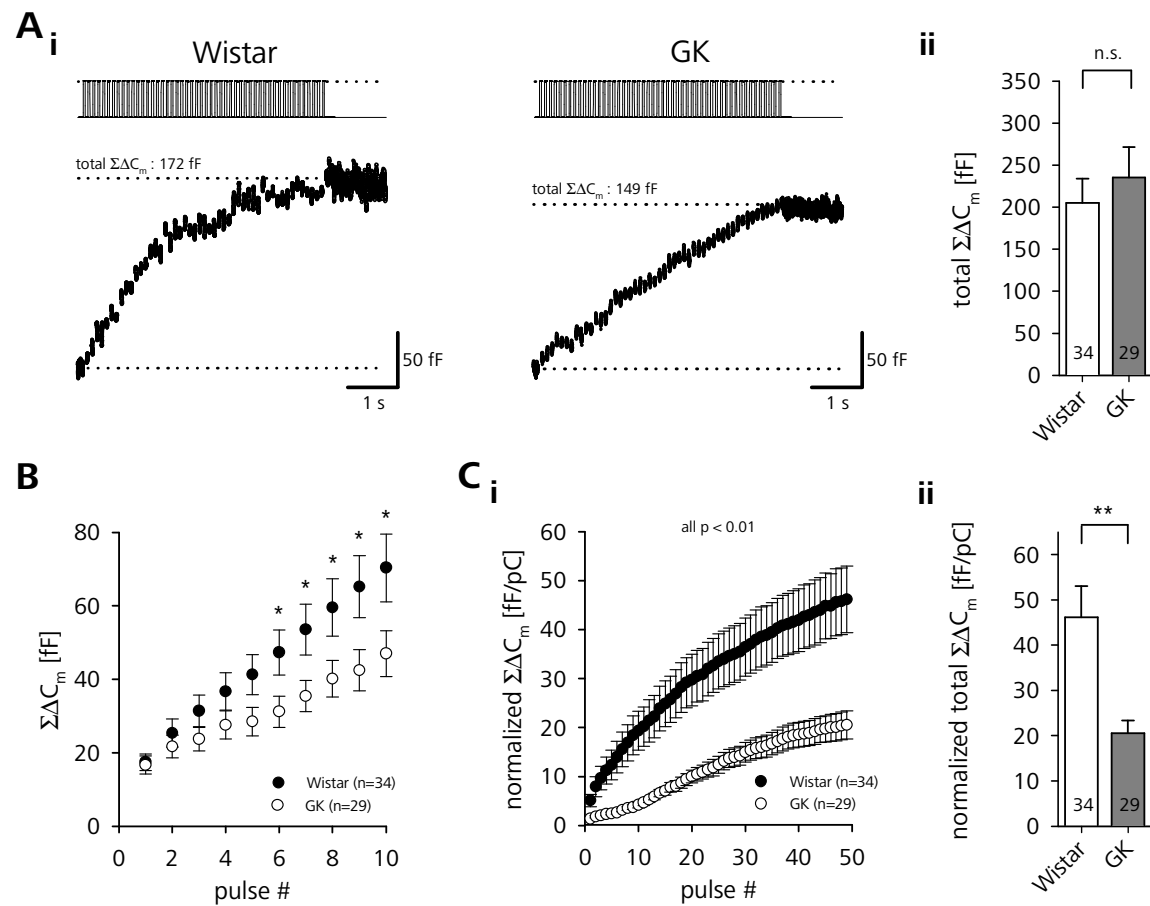

\section{$\mathbf{C}_{\mathbf{i}}$}

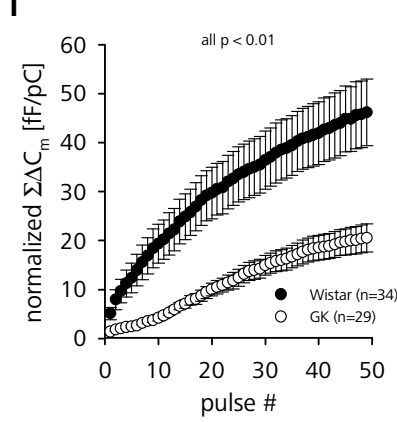

ii

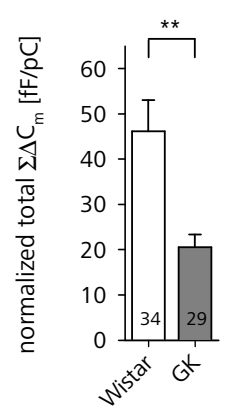

Figure 3.14: Exocytosis during repetitive stimulation is impaired in $\beta$-cells of diabetic rats. (A, i) Typical depolarization train-induced changes in $C_{m}$ (lower trace) in a $\beta$-cell of a Wistar (left) and GK rat (right). (ii) Comparison of total $\Sigma \Delta \mathrm{C}_{\mathrm{m}}$ reached after the end of the train between $\beta$-cells of control (open bars) and diabetic (gray bars) animals. (B) Average $\Sigma \Delta \mathrm{C}_{\mathrm{m}}$ during the first 10 pulses of train stimulation of Wistar (closed circles) and GK (open circles) rat $\beta$-cells. (C) Cell size normalized cumulative increase in $\mathrm{C}_{\mathrm{m}}$ during (i) and at the end (ii) of train stimulation (same data as in (A)). ${ }^{* *}$ $\mathrm{p} \leqslant 0.01,{ }^{*} \mathrm{p} \leqslant 0.05$, unpaired t-test.

depolarizations from -89 to $1 \mathrm{mV}, 40 \mathrm{~ms}$ duration, $10 \mathrm{~Hz}$ ) to elicit inward $\mathrm{Ca}^{2+}$ currents and trigger $\mathrm{Ca}^{2+}$-dependent secretion (see section 3.1.3, p. 48). In the representative recording of a Wistar rat $\beta$-cell shown in fig. $3.14 \mathrm{Ai}$, stimulation with a train of depolarizing pulses led to a steady increase in $\mathrm{C}_{\mathrm{m}}$ that reached $172 \mathrm{fF}$ (51-57 insulincontaining LDCVs) at the end of the stimulation. $\beta$-cells of diabetic GK rats were subjected to the same stimulation protocol. The exemplary $\beta$-cell of the diabetic animal reached a total $\Sigma \Delta \mathrm{C}_{\mathrm{m}}$ of $149 \mathrm{fF}$. The quantitative analysis of the data showed that there was no significant difference in the absolute $\Sigma \Delta \mathrm{C}_{\mathrm{m}}$ reached at the end of the train stimulation between Wistar and GK rat $\beta$-cells (see fig. 3.14 Aii). 
A

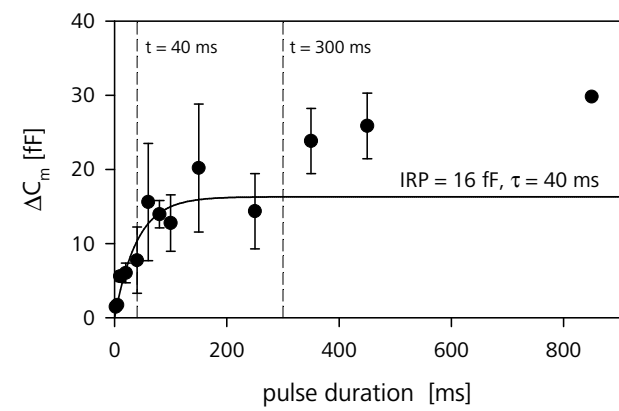

B

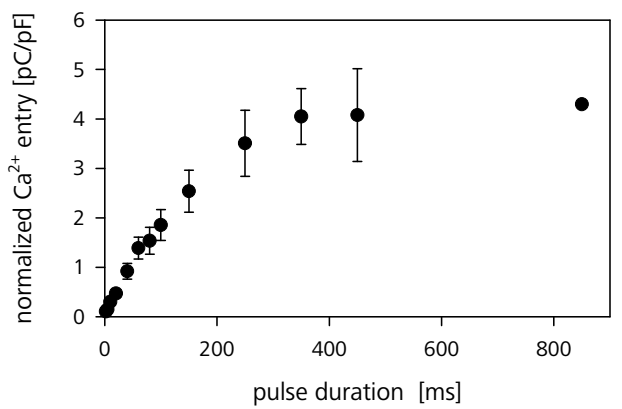

Figure 3.15: Exocytosis (A) and $\mathrm{Ca}^{2+}$ influx (B) elicited by depolarizations (-89 to $1 \mathrm{mV}$ ) of progressively longer duration to estimate the size of IRP and derive suitable double-pulse protocol parameters (dashed lines, see fig. 3.16 and 3.17). Experiment was performed with $\left[\mathrm{Ca}^{2+}\right]_{\mathrm{o}}=7 \mathrm{mM}$, pulse durations have been randomized and pauses of at least $30 \mathrm{~s}$ were given between stimulation to allow for RRP refilling.

The kinetics of the $C_{m}$ increase, however, where significantly different between Wistar and GK rat $\beta$-cells: Whereas the average release rate in controls stayed high from the $2^{\text {nd }}$ to the $11^{\text {th }}$ depolarization $\left(137 \pm 8 \mathrm{fF} \mathrm{s}^{-1}, n=34\right)$, GK $\beta$-cells showed a much slower initial response $\left(88 \pm 12 \mathrm{fF} \mathrm{s}^{-1}, n=29, \mathrm{p} \leqslant 0.01\right)$. This led to a significantly lower initial $\Sigma \Delta \mathrm{C}_{\mathrm{m}}$ in $\mathrm{GK}$ rats (see fig. $3.14 \mathrm{~B}$ ).

The secretory capacity of non-diabetic rat and mouse $\beta$-cells is positively correlated to the size of the cells (Giordano et al., 1993; Leung et al., 2005). However, if the $\Delta C_{m}$ of control and diabetic $\beta$-cells was normalized to the cell size, the relative amount of exocytosis in GK rat $\beta$-cells was much smaller throughout the train (see fig. 3.14 Ci). The size normalized release after cessation of the last pulse in GK rat $\beta$-cells was reduced by more than $50 \%$ (see fig. 3.14 Cii).

\section{The secretory dysfunction in diabetic $\beta$-cells is not caused by differences in functional pool sizes}

Defective depolarization-induced secretion can principally be caused by three factors: (i) an altered $\mathrm{Ca}^{2+}$ signal resulting from a changed $\mathrm{Ca}^{2+}$ influx or a change in the intracellular propagation of $\mathrm{Ca}^{2+}$, (ii) a change in the $\mathrm{Ca}^{2+}$ sensitivity of the release machinery and (iii) a decrease in the number and/or refilling kinetics of release-ready 
LDCVs. To address the first part of the last possibility we applied depolarization pulses of progressively longer duration (randomized intervals from $2 \mathrm{~ms}$ to $850 \mathrm{~ms} ;-89$ to $1 \mathrm{mV}$, interpulse interval $\geqslant 30 \mathrm{~s}$ ) and measured the resulting $\Delta \mathrm{C}_{\mathrm{m}}$ in control $\beta$-cells. Protocols like this can be used to reconstruct the release kinetics in response to an ideal constant elevation of $\mathrm{Ca}^{2+}$ at the LDCV release sites (Horrigan and Bookman, 1994; Moser and Neher, 1997). Fig. $3.15 \mathrm{~B}$ shows that up to a pulse duration of $250 \mathrm{~ms}$ the $\mathrm{Ca}^{2+}$ charge entry increased almost linearly with the length of the depolarization. The exocytotic $\Delta \mathrm{C}_{\mathrm{m}}$, however, increased rapidly and showed saturation already around $200 \mathrm{~ms}$ (see fig. $3.15 \mathrm{~A})$. The increase in $\Delta \mathrm{C}_{\mathrm{m}}$ up to that point could be fitted with a single exponential function that approached $16 \mathrm{fF}$ with a time constant of $40 \mathrm{~ms}$. Derivation of this function reveals a theoretical maximum exocytotic speed of $400 \mathrm{fF} \mathrm{s}^{-1}$. At a pulse duration of $250 \mathrm{~ms} \mathrm{Q}_{\mathrm{Ca}^{2+}}$ showed no sign of saturation, therefore the depression of $\Delta \mathrm{C}_{\mathrm{m}}$ can be interpreted as the fast depletion of a release-ready pool. Because of its fast release kinetics and small size this pool is likely to be identical with the IRP that has been described in many neuroendocrine cells, including $\beta$-cells (Horrigan and Bookman, 1994; Barg et al., 2001). This pool is released rapidly upon short depolarization presumably because it is comprised of LDVCs experiencing high $\left[\mathrm{Ca}^{2+}\right]_{\mathrm{i}}$ by being closely connected to the $\mathrm{Ca}^{2+}$ channels (Moser and Neher, 1997; Voets et al., 1999; Barg et al., 2001). Longer depolarizations led to the saturation of $\mathrm{Q}_{\mathrm{Ca}^{2+}}$ entry-putatively attributable to $\mathrm{Ca}^{2+}$ current inactivation. This and the likely possibility of RRP-refilling during prolonged depolarizations prohibited the use of $\Delta \mathrm{C}_{\mathrm{m}}$ resulting from pulses of longer duration (> $250 \mathrm{~ms}$ ) to derive further information about LDCV pool sizes using this protocol. Furthermore, a comparative assessment of functional pool sizes in Wistar and GK rat $\beta$-cells would have been complicated by the different $\mathrm{Ca}^{2+}$ current density in these animals (see fig. 3.13, p. 55).

Therefore we used a dual-pulse protocol that allows quick estimates of pool sizes independently from the absolute $\mathrm{Ca}^{2+}$ entry (Gillis et al., 1996): From the sum (S) and the reverse ratio $(\mathrm{R})$ of the capacitance increases $\left(\Delta \mathrm{C}_{\mathrm{m}, 1}, \Delta \mathrm{C}_{\mathrm{m}, 2}\right)$ resulting from two identical $\mathrm{Ca}^{2+}$ elevations elicited at a short interval, the upper limit of a releasable pool 
A

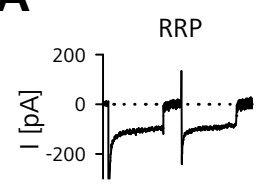

$10 \mathrm{mM}\left[\mathrm{Ca}^{2+}\right]_{0}$

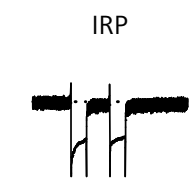

$2 \mathrm{mM}\left[\mathrm{Ca}^{2+}\right]_{0}$
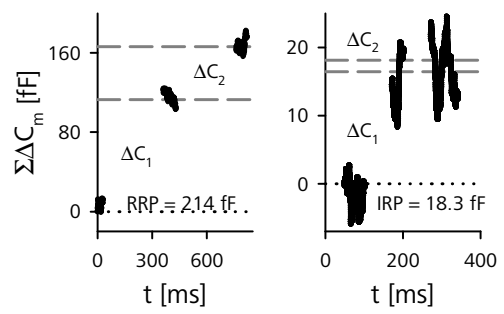

B

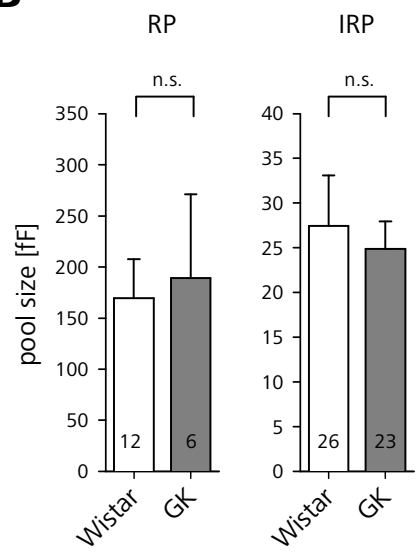

Figure 3.16: Sizes of release-ready pools are not changed in $\beta$-cells of diabetic rats. (A) Dual-pulse protocols used to estimate the maximal size of RRP (300 ms duration, $100 \mathrm{~ms}$ interpulse interval, -89 to $-4 \mathrm{mV}$ ) and IRP ( $40 \mathrm{~ms}$ duration, $60 \mathrm{~ms}$ interpulse interval, -89 to $1 \mathrm{mV}$ ) in $\beta$-cells. (A, upper panels) Elicited inward $\mathrm{I}_{\mathrm{Na}, \mathrm{Ca}}$ (peak $\mathrm{I}_{\mathrm{Na}^{+}}$ transients truncated). (Lower panels) $\Sigma \Delta \mathrm{C}_{\mathrm{m}}$ in response to the depolarizations. (B) Average values for the maximal RRP (left) and IRP (right) pool size estimates in Wistar and GK rat $\beta$-cells. n.s., unpaired t-test. Experiment performed with $\left[\mathrm{Ca}^{2+}\right]_{\mathrm{o}}=10 \mathrm{mM}$ and $2 \mathrm{mM}$ for RRP and IRP size estimation, respectively.

size $\left(\mathrm{B}_{\max }\right)$ can be estimated if the pulses release the same fraction of the available pool of vesicles according to:

$$
\mathrm{B}_{\text {max }}=\frac{\mathrm{S}}{1-\mathrm{R}^{2}}
$$

Pulses of a duration longer than $250 \mathrm{~ms}$ at $\left[\mathrm{Ca}^{2+}\right]_{\mathrm{o}}=7 \mathrm{mM}$ completely depleted the fast IRP component of the $\mathrm{C}_{\mathrm{m}}$ response (see fig. 3.15). Accordingly, $\Delta \mathrm{C}_{\mathrm{m}}$ elicited by pulses of longer duration would lead to the partial or full depletion of the remaining part of the RRP. To be sure to achieve sufficient RRP depletion, we chose pulse durations of $300 \mathrm{~ms}$ and an interpulse interval of $100 \mathrm{~ms}$ for the estimation of the maximal size of this pool. To further maximize release in response to the stimulation, $\left[\mathrm{Ca}^{2+}\right]_{0}$ was increased to $10 \mathrm{mM}$ and the step depolarizations were performed from a holding $\mathrm{V}_{\mathrm{m}}$ of -89 to $-4 \mathrm{mV}$-a potential close to the peak HVA $\mathrm{Ca}^{2+}$ current influx (see fig. 3.13, p. 55). Using this protocol we achieved a satisfactory depletion ratio of $\mathrm{R}=0.59 \pm 0.4$ ( $n$ $=17)$ for Wistar and $\mathrm{R}=0.55(n=9)$ for GK rats. Only cells with $\mathrm{R}<0.7$ were taken for analysis, thus excluding $35 \%$ of the Wistar and $33 \%$ of the GK rat $\beta$-cells. 
We found that the maximal size of RRP in diabetic $\beta$-cells was the same as in the controls (Wistar: $170 \pm 38 \mathrm{fF}, n=12$ vs. GK: $189 \pm 82 \mathrm{fF}, n=6$ ). The $\Delta \mathrm{C}_{\mathrm{m}}$ response to the first depolarization can be used as an estimate of the lower boundary of RRP size (Gillis et al., 1996). With $79 \pm 18 \mathrm{fF}(n=12)$ for Wistar and $95 \pm 37 \mathrm{fF}(n=6)$ for GK rat $\beta$-cells, again no significant pool size difference was found.

According to fig. 3.15 short pulses of the duration of the time constant of the fast secretory component (IRP: $\tau=40 \mathrm{~ms})$ would release $63.2 \%(1-(1 / \mathrm{e}))$ of the IRP, thus leading to a satisfactory paired-pulse ratio $\left(\Delta \mathrm{C}_{\mathrm{m}, 2} / \Delta \mathrm{C}_{\mathrm{m}, 1}\right)$ of $\mathrm{R}=0.58\left(1 / \mathrm{e} \times(1-(1 / \mathrm{e}))^{-1}\right)$. Therefore we could use the $\Delta \mathrm{C}_{\mathrm{m}}$ responses to the first two $40 \mathrm{~ms}$ pulses ( -89 to $1 \mathrm{mV}$, $60 \mathrm{~ms}$ interpulse interval) obtained with the standard train depolarization protocol (data from fig. 3.14) to estimate the maximal IRP size. In spite of the lower ambient $\left[\mathrm{Ca}^{2+}\right]$ $(2 \mathrm{mM})$, the paired-pulse analysis showed sufficient pool depletion by each pulse. With $\mathrm{R}=0.44(n=34)$ for Wistar and $\mathrm{R}=0.17(n=28)$ for GK rats, the latter showed a slightly but not significantly higher degree of depression than controls. However, the upper IRP size as estimated with this protocol again was the same in $\beta$-cells of healthy and diabetic rats (Wistar: $24 \pm 5 \mathrm{fF}, 26$ of 34 cells $\mathrm{R}<0.7$; GK: $25 \pm 3 \mathrm{fF}, 23$ of 28 cells $\mathrm{R}<0.7$; n.s.). Also the minimal IRP size estimated from the $\mathrm{C}_{\mathrm{m}}$ response to the first depolarization showed no differences (Wistar: $17 \pm 2.4 \mathrm{fF}, n=26$ vs. GK: $19 \pm 2.5 \mathrm{fF}, n$ $=23$; n.s.).

\section{The secretory dysfunction in diabetic $\beta$-cells is not caused by differences in the RRP refilling kinetics}

Since the RRP sizes of Wistar and GK rat $\beta$-cells have been determined to be similar and diabetic and non-diabetic cells showed the same amount of LDCV-release after the end of the train stimulation (see fig. 3.14) the depressed secretion speed during the train in GK rats could result from differences in the refilling kinetics of the RRP.

We therefore measured the time-course of RRP refilling by probing the pool size at different times after a pool-depleting stimulus (see fig. 3.17). In the exemplary recording shown in fig. $3.17 \mathrm{~A}$ (left panel) maximal RRP size $\left(\mathrm{B}_{\max }\right)$ was assessed by a double-pulse protocol similar as in fig. 3.16. Because of the achieved pool depletion a subsequent double-pulse following $2.3 \mathrm{~s}$ afterwards showed that the RRP has only 
A

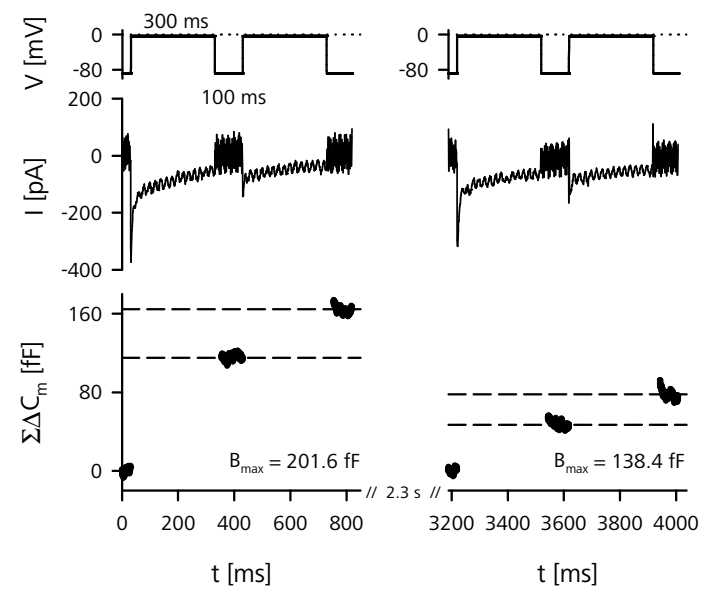

B
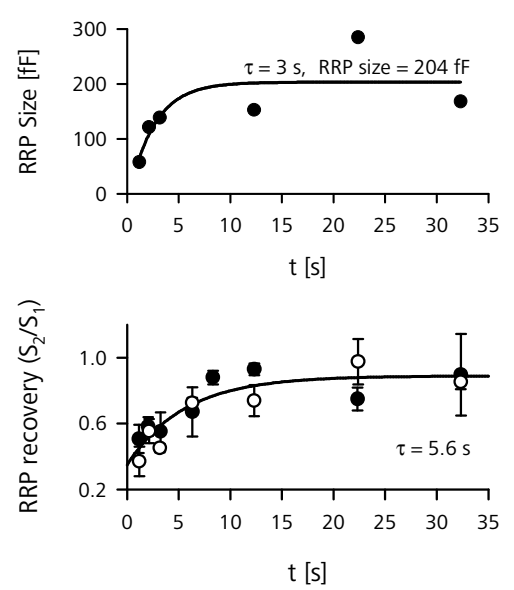

Figure 3.17: The time course of RRP recovery is similar in Wistar and GK $\beta$-cells. (A) Protocol used to assess the recovery time course of RRP: Maximal RRP size $\left(B_{\max }\right)$ was measured by a double-pulse protocol (left panels, also see fig. 3.16). A successive double pulse applied $2.3 \mathrm{~s}$ later showed that the RRP has only partially been refilled by mobilization of granules from the reserve pool (right panel). (B) RRP recovery time course of the cell shown in (A). The solid line represents a single exponential fit through the data with a time constant and maximal RRP size as indicated. (C) The ratio of the summed $C_{m}$ responses $\left(S_{2} / S_{1}\right)$ to two successive dual-pulse stimulations as a function of the delay time between the double pulses is shown for Wistar (closed circles) and GK rat $\beta$-cells (closed circles) (data binned for delay times, n.s., unpaired t-test).The solid line represents an exponential fit through the combined data with a time constant $\tau=5.6 \mathrm{~s}$ and a y-intercept of $S_{2} / S_{1}=0.35$. Inter-pulse intervals have been randomized and at least $30 \mathrm{~s}$ between two dual-pulse pairs were allowed to ensure complete recovery of RRP. The experiment was performed with $\left[\mathrm{Ca}^{2+}\right]_{\mathrm{o}}=10 \mathrm{mM}$.

partially recovered. Whereas the first measurement resulted in a RRP size of $B_{\max }=$ $201 \mathrm{fF}$ the subsequent $B_{\max }$ was $138 \mathrm{fF}$. Using several delay times reaching from 1.2 to $52 \mathrm{~s}$ we could demonstrate that the RRP of the representative cell recovered with a single exponential time constant of $3 \mathrm{~s}$. Because the absolute RRP size has already been demonstrated to be constant, only the time course of refilling was of interest. Therefore we could use the ratio of the summed $C_{m}$ responses $\left(S_{2} / S_{1}\right)$ instead of the absolute $B_{\max }$ values to represent the relative RRP recovery (Dinkelacker et al., 2000). However, as can be seen in fig. 3.17 C, the refilling kinetics in Wistar and GK rats were almost identical. The combination of the data of Wistar and GK rats showed that rat $\beta$-cells 

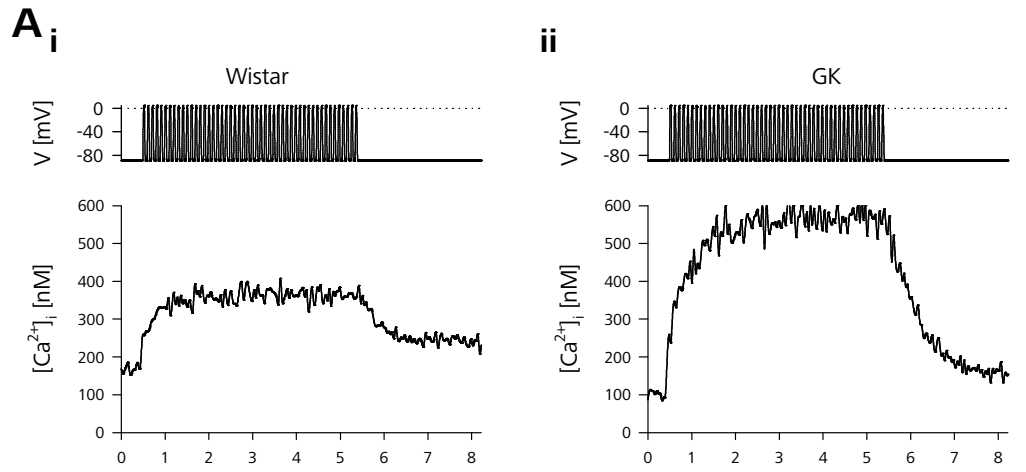

$\mathrm{t}[\mathrm{s}]$
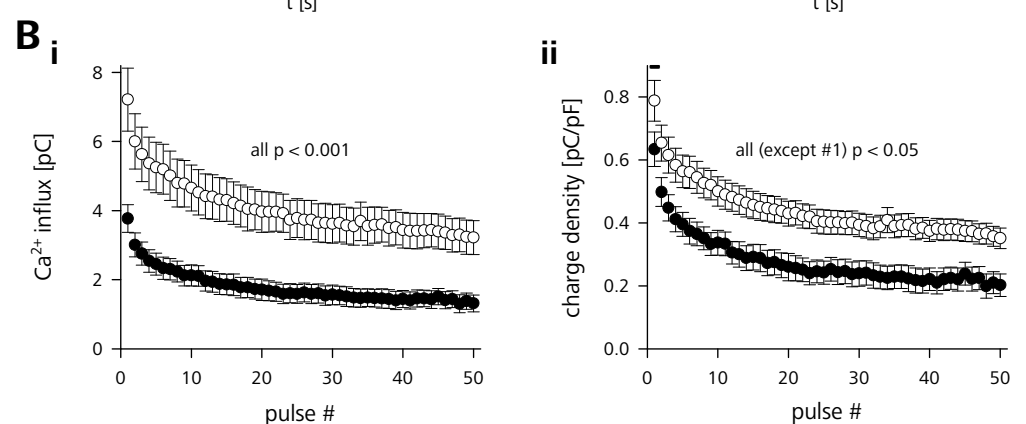

Figure 3.18: $\mathrm{Ca}^{2+}$ influx during train stimulation is higher in GK rats. (A) Depolarization train evoked change in $\left[\mathrm{Ca}^{2+}\right]_{i}$ in (i) a Wistar and (ii) a GK rat $\beta$-cell measured by ratiometric imaging of cells loaded with $50 \mu \mathrm{M}$ Fura-PE3. (B, i) Average $\mathrm{Ca}^{2+}$ influx for each depolarization pulse in control (closed symbols, $n=33$ ) and diabetic (open symbols, $\mathrm{n}=20) \beta$-cells measured as integrated $\mathrm{Ca}^{2+}$ current. (ii) Same as in (i) but normalized to the cell size (unpaired t-test).

in tissue slices exhibit a much faster RRP-recovery $(\tau=5.6 \mathrm{~s})$ in comparison to the only reference in the literature using isolated mouse $\beta$-cells $(\tau=31 \mathrm{~s})$ (Gromada et al., 1999).

\section{The apparent $\mathrm{Ca}^{2+}$ sensitivity is reduced in $\mathrm{GK}$ rat $\beta$-cells}

To further elucidate defective $\mathrm{Ca}^{2+}$-secretion coupling in $\beta$-cells of diabetic rats we needed to account for the fact that the triggering $\mathrm{Ca}^{2+}$ signal is prominently enhanced in the GK model (see fig. 3.13). During train stimulation both $\mathrm{Ca}^{2+}$ charge entry as well as the size-normalized charge-density were significantly higher for each of the single depolarization pulses of a standard train stimulation (see fig. 3.18 B). In the cells shown 
in fig. $3.18 \mathrm{~A}$ this led to an increase in the global cytosolic $\left[\mathrm{Ca}^{2+}\right]_{\mathrm{i}}$ that reached a stable level after $\sim 2 \mathrm{~s}$. Whereas the Wistar rat $\beta$-cell showed an increase in $\left[\mathrm{Ca}^{2+}\right]_{\mathrm{i}}$ of $200 \mathrm{nM}$, $\left[\mathrm{Ca}^{2+}\right]_{\mathrm{i}}$ in the diabetic $\beta$-cell increased by $460 \mathrm{nM}$. No significant difference in the buffered resting $\left[\mathrm{Ca}^{2+}\right]_{\mathrm{i}}$ between Wistar and GK rat $\beta$-cells was found (Wistar: $\left[\mathrm{Ca}^{2+}\right]_{\mathrm{i}}$ $=120 \pm 30 \mathrm{nM} ; n=9$ vs. GK: $\left.\left[\mathrm{Ca}^{2+}\right]_{\mathrm{i}}=130 \pm 20 \mathrm{nM} ; n=5\right)$.

Fig. $3.18 \mathrm{~B}$ furthermore shows that the $\mathrm{Ca}^{2+}$ charge entry during train stimulation showed prominent inactivation. In Wistar as well as GK rat $\beta$-cells the first pulse elicited $\sim 100 \%$ more charge entry than the $50^{\text {th }}$ depolarization in the train. The inactivating $\mathrm{Ca}^{2+}$ charge entry and not the relatively uniform increase in global cytosolic $\left[\mathrm{Ca}^{2+}\right]_{\mathrm{i}}$ is more likely to represent the submembrane $\left[\mathrm{Ca}^{2+}\right]_{\mathrm{i}}$ relevant for fast $\mathrm{LDCV}$ release (Neher, 1998). We therefore correlated the cumulative $C_{m}$ change during train stimulation to the respective cumulative $\mathrm{Ca}^{2+}$ charge entry $\left(\Sigma \mathrm{Q}_{\mathrm{C}^{2+}}\right)$ to compare the secretory activity with respect to the actual stimulus intensity. Fig. 3.19 shows, that whereas $\Sigma \Delta \mathrm{C}_{\mathrm{m}}$ in the representative GK $\beta$-cell was higher than in control ( $422 \mathrm{fF}$ vs. $217 \mathrm{fF}$ ), $\mathrm{Ca}^{2+}$ entry was more than doubled as well $(268 \mathrm{pC}$ vs. $111 \mathrm{pC})$. This led to a relative secretory efficacy $\left(\Sigma \Delta \mathrm{C}_{\mathrm{m}} / \Sigma \mathrm{Q}_{\mathrm{C}^{2+}}\right)$ of $2 \mathrm{fF} \mathrm{pC}^{-1}$ in the Wistar and $1.6 \mathrm{fF} \mathrm{pC}^{-1}$ in the GK rat.

It turned out that for approximately up to the $10^{\text {th }}$ pulse a linear function describes the data best regardless of the inherent variability due to non-linear increases (facilitation) or decreases (depression) in exocytotic efficacy during later phases of train stimulation. In addition, the most prominent impairment of secretory function in GK rat $\beta$-cells took place during the first 25 pulses of the stimulation (see fig. $3.14 \mathrm{~B}$ ). Therefore we chose the slope of the zero-constrained linear fit as the parameter to represent secretory efficacy $(E)$ in our experiments.

Fig. 3.19 B shows the average $\Sigma \Delta \mathrm{C}_{\mathrm{m}}$ as a function of $\Sigma \mathrm{Q}_{\mathrm{Ca}^{2+}}$ for Wistar and $\mathrm{GK} \beta$ cells. Clearly, $\beta$-cells from healthy rats responded to any given amount of $\mathrm{Ca}^{2+}$ entering during the train stimulation with a higher number of secreted vesicles leading to an average secretion of $161 \pm 39 \mathrm{fF}$ in response to a cumulative $\mathrm{Ca}^{2+}$ entry of $125 \pm 19 \mathrm{pC}$ $(n=22)$. With $196 \pm 45 \mathrm{fF}(n=15)$ the total secretion after train cessation in GK rat $\beta$-cells again was not significantly different from controls, but the corresponding total $\mathrm{Ca}^{2+}$ entry was much higher $(243 \pm 35 \mathrm{pC}, n=14 ; \mathrm{p} \leqslant 0.001) . \mathrm{Ca}^{2+}$ in controls was almost twice as efficient in triggering secretion as in GK $\beta$-cells $\left(E=1.5 \pm 0.2 \mathrm{fF} \mathrm{pC}^{-1}\right.$, $n=22$ vs. $\left.E=0.9 \pm 0.1 \mathrm{fF} \mathrm{pC}^{-1}, n=15, \mathrm{p} \leqslant 0.01\right)$. 
A

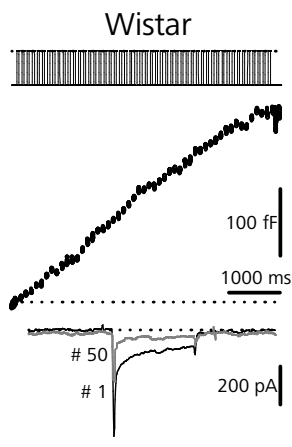

GK

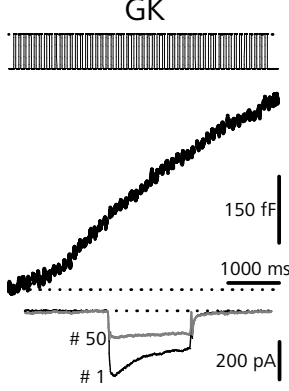

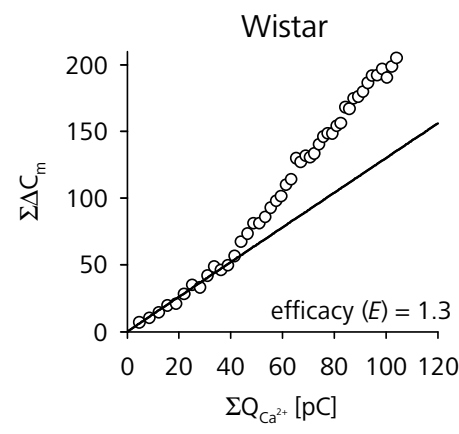

GK

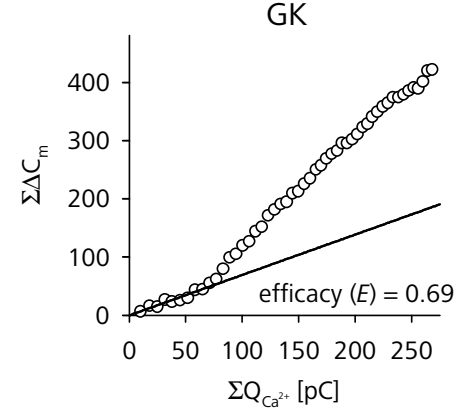

B

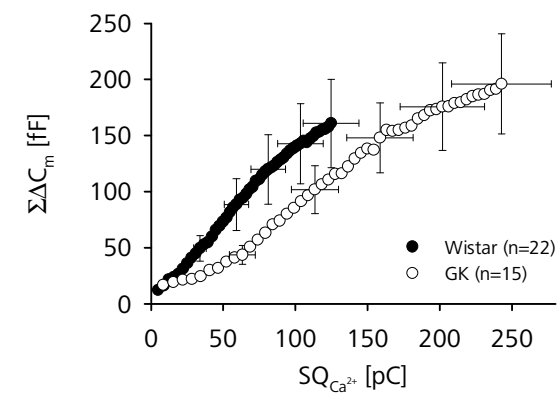

C

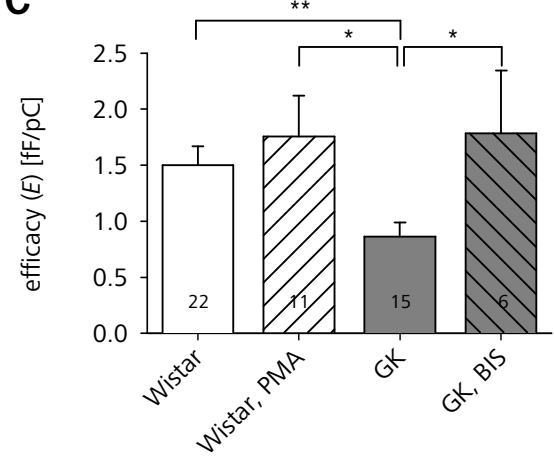

Figure 3.19: The apparent $\mathrm{Ca}^{2+}$ sensitivity is decreased in a PKC-dependent manner in $\beta$-cells of diabetic GK rats. (A) $C_{m}$ traces from depolarization train stimulated $\beta$-cells of Wistar (upper left) and GK (lower left) rats. The respective $\mathrm{I}_{\mathrm{Na}, \mathrm{Ca}}$ resulting from the $1^{\text {st }}$ (black traces) and $50^{\text {th }}$ (gray traces) depolarization are shown below. The right panels show the $\Sigma \Delta \mathrm{C}_{\mathrm{m}}$ of the same cells plotted against the cumulative $\mathrm{Ca}^{2+}$ current integrals $\left(\Sigma \mathrm{Q}_{\mathrm{Ca}^{2+}}\right)$. Straight lines represent linear fits $\left(\Sigma \Delta \mathrm{C}_{\mathrm{m}}\left(\Sigma \mathrm{Q}_{\mathrm{Ca}^{2+}}\right)=E \times \Sigma \mathrm{Q}_{\mathrm{Ca}^{2+}}\right)$ through the first 10 data points. The slope factor $E$ is taken to represent the exocytotic efficacy of $\mathrm{Ca}^{2+}$ to trigger LDCV secretion. (B) Average $\mathrm{Ca}^{2+}$-exocytosis relationship during pulse trains in Wistar (closed circles) and GK rat (open circles) $\beta$-cells. For clarity, error bars are only shown for every $10^{\text {th }}$ data point. (C) Comparison of $E$ during train stimulation between Wistar (open bars) and GK (gray bars) $\beta$-cells. The same protocol was repeated for Wistar $\beta$-cells superfused with PMA and GK $\beta$-cells treated with BIS-1 (hatched bars). ${ }^{* *} \mathrm{p} \leqslant 0.01,{ }^{*} \leqslant 0.05$, unpaired t-test. 
Surprisingly, BIS-1, a potent multi-isoform inhibitor of PKC (Toullec et al., 1991), restored secretory efficacy in GK rats. $500 \mathrm{nM}$ BIS-1 in the extracellular solution and in the pipette solution elevated $E$ in GK $\beta$-cells to the level of Wistar controls $(E=$ $\left.1.8 \pm 0.6 \mathrm{fF} \mathrm{pC}^{-1}, n=6, \mathrm{p} \leqslant 0.05\right)$. Acute stimulation of control cells with a potent PKC activator (PMA) (see fig. 3.19) did not yield the opposite result, as $100 \mathrm{nM}$ PMA added to the extracellular solution of control $\beta$-cells slightly but not significantly enhanced $E$ to $1.8 \pm 0.4 \mathrm{fF} \mathrm{pC}^{-1}(n=11)$. Phorbol esters in isolated mouse $\beta$-cells have been reported to decrease VACCs whereas a similar bisindolylmaleimide (Gö-6976) has been reported to enhance $\mathrm{I}_{\mathrm{Ca}^{2+}}$ (Zhang et al., 2004). However, application of neither of the pharmacological agents had a significant influence on the total $\Sigma \mathrm{Q}_{\mathrm{Ca}^{2+}}$ reached after train stimulation compared to the untreated group (Wistar + PMA: $116 \pm 23 \mathrm{pC}, n=$ 12 vs. GK + BIS-1: $166 \pm 38 \mathrm{pC}, n=11$; n.s.).

\section{Activity-dependent facilitation in GK rats}

Next we needed to answer the question how a decreased exocytotic efficacy in GK rat $\beta$-cells relates to the published reports that insulin release in response to non-nutrient depolarizing stimuli is not impaired and in some cases is even higher in GK rats and other models of type-2 diabetes than in healthy control (Giroix et al., 1983; Leahy et al., 1992; Abdel-Halim et al., 1996). Many neuroendocrine and synaptic preparations respond to intense stimulation with a short- to long-term enhancement of their secretory efficacy (Peng and Zucker, 1993). We tested if a similar form of facilitation could explain the exaggerated non-nutrient-stimulated secretion of GK rats.

If we applied two identical trains of depolarizations $(2 \times 50$ pulses, $10 \mathrm{~Hz})$ the secretory response to the second stimulation $4 \mathrm{~min}$ after the first was markedly altered between healthy and diabetic $\beta$-cells (see fig. 3.20). Whereas $\Sigma \Delta C_{m}$ in the exemplary control $\beta$-cell shown in fig. 3.20 A was decreased during the $2^{\text {nd }}$ stimulation, the GK $\beta$-cell demonstrated a clear increase in its secretory capacity. Fig. 3.20 B shows two further $\beta$-cells in which $\Sigma \Delta \mathrm{C}_{\mathrm{m}}$ is related to the respective stimulus intensity. $\Sigma \mathrm{Q}_{\mathrm{Ca}^{2+}}$ is reduced in both cases due to $\mathrm{Ca}^{2+}$ current rundown (also see fig. 3.7, p. 47). In controls $E$ stayed constant in spite of reduced charge entry $\left(1^{\text {st }}\right.$ train: $E=0.95 \mathrm{fF} \mathrm{pC}^{-1}$ vs. $2^{\text {nd }}$

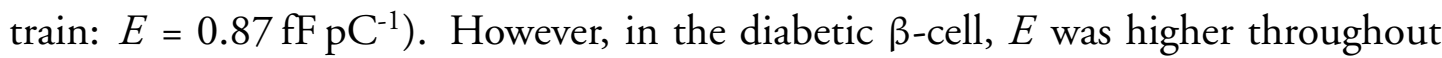


A

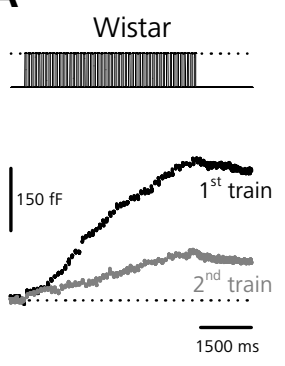

GK

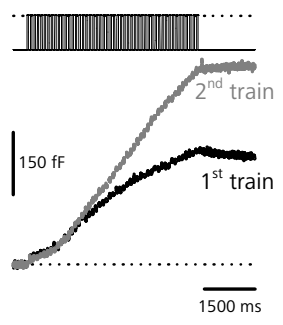

B

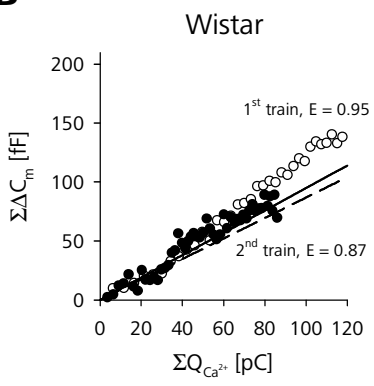

GK

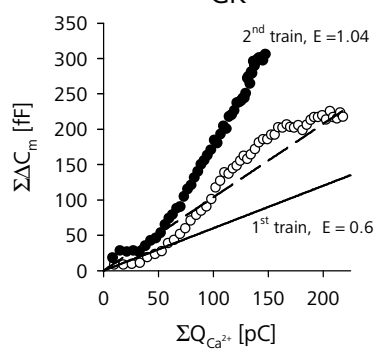

C

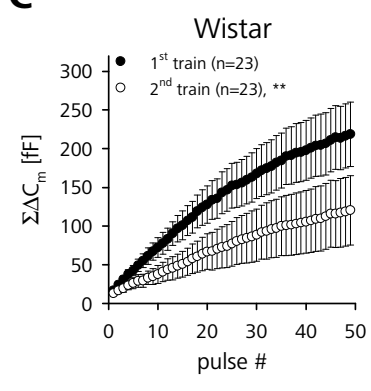

GK

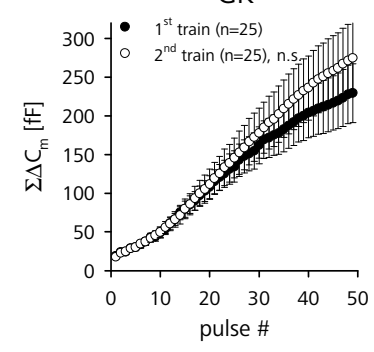

D

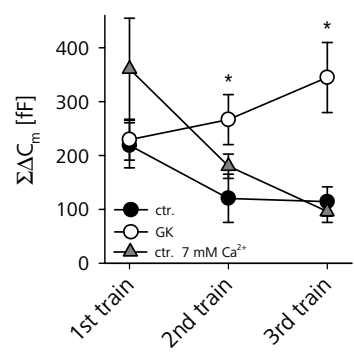

E

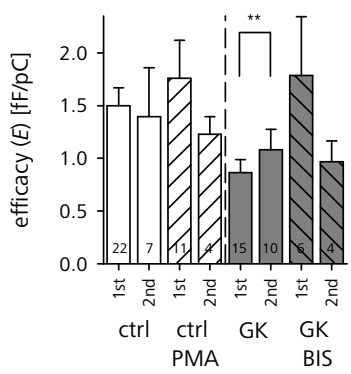

Figure 3.20: GK rat $\beta$-cells show PKC-mediated activity-dependent facilitation of release. (A) $\Sigma \Delta \mathrm{C}_{\mathrm{m}}$ in response to 2 successive depolarization trains (inter stimulus interval: $4 \mathrm{~min}$ ) in a Wistar (upper panel) and GK (lower panel) $\beta$-cell. (B) $\Sigma \Delta \mathrm{C}_{\mathrm{m}}$ of two further individual Wistar and GK $\beta$-cells as a function of $\Sigma \mathrm{Q}_{\mathrm{Ca}^{2+}}$. Straight lines represent linear fits through the first 10 data points of the $1^{\text {st }}$ (solid) and $2^{\text {nd }}$ (dashed) stimulus train. (C) Averaged $\Sigma \Delta \mathrm{C}_{\mathrm{m}}$ during repetitive train stimulation of Wistar and GK $\beta$-cells. (D) Total $\Sigma \Delta \mathrm{C}_{\mathrm{m}}$ after the end of the train plotted against the stimulus train number for Wistar (closed circles, $n=8-23$ ) and GK (gray triangles, $n=11-25$ ) $\beta$-cells. Additionally, $\Sigma \Delta \mathrm{C}_{\mathrm{m}}$ for Wistar $\beta$-cells perifused with $7 \mathrm{mM} \mathrm{Ca}^{2+}$ is shown (open circles, $n=4)$. Asterisks indicate differences ( ${ }^{*} \mathrm{p} \leqslant 0.05$, unpaired t-test) between $\Sigma \Delta \mathrm{C}_{\mathrm{m}}$ of the GK rat group after each train and the respective Wistar rat control in high and low external $\mathrm{Ca}^{2+}$. (E) $E$ of Wistar and GK $\beta$-cells in the absence and presence of PMA and BIS-1. Only paired groups of the same category ( $2^{\text {nd }}$ vs. $1^{\text {st }}$ train controls) were tested for statistical significance. ${ }^{* *} \mathrm{p} \leqslant 0.01$, paired t-test. 
the $2^{\text {nd }}$ train, almost reaching a value similar to that of Wistar cells ( $1^{\text {st }}$ train: $E=$ $0.6 \mathrm{fF}^{-1}, 2^{\text {nd }}$ train: $\left.E=1.0 \mathrm{fF} \mathrm{pC}^{-1}\right)$.

On average, total $\Sigma \Delta \mathrm{C}_{\mathrm{m}}$ in controls was significantly lower after the $50^{\text {th }}$ depolarization of the $2^{\text {nd }}$ train than after the $1^{\text {st }}(219 \pm 42 \mathrm{fF}$ vs. $120 \pm 45 \mathrm{fF}, n=23, \mathrm{p} \leqslant 0.01$, paired t-test) (see fig. $3.20 \mathrm{C}$ ). In GK rat $\beta$-cells the same stimulation led to a small, albeit not significant increase in $\Sigma \Delta \mathrm{C}_{\mathrm{m}}(229 \pm 38 \mathrm{fF}$ vs. $266 \pm 46 \mathrm{fF}, n=25)$. This discriminative behavior occurred in spite of a comparable $\mathrm{Ca}^{2+}$ current rundown in Wistar ( $1^{\text {st }}$ train: $122 \pm 45 \mathrm{pC}$ vs. $2^{\text {nd }}$ train: $47 \pm 37 \mathrm{pC}, n=7, \mathrm{p} \leqslant 0.01$, paired t-test) and GK rat $\beta$-cells $\left(1^{\text {st }}\right.$ train: $248 \pm 29 \mathrm{pC}$ vs. $2^{\text {nd }}$ train: $152 \pm 28 \mathrm{pC}, n=11, \mathrm{p} \leqslant 0.01$, paired t-test).

In terms of the secretory efficacy this means that whereas in controls $E$ stayed relatively constant during repetitive train stimulation $\left(E=1.7 \pm 0.3 \mathrm{fF} \mathrm{pC}^{-1}\right.$ to $E=$ $1.4 \pm 0.5 \mathrm{fF} \mathrm{pC}^{-1}, n=7$, n.s., paired t-test), GK $\beta$-cells displayed significant facilitation $\left(E=0.8 \pm 0.1 \mathrm{fF} \mathrm{pC}^{-1}\right.$ to $1.1 \pm 0.2 \mathrm{fF} \mathrm{pC}^{-1}, n=11, \mathrm{p} \leqslant 0.01$, paired t-test). The effect could not be explained by the increased $\mathrm{Ca}^{2+}$ entry in diabetic $\beta$-cells because if we elevated $\left[\mathrm{Ca}^{2+}\right]_{0}$ in the controls to $7 \mathrm{mM}$ in order to match the $\mathrm{Ca}^{2+}$ entry of GK rats (resulting peak ramp HVA density: $15.1 \pm 1.6 \mathrm{pA} \mathrm{pF}^{-1}, n=8$, n.s., also see fig. 3.13 , p. 55), rundown of $\Sigma \Delta \mathrm{C}_{\mathrm{m}}$ was still present in Wistar $\beta$-cells (see fig. 3.20). In contrast to the $1^{\text {st }}$ train, the total release in GK $\beta$-cells after a $2^{\text {nd }}$ or even a $3^{\text {rd }}$ stimulation was significantly higher compared to the high and low $\left[\mathrm{Ca}^{2+}\right]_{0}$ controls.

Similar as has been shown in chromaffin cells (Smith, 1999), the facilitation of release in GK rats could be prevented by blocking PKC activity with BIS-1 (see fig. 3.20 E). Whereas untreated GK rat $\beta$-cells show a robust increase in secretory efficacy, there was no facilitation visible during the $2^{\text {nd }}$ train stimulation in the presence of $500 \mathrm{nM}$ BIS. Again, activation of PKC in Wistar rat controls by PMA did not significantly change $E$, neither for the $1^{\text {st }}$ nor for the $2^{\text {nd }}$ stimulation. 


\section{Discussion}

\subsection{The rat pancreatic tissue slice preparation}

In comparison to mice, rats are widely regarded as the preferable animal model to study the regulation of glucose homeostasis - mainly because nutrient-induced insulin release in rats is more comparable to humans (Gerich et al., 1974; Lenzen, 1979; Misler et al., 1992; Elahi, 1996). Furthermore, intact or semi-intact preparations enabling biochemical measurements of insulin release are technically less demanding than in mice and the comparably high number of islets that can be obtained by the standard enzymatic islet isolation procedures enables convenient in vitro experiments. Partly for this reasons the currently most widely used animal models of type-2 diabetes are rats (Sima and Shafrir, 2000; Rees and Alcolado, 2005; Chen and Wang, 2005).

On the other hand, the electrophysiology of $\beta$-cell stimulus-secretion coupling has mostly been studied using mice. Especially for electrophysiological experiments on $\beta$-cells within intact islets mice are favorably used because their islets are known to be much easier to isolate and fix in a way suitable for the use in an electrophysiological recording chamber (Antunes et al., 2000). Hence, data obtained from these experiments had either to be extrapolated for the rat pancreas- thus disregarding known species differences (see section 1.5, p. 20) - or dispersed and cultured rat $\beta$-cells had to be used instead. Yet studying insulin release from single isolated $\beta$-cells only has a limited explanatory power for the in vivo situation because the secretory capacity of rat $\beta$ cells critically depends on the functional cooperation between the islet cells: Pipeleers et al. (1982) demonstrated that in rats glucose leads to a $\sim 30$ times higher insulin secretion from $\beta$-cells within intact islets than from isolated $\beta$-cells. This prompted us to readdress some of the electrophysiological questions of stimulus-secretion coupling in $\beta$-cells from healthy and diabetic rats using a more in situ approach. 
In this work we adapted a novel tissue slice preparation that has recently been developed for the mouse pancreas (Speier and Rupnik, 2003). We show that the advantages that have originally been described for the mouse preparation also apply for rats. Most importantly, the microanatomy of the endocrine and also exocrine pancreas remains largely intact, therefore conserving the functional interactions of $\beta$ cells. Moreover, whereas dispersed islet cells can at the earliest be obtained after about two hours of preparation and incubation (Lacy and Kostianovsky, 1967; Lernmark, 1974), slices of rat pancreas can routinely be used one hour after the sacrifice of the animal. The islet isolation procedure requires long incubation periods (up to $50 \mathrm{~min}$ ) at $37^{\circ} \mathrm{C}$ in the presence of digestive enzymes. In contrast, uncooled periods in the course of the tissue slice preparation are limited to the duration of the agarose injection and the warm-up period preceding the experiments. These measures result in a to date unprecedented degree of immediacy and likely also conservation of the in vivo characteristics of endocrine physiology.

A seminal advantage over other preparations is that tissue slices allow a more precise control over the experimental conditions. The commonly used isolation procedures tend to be selective for islets of a certain size, shape and cell-density. This is evident from the comparable small islet yield from collagenase digestions, because whereas the adult rat possesses $\sim 5000$ islets of highly variable shape (Hughes, 1956; Lifson et al., 1985) (see fig. 3.2 , p. 40) only a maximum of $\sim 500$ relatively uniform islets can be isolated from a single pancreas (Kinasiewicz et al., 2004). Furthermore, any morphological or topological information is lost during islet isolation. This is disadvantageous because the secretory capacity of islets is known to be heterogenous resulting from morphological differences. This applies for varying islet sizes (Aizawa et al., 2001) but also for differences in the position within the organ. The relative distribution of islet cell types but also the secretory capacity of $\beta$-cells differs significantly between islets from different parts of the pancreas-e.g. insulin release from the splenic part has been reported to be higher than from the duodenal part of the rat pancreas (Trimble et al., 1982; Stefan et al., 1987). In slices the experimenter is able to deliberately choose the origin and define the morphological properties of the islets to be studied. Especial in the case of pathophysiological alterations of islet morphology this poses an advantage because the selectivity of the isolation procedure might lead to a significant experimental bias. 
Diabetic GK rat islets often tend to be of irregular shape because of islet fibrosis (see fig. 3.9, p. 50) and consequentially the yield of islets by enzymatic isolation has been reported to be much lower (Östenson, 2000). This suggests that the islet isolation procedure itself might lead to a selective bias towards non-diseased islets which might partly explain the inconsistent results of the electrophysiological and $\mathrm{Ca}^{2+}$ imaging studies on isolated and cultured GK rat $\beta$-cells and islets published so far (Kato et al., 1996; Hughes et al., 1998; Zaitsev et al., 1997; Marie et al., 2001) (see section 4.2.2, p. 76).

\subsubsection{Electrical activity in rat $\beta$-cells in tissue slices}

Mouse $\beta$-cells react to stimulatory glucose concentrations with a characteristic bursting pattern of electrical activity (Henquin and Meissner, 1984). These $V_{m}$ oscillations are thought to result in oscillatory changes of $\left[\mathrm{Ca}^{2+}\right]_{\mathrm{i}}$ (Santos et al., 1991) which in the end should lead to pulsatile insulin secretion. The insulin output of the whole endocrine pancreas is known to oscillate as well-a fact that received much attention because this pulsatile release pattern is disturbed in patients suffering from T2D (Bergsten, 2000).

In rats, pancreatic insulin release and insulin secretion from isolated islet has previously been reported to be pulsatile as well (Bergstrom et al., 1989; Cunningham et al., 1996). However, oscillatory changes in $\left[\mathrm{Ca}^{2+}\right]_{\mathrm{i}}$ have only been observed in some studies (Longo et al., 1991; Ahmed and Grapengiesser, 2002) whereas most groups found constant elevations of $\left[\mathrm{Ca}^{2+}\right]_{\mathrm{i}}$ in response to glucose (Martin et al., 1995; Antunes et al., 2000). A recent report received considerable attention because it stated that rat $\beta$-cells are not capable of exhibiting bursting electrical activity (Antunes et al., 2000). Using whole-cell current-clamp measurements of $\beta$-cells in addition to ratiometric $\mathrm{Ca}^{2+}$-imaging of islets in tissue slices we show here that rat $\beta$-cells in fact exhibit oscillatory activity-both in $\mathrm{V}_{\mathrm{m}}$ (see fig. 3.4, p. 43) and in $\left[\mathrm{Ca}^{2+}\right]_{\mathrm{i}}$ (see fig. 3.11, p. 52). However, we observed bursting activity in rats much less frequent than in mice where it is the dominating activity pattern (Speier and Rupnik, 2003). It is tempting to speculate that this is a direct consequence of the smaller residual membrane conductance after $\mathrm{K}_{\text {ATP }}$ channel inhibition (see fig. 3.6, p. 46) which we interpret as evidence for a lower degree of electrical coupling (here: $0.6 \mathrm{nS}$ vs. mouse $\beta$-cells, slice preparation: $1.7 \mathrm{nS}$; Speier et al., 
2005). Coupling between $\beta$-cells is believed to average the heterogeneous electrical properties of single cells by generating an electrical syncytium. Only this united cell structure is postulated to possess the right—but still largely hypothetical—parameters of cellular excitability that enable bursting activity (Sherman et al., 1988; Smolen et al., 1993; Zhang et al., 2003). This becomes evident from the observation that in contrast to coupled cell-clusters or whole islets, isolated $\beta$-cells usually only exhibit electrical activity consisting of single spikes (Zhang et al., 2003). Furthermore, according to a computational model of the gap junctional influence on $\beta$-cell electrical activity, a higher degree of electrical coupling leads to an increase in the glucose threshold and a sharpening of the dose-response-curve of glucose-induced electrical activity (Smolen et al., 1993). As has been previously reported, insulin secretion in rats indeed has a lower glucose-threshold (Henquin, 1978) and a shallower dose-response curve than in mice (Antunes et al., 2000). Similarly, also we observed electrical activity of a $\beta$-cell in $5 \mathrm{mM}$ glucose (see fig. 3.4, p. 43), a concentration which is usually not stimulatory in mouse $\beta$-cells (Antunes et al., 2000). To our knowledge, no differences in coupling strength between individual $\beta$-cells have been reported for the murine species. Therefore the decreased residual conductance most likely results from a smaller number of coupled cells, which would concur with the more loosely packed cellular structure of rat islets (see section 3.1.1, p. 40). However, the comparison of residual conductances is only valid if identical electrical cellular parameters (essentially leak- and resting membraneconductances) are assumed for $\beta$-cells in the mouse and rat tissue slice preparations. Whereas this is a reasonable assumption, further experiments are needed to quantify the influence of electrical coupling between $\beta$-cells on species differences of electrical activity. Also in this case the tissue slice preparation lends itself to study this promising subject.

\subsubsection{Whole-cell measurements of insulin secretion}

Most data on the secretory function of pancreatic $\beta$-cells has been obtained with biochemical measurements of insulin-release from isolated islets or perfused pancreata. Although $C_{m}$ measurements are an established technique to study $\beta$-cell physiology 
(Kanno et al., 2004) it is occasionally questioned that these measurements are faithfully reporting insulin release.

Mostly it is stated that the insulin release rates assessed by biochemical methods are much lower than the rates obtained from $\mathrm{C}_{\mathrm{m}}$ measurements. In this study we are reporting a theoretical maximal release rate of $118-133$ vesicles $\mathrm{s}^{-1}\left(400 \mathrm{fF} \mathrm{s}^{-1}\right)$ (see fig. 3.15 , p. 57). Albeit being in the range of previously published data for mouse $\beta$-cells (Barg et al., 2001; Göpel et al., 2004) this is more than two orders of magnitude higher than the biochemically measured insulin release rate of a single $\beta$-cell in isolated rat islets, which is estimated to be $\sim 0.2$ granules $^{-1}$ at the peak of the $1^{\text {st }}$ phase of GSIS (Straub and Sharp, 2004).

However, it has to be considered that the theoretical maximum release rate of a responsive $\beta$-cell decays exponentially and already $40 \mathrm{~ms}(\hat{=} \tau)$ after stimulus onset this rate is reduced to $37 \%(100 \%)$ of its initial value-the depletion of the fast secretory component therefore almost immediately leads to a decrease in the global release rate in response to a constant stimulus. We also used a less artificial stimulation regime by applying repetitive depolarization pulses from a negative holding potential to a $V_{m}$ that guarantees maximum $\mathrm{Ca}^{2+}$-influx. This train stimulation evoked a total $\Sigma \Delta \mathrm{C}_{\mathrm{m}}$ of $\sim 200 \mathrm{fF}$ (see fig. 3.8 and 3.14, pp. 49 and 56) after $5 \mathrm{~s}$ which corresponds to an average release rate of $12-13$ vesicles $\mathrm{s}^{-1}\left(40 \mathrm{fF} \mathrm{s}^{-1}\right)$. This rate is still higher than biochemically assessed. However, also a depolarization train with a pulse frequency of $10 \mathrm{~Hz}$ can still be considered to be an unphysiological high stimulus: Similar as Antunes et al. (2000) we recorded a spike frequency of $1.5 \mathrm{~Hz}$ in a $\beta$-cell at $10 \mathrm{mM}$ glucose (see fig. 3.4, p. 43) and even during bursting activity the action potential frequency usually did not exceed $\sim 5 \mathrm{~Hz}$. In addition, one has to take into account that action potentials of rat $\beta$-cells only reach $-20 \mathrm{mV}$ (Antunes et al., 2000) resulting in a lower $\mathrm{Ca}^{2+}$ influx than in the stimulation protocol used here. Mouse $\beta$-cells show a $3-4 \times$ higher $\Delta C_{m}$ if depolarized to $0 \mathrm{mV}$ in comparison to $-20 \mathrm{mV}$ (Smith et al., 1999; Göpel et al., 2004). It is not straightforward to deduce the hypothetical $\Delta \mathrm{C}_{\mathrm{m}}$ in response to a stimulation mimicking physiological spiking behavior from this data, but it should approach the rate of insulin measurements while likely being still higher. However, up to now our data only applies for the average responsive $\beta$-cell and no concession was made for the inherent response heterogeneity. It is well known that the endocrine pancreas is characterized by a high 
degree of redundancy. In humans only $50 \%$ of the pancreatic $\beta$-cell mass is thought to be responsive to glucose under normal conditions (Clark et al., 2001) and in rats 95\% of the whole pancreas has to be removed to induce hyperglycaemia (Bonner-Weir et al., 1983). Even in isolated $\beta$-cells the percentage of $\beta$-cells releasing insulin in response to $20 \mathrm{mM}$ glucose as estimated with the reverse hemolytic plaque assay is $66.4 \%$ (Hiriart and Matteson, 1988) — a value strikingly similar to the fraction of responsive $\beta$-cells we report here (see fig. 3.8, p. 49).

$\mathrm{C}_{\mathrm{m}}$ measurements in pancreatic $\beta$-cells are criticized in two more points. First, similar to other cells containing secretory granules, $\beta$-cells hold small synaptic like microvesicles (SLMVs) in addition to LDCVs (Reetz et al., 1991; Thomas-Reetz and De Camilli, 1994; Takahashi et al., 1997). These GABA-containing (Reetz et al., 1991) vesicles are capable of undergoing regulated exocytosis (Braun et al., 2004; MacDonald et al., 2005) which could possibly lead to a contamination of the $\mathrm{C}_{\mathrm{m}}$ measurements. However, it has been demonstrated that the contribution of SLMVs to the total $\Delta \mathrm{C}_{\mathrm{m}}$ in response to depolarizing stimulation is $\leqslant 1 \%$ (Braun et al., 2004). Second, $C_{m}$ measurements only detect membrane fusion and therefore the actual release of insulin into the extracellular space cannot be assayed by this technique. For the comparative analysis of the data obtained from healthy and diabetic rats this might indeed lead to a bias, because one study found a higher occurrence of electron-translucent vesicles of LDCV size in islets of GK rat $\beta$-cells (Höög et al., 1997). However, whereas in a more recent study these putatively immature vesicles were also observed in obese fa/fa rats, no ultrastructural difference between $\beta$-cells of diabetic GK rats and healthy Wistar rat controls was found (Sondergaard et al., 2003). Taking all this into consideration, it is reasonable to assume that our $\mathrm{C}_{\mathrm{m}}$ measurements indeed report LDCV secretion-albeit necessarily elicited by a more intense stimulation regime than by nutrient-induced electrical activity (see section 3.1.3, p. 48).

A further possible objection against our approach regards the use of the standard whole-cell technique. During whole-cell recording, substances are lost from the cell due to the effects of dialysis with the pipette solution (Pusch and Neher, 1988). Therefore we performed an experiment to test the influence of whole-cell dialysis on the secretory capacity of the patched cells. Fig. 3.7 (p. 47) indeed shows that both $\Delta \mathrm{C}_{\mathrm{m}}$ and $\mathrm{Ca}^{2+}$ influx are declining during the recordings. The experiment further shows, however, that 
decrease in $\Delta \mathrm{C}_{\mathrm{m}}$ is likely attributable to the rundown of $\mathrm{Ca}^{2+}$ current and not due to the washout of factors vital for secretion, since the dependency of $\mathrm{C}_{\mathrm{m}}$ on $\mathrm{Ca}^{2+}$-influx stays within the reported low power relation for depolarization-induced exocytosis (Engisch and Nowycky, 1996; Smith and Neher, 1997; Mansvelder and Kits, 1998; Kits and Mansvelder, 2000). Therefore, as long as care is taken to monitor $\mathrm{Ca}^{2+}$ influx together with $\Delta \mathrm{C}_{\mathrm{m}}$ meaningful whole-cell measurements of LDCV secretion can readily be performed in $\beta$-cells in tissue slices. For the comparison of healthy and diabetic rats the use of the controlled whole-cell dialysis is particularly advantageous because it enables us to largely exclude the signaling differences resulting from dissimilar concentrations of diffusible cytosolic factors and focus on the distal steps of $\mathrm{Ca}^{2+}$-secretion coupling: Different resting levels of ATP and cAMP in Wistar and GK rat $\beta$-cells have repeatedly been reported (Hughes et al., 1998; Dachicourt et al., 1997). However, because cytosolic ATP is kept constant and in contrast to single cell preparations cAMP can completely be omitted from the pipette solution this is unlikely to bias our results.

Needless to say that several aspects of comparative physiology of healthy and diabetic $\beta$-cells necessarily would have to be studied in metabolically more intact cells. Both long-term monitoring of glucose-induced electrical activity and secondary glucosedependent modulations of $\mathrm{Ca}^{2+}$-induced secretion-i.e. the triggering and amplifying pathway-need intact metabolism leading to changes in intracellular metabolites that are unlikely to take place in dialyzed cells. The perforated patch clamp technique would allow these changes to occur and therefore it would be desirable to establish this technique for future experiments studying this subjects.

\section{2 $\mathrm{Ca}^{2+}$-secretion coupling in healthy vs. diabetic rats}

\subsubsection{Increased basal electrical activity and higher $\mathrm{Ca}^{2+}$ current density in GK rat $\beta$-cells}

The first feature we observed in the course of the electrophysiological characterization of GK rat $\beta$-cells was the occurrence of electrical activity at low concentrations of ambient glucose (see fig. 3.10 and also 4.1, pp. 51 and 82). This to date undescribed 
feature of GK rat $\beta$-cells might at least partly be the reason for the reported basal hyperinsulinaemia of these animals (Abdel-Halim et al., 1996).

We have to acknowledge the possibility that the GK rat cells which showed spontaneous electrical activity are not actually $\beta$-cells but in fact glucagon-releasing $\alpha$-cells that are known to be active at low glucose concentrations (Göpel et al., 2000). The morphology of GK rat islets is often irregular as a result of fibrosis. Additionally, also the characteristic mantle/core organization of the GK rat islets has been reported to be disturbed (Östenson, 2000). However, not only did the respective cells show a $\beta$-cell-like $\mathrm{I}_{\mathrm{Na}^{+}}$inactivation profile but in some cases we also saw current injections from neighboring cells (not shown). Since electrical coupling has been demonstrated to be a $\beta$-cell exclusive feature (Göpel et al., 1999; Nadal et al., 1999; Quesada et al., 1999) it is unlikely that we mistakenly recorded from $\alpha$-cells.

The increased basal activity in GK rat $\beta$-cells is not only reflected by the current-clamp data showing electrical activity in low glucose but also conformed by $\mathrm{Ca}^{2+}$-imaging where we showed a higher level of resting $\left[\mathrm{Ca}^{2+}\right]_{\mathrm{i}}$ in GK rat islets. Further evidence is provided by the fact that $\mathrm{GK}$ rat islets exhibited $\left[\mathrm{Ca}^{2+}\right]_{i}$ oscillations in $3 \mathrm{mM}$ glucose (see fig. $3.11 \mathrm{~B}$, islet GK1, p. 52).

The spontaneous $\beta$-cell activity in GK rats likely results from the increased LVA Ca ${ }^{2+}$ current amplitudes we and others (Kato et al., 1996) observe in this animal model (see fig. 3.13, p. 55) because increased T-type currents are known to lower the threshold for action potential firing in an insulin-secreting cell line (INS-1) (Bhattacharjee et al., 1997). Interestingly, very similar observations were made in NOD-mice-a model of type-1 diabetes - where, in contrast to non-diabetic controls, LVA currents were well developed and also the resting $\left[\mathrm{Ca}^{2+}\right]_{\mathrm{i}}$ was significantly increased (Wang et al., 1996).

Co-expression of syntaxin-1A and B together with the $\alpha_{1} 1.2$ subunit of the $\mathrm{Ca}_{\mathrm{v}} 1.2$ channel prominently depresses L-type $\mathrm{Ca}^{2+}$ currents (Wiser et al., 1996). Therefore, downregulation of syntaxin-1A in GK rat islets (Nagamatsu et al., 1999a; Gaisano et al., 2002; Zhang et al., 2002) might not only be responsible for a secretory dysfunction but also for the upregulation of at least the HVA current amplitude. A significant increase in the $\mathrm{L}$ - and T-type $\mathrm{Ca}^{2+}$ current amplitudes has also been described for the neonatally streptozocin-induced diabetic rats, an animal model with pharmacologically induced diabetes (Kato et al., 1996). It would be of interest to also test the expression of secretory 
proteins in this animal model. Similarly, it appears worthwhile to assess $\mathrm{Ca}^{2+}$ current density-and $\mathrm{Ca}^{2+}$-secretion coupling - in the hypertrophied (see below) $\beta$-cells of $\mathrm{fa} / \mathrm{fa}$ rats, the first model of impaired glucose tolerance that showed downregulation of exocytotic proteins, namely syntaxin-1A and synaptobrevin-2 (Chan et al., 1999).

\subsection{2 $\beta$-cell hypertrophy}

Whereas upregulation of VACCs has previously_although not consequently (Hughes et al., 1998) - been reported using cultured GK rat $\beta$-cells (Kato et al., 1996), we additionally found that diabetic $\beta$-cells in fresh slices are significantly hypertrophic.

Short- to long-term increases in $\beta$-cell size in response to hyperglycaemia have been demonstrated repeatedly in both lean and obese rats (Hayek and Woodside, 1979; Bonner-Weir et al., 1989). Because it has also been shown that the secretory capacity of single $\beta$-cells is positively correlated to the cell size (Giordano et al., 1993), $\beta$ cell hypertrophy is generally believed to enhance secretion to cope with the increased secretory demand during hyperglycaemia (Bonner-Weir et al., 1989).

In GK rat $\beta$-cells, however, no increase in cell size has been observed to date. Tourrel et al. (2002) recently compared fixed and stained pancreatic tissue of two month old female GK rats with age- and sex-matched Wistar rat controls. The reported mean crosssectional area of Wistar rat $\beta$-cells $\left(198 \mu \mathrm{m}^{2}\right)$ is very comparable to the area we derived from our resting $\mathrm{C}_{\mathrm{m}}$ measurements $\left(179 \mu^{2} ; \mathrm{F} / 4\right.$, see eq. 2.4 , p. 32). In fact, our value is even closer to the mean cross-sectional area of $137 \mu \mathrm{m}^{2}$ that can be obtained from the ultrastructural data of Straub et al. (2004). The size we determined for GK rat $\beta$-cells, however, is much biger than previously reported $\left(271 \mathrm{vs.} 196 \mu \mathrm{m}^{2}\right)$. Interestingly, our data describing a $50 \%$ increase in mean cross-sectional area is well within the range of the $20-40 \%$ hypertrophy previously reported for obese fa/fa rats (Chan et al., 1999, 2002).

In mice, prominent cell size difference between cultured $\beta$-cells and $\beta$-cells in tissue slices have been observed (Speier et al., 2005). Therefore, it is understandable that neither Kato et al. (1996) nor Hughes et al. (1998) reported different resting $C_{m}$ values between isolated diabetic and non-diabetic cells: Any original size difference likely would have already been masked by the culturing effect on cell-size. Since our results 
are further backed up by morphometric data it is safe to say that our data corresponds well to the in vivo situation. It is difficult to say, however, why Tourrel et al. (2002) did not observe hypertrophic $\beta$-cells using fixed pancreatic tissue. Further experiments are needed to establish whether this discrepancy represents a sexual dimorphism or whether animals from the Paris GK rat colony (GK/Par) exhibit different features than the GK rats used here and elsewhere (Östenson, 2000; Portha et al., 2001).

\subsubsection{Impaired $\mathrm{Ca}^{2+}$-secretion coupling}

It has been suggested that the primary lesion in GK rats is impaired coupling of the glucose signal to insulin secretion, while the secretory machinery itself is not affected directly (Abdel-Halim et al., 1996; Katayama et al., 1995). Another study using isolated and cultured GK rat $\beta$-cells came to similar conclusions using cell size-normalized $C_{m}$ measurements (Hughes et al., 1998).

However, it speaks against an impairment of upstream glucose-dependent signalling in diabetic $\beta$-cells that glucose is still able to increase $\left[\mathrm{Ca}^{2+}\right]_{i}$ in a way, which-at least in our hands - is indistinguishable from controls (see fig. 3.11, p. 52). If the major lesion site in GK rat $\beta$-cells was a dysfunctional step in glucose-metabolism, one would expect a reduced ATP-generation leading to a decreased $\mathrm{K}_{\text {ATP }}$ channel-dependent depolarization of the membrane which would result in a decreased amplitude of the glucose-induced $\Delta\left[\mathrm{Ca}^{2+}\right]_{\mathrm{i}}$. In acute tissue slices, however, we did not observe a difference in the $\mathrm{Ca}^{2+}$ response which is similar to the data of Zaitsev et al. (1997) who, in contrast to two further studies using isolated GK rat islets (Kato et al., 1996; Marie et al., 2001), also did not observe different total $\Delta\left[\mathrm{Ca}^{2+}\right]_{i}$ amplitudes. Interestingly, the animals used by Marie et al. (2001) again were from the GK/Par colony whereas the GK rats showing no difference in $\Delta\left[\mathrm{Ca}^{2+}\right]_{\mathrm{i}}$ stemmed from a colony in Stockholm - the same colony that was used in most of the reports that demonstrated the down-regulation of exocytotic proteins in GK rat islets (Gaisano et al., 2002; Zhang et al., 2002; Sheu et al., 2003).

It has been reported for GK/Par rats that an early reduction in $\beta$-cell mass (Movassat et al., 1995) — probably caused by fetal malnutrition and epigenetic in utero programming of $\beta$-cells (Portha, 2005) — is the primary deficit in diabetic GK rats. Yet for other colonies this has been shown clearly not to be the case because both $\beta$-cell mass and 
$\beta$-cell density are found to be unchanged in 8-14 weeks old GK rats (Guenifi et al., 1995; Höög et al., 1997; Metz et al., 1999; Svensson et al., 2005). Furthermore, it seems unlikely that a simple reduction in the number of $\beta$-cells leads to the diabetic phenotype because if this would be the case, a further reduction of $\beta$-cell mass should worsen the disease. However, similar as in Wistar rat controls a $60 \%$ pancreatectomy in GK rats neither alleviates nor aggravates glucose homeostasis (Svensson et al., 2005).

It is very well conceivable that both $\beta$-cell hypertrophy and prominently increased $\mathrm{Ca}^{2+}$ currents in GK rats represent compensatory measures to overcome a defect late in stimulus-secretion coupling. However, this compensation is clearly not sufficient, because though intense stimulation with repetitive depolarizing pulses finally leads to the same amount of secretion, the initial release rate is significantly depressed in diabetic $\beta$-cells (see fig. 3.14 B, p. 56). Seward and Nowycky (1996) found very comparable kinetics of $\Sigma \Delta \mathrm{C}_{\mathrm{m}}$ in response to repetitive stimulation in adrenal chromaffin cells: During train stimulation an initially low release rate is followed by increased secretion that saturates at the end of the depolarization train. By decreasing the amount of $\mathrm{Ca}^{2+}$ influx per pulse they showed that the duration of the initially depressed secretion is positively correlated to the stimulus intensity. As stated above, glucose-induced electrical activity constitutes a less intense $\beta$-cell stimulation than the depolarization train used here. Therefore it is reasonable to assume that the defect is much more pronounced under physiological, nutrient-stimulated conditions, since any decrease in the stimulus intensity would likely prolong the initial phase of depressed secretion.

To exclusively study the secretory dysfunction of GK rat $\beta$-cells and exclude the putatively compensatory effects of hypertrophy and increased $\mathrm{Ca}^{2+}$ influx, we normalized the evoked secretion to the respective parameters. Accordingly, when the secretory response of $\beta$-cells from hyperglycemic GK rats is normalized to the cell size, the secretory lesion becomes even more apparent (see fig. 3.14 C, p. 56). By monitoring $\mathrm{C}_{\mathrm{m}}$ in parallel with $\mathrm{Ca}^{2+}$ charge entry, we demonstrate that Wistar $\beta$-cells are almost twice as efficient as $\beta$-cells from diabetic rats in conveying the evoked $\mathrm{Ca}^{2+}$ signal to LDCV release (see fig. 3.19, p. 64).

Using double-pulse protocols we found no differences in functional pool sizes between healthy and diabetic rats (see fig. 3.16, p.59). These size estimates are in good agreement with previously reported values for isolated Wistar rat $\beta$-cells using similar protocols 
and flash photolysis of a caged $\mathrm{Ca}^{2+}$-compound (Wan et al., 2004, RRP: 200 fF; IRP: $\sim 20 \mathrm{fF}$ ). The comparison with mouse $\beta$-cells is more difficult because of the large heterogeneity of the reported values which likely result from the various different experimental conditions used: The reported RRP sizes range from $35.5 \mathrm{fF}$ (Kanno et al., 2004) to $341 \mathrm{fF}$ (Barg et al., 2001) and for IRP sizes values from $11 \mathrm{fF}$ (Eliasson et al., 2003) to $101 \mathrm{fF}$ (Barg et al., 2001) are published.

The unaltered pool sizes in healthy and diabetic rat $\beta$-cells are in contrast to the findings of Ohara-Imaizumi et al. (2004a). They found a decreased number of docked insulin granules in cultured GK rat $\beta$-cells using total internal reflection microscopy (TIRF) of vesicles expressing a fluorescent cargo protein. Assuming that the IRP consists of granules docked to- or in close vicinity to- $\mathrm{Ca}^{2+}$-channels one would expect a decrease in the functional pool size according to the TIRF data. However, not only has the use of fluorescent cargo proteins to study insulin-containing LDCV release recently been challenged (Michael et al., 2004), but the morphological release data obtained from TIRF measurements has to date not been readily transferable to the functionally defined pools obtained by $\mathrm{C}_{\mathrm{m}}$ measurements of membrane fusion.

Nonetheless, since the pool sizes are similar and also the recovery kinetics show no significant difference (see fig. 3.17, p. 61) it is reasonable to assume that the $\mathrm{Ca}^{2+}$ sensitivity of the secretory machinery of GK rat $\beta$-cells is reduced. At first, the finding of unchanged RRP pool sizes appears to be inconsistent with the reduced expression of t-SNARES and Munc13-1/18-1, because in general these proteins are believed to be involved in determining RRP size (Sø rensen, 2004). However, mutations of SNAP-25 have been shown to directly interfere with $\mathrm{Ca}^{2+}$ sensing (Sø rensen et al., 2002) and selective cleavage of SNAP-25 has recently been demonstrated to prominently reduce the $\mathrm{Ca}^{2+}$-sensitivity in neurons (Sakaba et al., 2005). Furthermore, synaptotagmin III is reported to be a high affinity $\mathrm{Ca}^{2+}$ sensor involved in insulin secretion from $\beta$-cells (Brown et al., 2000). Accordingly, our findings are in line with the reduced expression of these proteins in GK $\beta$-cells (Zhang et al., 2002). Clearly it would be desirable to perform experiments that allow a more precise control over $\left[\mathrm{Ca}^{2+}\right]_{\mathrm{i}}$ to exclude that differences in the spatio-temporal propagation of the depolarizationinduced intracellular $\mathrm{Ca}^{2+}$ signal and not a decreased $\mathrm{Ca}^{2+}$-sensitivity are causing the 
depressed secretion. However, given the prominent reduction of the apparent $\mathrm{Ca}^{2+}$ sensitivity in GK rat $\beta$-cells this appears unlikely.

Several PKC isoforms are expressed in pancreatic $\beta$-cells and it has been shown that they are involved in the regulation of GSIS (Arkhammar et al., 1989), but their precise role is still controversial (Carpenter et al., 2004). Both secretory anomalies described in this report appear to be dependent on enhanced PKC activity since inhibition of the kinase by BIS-1 both increased the exocytotic efficacy and inhibited the activitydependent facilitation of GK rat $\beta$-cells. In general, activation of PKC by PMA has been reported to result in increased secretion in the synaptic as well as neuroendocrine preparations (Gillis et al., 1996; Hori et al., 1999). However, in a neuronal system it has been demonstrated that PKC inhibition by BIS-1 increases the presynaptic $\mathrm{C}_{\mathrm{m}}$ response to depolarizing pulses (Wu and Wu, 2001). More importantly, several reports in which glucose and $\mathrm{K}^{+}$-stimulated insulin release from rats were measured show that inhibition of PKC results in a transient increase in exocytotic efficacy $\left(1^{\text {st }}\right.$ phase of insulin release, see section 1.2, p. 1.2) which is, in the case of glucose, followed by a decrease in the sustained response ( $2^{\text {nd }}$ phase of insulin release) (Zawalich et al., 1998; Zhang et al., 2004; Zawalich and Zawalich, 2001). First phase GSIS is commonly attributed to the $\mathrm{Ca}^{2+}$-dependent release of a RRP of LDCVs. The same pool of vesicles is supposedly released during train stimulation (Rorsman et al., 2000). Our finding that the decreased secretory efficacy of GK rat $\beta$-cells can be significantly ameliorated by blocking PKC is thus in line with the finding of increased $1^{\text {st }}$ phase release due to PKC inhibition. Further clues for a possible involvement of elevated basal PKC activity in GK rats come from the observations of enhanced activity of the kinase in skeletal and smooth muscle cells of diabetic rats (Inoguchi et al., 1992; Avignon et al., 1996).

Why then does PMA application in our hands not mimic the GK rat phenotype? One possibility is that the relative lack of specificity of PMA treatment on PKC activation results in a stimulation of secretion that is not dependent on kinase activity but on other effectors of phorbol esters such as Munc 13-1 (Betz et al., 1998). Thus, an inhibitory action of PKC in Wistar rats could have been masked by an enhanced priming rate resulting from Munc 13-1 activation (Sheu et al., 2003). However, PMA has recently been demonstrated to enhance $\mathrm{Ca}^{2+}$-induced secretion in isolated insulin-secreting cells in a PKC-dependent manner (Yang and Gillis, 2004). Therefore we think that 
the phenotype we observed in GK rats is due to the selective upregulation of one or more PKC isoforms. This cannot be reproduced by broad range activation by PMA in controls, since this might lead to the activation of multiple $\mathrm{PKC}$ isoforms of potentially opposing effects (Song et al., 2002). Furthermore, BIS-1 has a certain, albeit low, affinity for other protein kinases like AMP-activated kinase (AMPK) (Davies et al., 2000), the inhibition of which is also known to stimulate GSIS (da Silva Xavier et al., 2003). Clearly, further experiments using for instance PKC isoform-specific inhibitory peptides would be needed in addition to studies assessing PKC activity and possible phosphorylation targets in GK rat $\beta$-cells to more thoroughly address a possible role of chronic PKC activity in diabetic $\beta$-cells. However, it is a very interesting possibility that in T2D, enhanced PKC activity might not only participate in desensitizing the peripheral tissues to insulin (Idris et al., 2001) but might also be partly responsible for impaired insulin release.

We have to acknowledge a further explanation for the altered secretory response in GK rats which is unique to the in situ character of the slice preparation used in the present study. Abdel-Halim et al. (1993) demonstrated that somatostatin release from $\delta$-cells in GK rat islets is enhanced by $53 \%$. Somatostatin exerts a potent paracrine inhibitory effect on $\beta$-cells (Sieradzki et al., 1975; Hsu et al., 1991). Because of the microvascular $\beta \rightarrow \alpha \rightarrow \delta$ blood perfusion direction (Samols and Stagner, 1988) this is unlikely to have a prominent effect on insulin secretion in vivo. The lack of blood circulation and the close vicinity of mantle $\delta$-cells to the $\beta$-cells patched in the second or third islet cell layer opens the possibility that local paracrine regulation might be more prominent in tissue slices than in vivo. Accordingly, depression of $\delta$-cell release by PKC inhibition might in turn lead to relief from paracrine inhibition in $\beta$-cells. However, a PKC effect on $\delta$-cell secretion has not been demonstrated yet and $\delta$-cell disinhibition by PKC inactivation cannot explain the facilitatory effect we observed in $\beta$-cells after intense stimulation (see fig. 3.20, p. 66).

The central point of reference to which our findings have to be compared are the in vivo and in situ kinetics of insulin release in response to nutrient and non-nutrient stimulation. In this context, our observed decreased secretory efficacy is challenged by the reported normo- or even hyper-responsiveness to $\mathrm{K}^{+}$stimulation in GK rats (Abdel-Halim et al., 1996). 


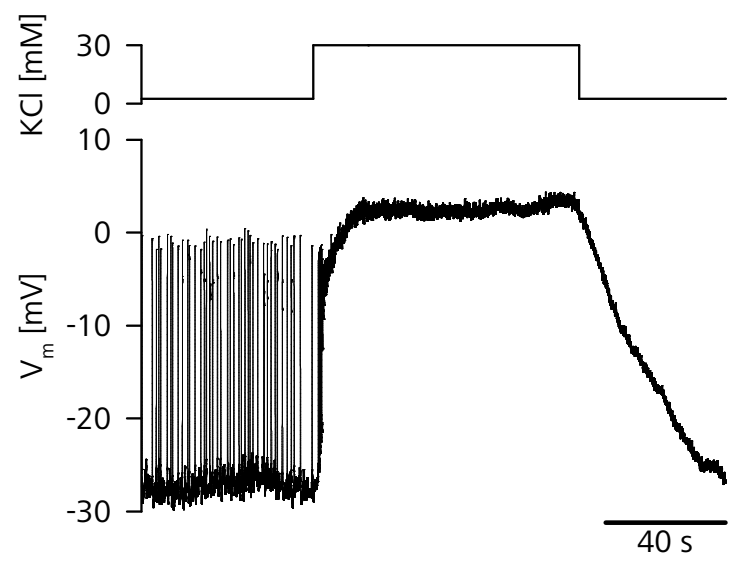

Figure 4.1: Electrical activity in a GK rat $\beta$-cell during stimulation with high $\left[\mathrm{K}^{+}\right]_{\mathrm{o}}$. A $\mathrm{GK}$ rat $\beta$-cell was stimulated with $30 \mathrm{mM} \mathrm{K}^{+}$in low external glucose $(3 \mathrm{mM})$. Duration of whole-cell recording: $\sim 45 \mathrm{~min}$. Note the spiking activity in low glucose.

However, as recently discussed by Kasai et al. (2005), one must take into account that glucose and high $\left[\mathrm{K}^{+}\right]_{\mathrm{o}}$ stimulation exert a very distinct pattern of $\mathrm{V}_{\mathrm{m}}$ change and subsequent increases in $\left[\mathrm{Ca}^{2+}\right]_{i}$. Glucose stimulation leads to spiking (Antunes et al., 2000) and even bursting (see fig. 3.4, p. 43) electrical activity in $\beta$-cells, resulting in oscillatory changes in $\left[\mathrm{Ca}^{2+}\right]_{\mathrm{i}}$ (Ahmed and Grapengiesser, 2002). High $\left[\mathrm{K}^{+}\right]_{\mathrm{o}}$ stimulation, on the other hand, gives rise to a much more pronounced, but plateau-like change in $\mathrm{V}_{\mathrm{m}}$ (see fig. 4.1) and also $\left[\mathrm{Ca}^{2+}\right]_{\mathrm{i}}$ (Miura et al., 1997). According to our data, the most likely explanation for the non-nutrient hypersecretion is therefore, that, in contrast to GSIS, islet depolarization by high $\mathrm{K}^{+}$is strong enough to initiate the activity-dependent facilitation putatively caused by chronically enhanced PKC activity in GK rats. Glucose stimulation, in turn, might be impaired because the spiking electrical activity fails to sufficiently elevate $\left[\mathrm{Ca}^{2+}\right]_{\mathrm{i}}$ and activate facilitation to overcome the decreased apparent $\mathrm{Ca}^{2+}$ sensitivity of the secretory machinery. 


\section{Summary}

Here we studied stimulus-secretion coupling in insulin-releasing $\beta$-cells of healthy and diabetic rats using a pancreatic tissue slice preparation. Following the establishment of this novel and more in situ technique in rats, the electrophysiological characterization of $\beta$-cells in tissue slices revealed several new features of rat $\beta$-cell physiology. We found that similar to mice also rat $\beta$-cells are able to exhibit bursting electrical activity. Electrical coupling between the $\beta$-cells, however, was found to be less pronounced in rats than previously reported for mice.

The central question of this work was whether a possible defect in $\mathrm{Ca}^{2+}$-triggered secretion might be partly responsible for the hyperglycaemic phenotype of the Goto Kakizaki (GK) rat-a widely used animal model of type-2 diabetes. An impairment of glucose metabolism as previously shown is unlikely to be the sole reason for defective nutrient-induced insulin release because we found that glucose is still able to increase cytosolic $\mathrm{Ca}^{2+}$ in a similar way in islets from diabetic and non-diabetic rats.

Using highly time-resolved membrane capacitance measurements to assay secretion of insulin-containing large dense-core vesicles (LDCVs) we show that $\beta$-cells in acute pancreatic tissue slices of diabetic GK rats indeed display defective $\mathrm{Ca}^{2+}$-secretion coupling. This impairment presents itself as a reduction in the efficacy of $\mathrm{Ca}^{2+}$ entry to trigger secretion. In spite of prominently increased $\beta$-cell size and elevated $\mathrm{Ca}^{2+}$ current density, diabetic $\beta$-cells show a depressed response to stimulation with trains of depolarizing pulses. Unexpectedly, unlike in $\beta$-cells of healthy rats this secretory deficit is accompanied by a prominent facilitation of release after repetitive stimulation with depolarization trains. Whereas the first impairment might partially explain the blunted insulin secretion in response to glucose stimulation, the second feature is likely to explain the paradoxical hypersecretion in response to non-nutrient stimulation like physically depolarizing high external $\mathrm{K}^{+}$concentrations. 
Preliminary pharmacological experiments suggest that in addition to the previously reported downregulation of exocytotic proteins in this animal model, chronic activation of protein kinase $\mathrm{C}$ (PKC) might be causative for both effects. Broad range inhibition of PKC with bisindolylmaleimide-1 significantly increased the apparent $\mathrm{Ca}^{2+}$ sensitivity of LDCV exocytosis as well as it prevented the activity-dependent facilitation of release in GK rat $\beta$-cells.

In addition to the secretory abnormalities we found that GK rat $\beta$-cells display spiking electrical activity at low external glucose concentration. This finding is further underlined by a higher resting $\mathrm{Ca}^{2+}$ concentration in the islets of the diabetic animals. This increased basal activity likely leads to the increased basal insulin secretion reported for this animal model and putatively results from a lowering in the spike threshold by enhanced low voltage-activated $\mathrm{Ca}^{2+}$ currents. 


\section{Bibliography}

Abdel-Halim, S. M., Guenifi, A., Efendic, S., and Ostenson, C. G. (1993). Both somatostatin and insulin responses to glucose are impaired in the perfused pancreas of the spontaneously noninsulin-dependent diabetic GK (Goto-Kakizaki) rats. Acta Physiol Scand, 148(2):219-26. 4.2.3

Abdel-Halim, S. M., Guenif, A., Khan, A., Larsson, O., Berggren, P. O., Ostenson, C. G., and Efendic, S. (1996). Impaired coupling of glucose signal to the exocytotic machinery in diabetic GK rats: a defect ameliorated by cAMP. Diabetes, 45(7):934-40. 1.3, 1.5.1, 1.5.1, 3.2.2, 4.2.1, 4.2.3

Adams, M., Blundell, T., Dodson, E., Dodson, G., Vijayan, M., Baker, E., Harding, M., Hodgkin, D., Rimmer, B., and Sheat, S. (1969). Structure of rhombohedral 2 zinc insulin crystals. Nature, 224:491-495. 1.3.3

Ahmed, M. and Grapengiesser, E. (2002). Ca2+ handling of rat pancreatic $\beta$-cells exposed to ryanodine, caffeine, and glucagon. Endocrine, 17(2):103-8. 3.2.1, 4.1.1, 4.2.3

Ahren, B. (2000). Autonomic regulation of islet hormone secretion-implications for health and disease. Diabetologia, 43(4):393-410. 1.2

Aizawa, T., Kaneko, T., Yamauchi, K., Yajima, H., Nishizawa, T., Yada, T., Matsukawa, H., Nagai, M., Yamada, S., Sato, Y., Komatsu, M., Itoh, N., Hidaka, H., Kajimoto, Y., and Hashizume, K. (2001). Size-related and size-unrelated functional heterogeneity among pancreatic islets. Life Sci, 69(22):2627-39. 4.1

Ales, E., Tabares, L., Poyato, J. M., Valero, V., Lindau, M., and Alvarez de Toledo, G. (1999). High calcium concentrations shift the mode of exocytosis to the kiss-and-run mechanism. Nat Cell Biol, 1(1):40-4. 1.3.3

Ammala, C., Ashcroft, F. M., and Rorsman, P. (1993). Calcium-independent potentiation of insulin release by cyclic AMP in single $\beta$-cells. Nature, 363(6427):356-8. 1.3.4, 1.6, 3.1.3, 3.1.3 
Anderson, R. and Long, J. A. (1947). The effect of hyperglycemia on insulin secretion as determined with the isolated rat pancreas in a perfusion apparatus. Endocrinology, 40:92-97. 1.6

Antunes, C. M., Salgado, A. P., Rosario, L. M., and Santos, R. M. (2000). Differential patterns of glucose-induced electrical activity and intracellular calcium responses in single mouse and rat pancreatic islets. Diabetes, 49(12):2028-38. 1.3.5, 3.1.2, 3.2.1, $4.1,4.1 .1,4.1 .2,4.2 .3$

Arkhammar, P., Nilsson, T., Welsh, M., Welsh, N., and Berggren, P. O. (1989). Effects of protein kinase $\mathrm{C}$ activation on the regulation of the stimulus-secretion coupling in pancreatic $\beta$-cells. Biochem J, 264(1):207-15. 4.2.3

Asfari, M., Janjic, D., Meda, P., Li, G., Halban, P. A., and Wollheim, C. B. (1992). Establishment of 2-mercaptoethanol-dependent differentiated insulin-secreting cell lines. Endocrinology, 130(1):167-78. 1.6

Ashcroft, F. M. and Gribble, F. M. (1999). ATP-sensitive K+ channels and insulin secretion: their role in health and disease. Diabetologia, 42(8):903-19. 1.4.2

Ashcroft, F. M., Harrison, D. E., and Ashcroft, S. J. (1984). Glucose induces closure of single potassium channels in isolated rat pancreatic $\beta$-cells. Nature, 312(5993):446-8. 1.3.1

Ashcroft, F. M., Kelly, R. P., and Smith, P. A. (1990). Two types of Ca channel in rat pancreatic $\beta$-cells. Pflugers Arch, 415(4):504-6. 1.5

Ashcroft, F. M. and Rorsman, P. (1989). Electrophysiology of the pancreatic $\beta$-cell. Prog Biophys Mol Biol, 54(2):87-143. 1.3.1, 3.1.2, 3.1.2

Ashcroft, S. J., Weerasinghe, L. C., and Randle, P. J. (1973). Interrelationship of islet metabolism, adenosine triphosphate content and insulin release. Biochem J, 132(2):223-31. 2.2

Avignon, A., Yamada, K., Zhou, X., Spencer, B., Cardona, O., Saba-Siddique, S., Galloway, L., Standaert, M. L., and Farese, R. V. (1996). Chronic activation of protein kinase $\mathrm{C}$ in soleus muscles and other tissues of insulin-resistant type II diabetic Goto-Kakizaki (GK), obese/aged, and obese/Zucker rats. A mechanism for inhibiting glycogen synthesis. Diabetes, 45(10):1396-404. 4.2.3

Banerjee, A., Barry, V. A., DasGupta, B. R., and Martin, T. F. (1996). $\mathrm{N}$-Ethylmaleimide-sensitive factor acts at a prefusion ATP-dependent step in Ca2+-activated exocytosis. J Biol Chem, 271(34):20223-6. 1.3.3 
Banting, F. G., Best, C. H., Collip, J. B., Campbell, W. R., and Fletcher, A. A. (1922). Pancreatic extracts in the treatment of diabetes mellitus: preliminary report. Cmaj, 12:141-146. 1

Barclay, J. W., Morgan, A., and Burgoyne, R. D. (2005). Calcium-dependent regulation of exocytosis. Cell Calcium, 38(3-4):343-53. 1.3.4, 1.3.4

Barg, S., Ma, X., Eliasson, L., Galvanovskis, J., Gopel, S. O., Obermuller, S., Platzer, J., Renstrom, E., Trus, M., Atlas, D., Striessnig, J., and Rorsman, P. (2001). Fast exocytosis with few $\mathrm{Ca}(2+)$ channels in insulin-secreting mouse pancreatic B cells. Biophys J, 81(6):3308-23. 1.3.3, 1.3.3, 1.3.5, 1.6, 2.2, 3.1.3, 3.2.2, 4.1.2, 4.2.3

Barg, S., Olofsson, C. S., Schriever-Abeln, J., Wendt, A., Gebre-Medhin, S., Renstrom, E., and Rorsman, P. (2002). Delay between fusion pore opening and peptide release from large dense-core vesicles in neuroendocrine cells. Neuron, 33(2):287-99. 1.3.3

Barry, P. (1994). JPCalc, a software package for calculating liquid junction potential corrections in patch-clamp, intracellular, epithelial and bilayer measurements and for correcting junction potential measurements. J Neurosci Methods, 51(1):107-16. 2.2

Bell, G. I. and Polonsky, K. S. (2001). Diabetes mellitus and genetically programmed defects in $\beta$-cell function. Nature, 414(6865):788-91. 1.5.1

Berglund, O. (1980). Different dynamics of insulin secretion in the perfused pancreas of mouse and rat. Acta Endocrinol (Copenh), 93(1):54-60. 1.5

Bergsten, P. (2000). Pathophysiology of impaired pulsatile insulin release. Diabetes Metab Res Rev, 16(3):179-91. 4.1.1

Bergstrom, R. W., Fujimoto, W. Y., Teller, D. C., and de Haen, C. (1989). Oscillatory insulin secretion in perifused isolated rat islets. Am J Physiol, 257(4 Pt 1):E479-85. 4.1 .1

Berthoud, H. R., Trimble, E. R., Siegel, E. G., Bereiter, D. A., and Jeanrenaud, B. (1980). Cephalic-phase insulin secretion in normal and pancreatic islet-transplanted rats. Am J Physiol, 238(4):E336-40. 1.2

Betz, A., Ashery, U., Rickmann, M., Augustin, I., Neher, E., Südhof, T. C., Rettig, J., and Brose, N. (1998). Munc13-1 is a presynaptic phorbol ester receptor that enhances neurotransmitter release. Neuron, 21(1):123-36. 4.2.3

Bhattacharjee, A., Whitehurst, R. M., J., Zhang, M., Wang, L., and Li, M. (1997). T-type calcium channels facilitate insulin secretion by enhancing general excitability in the insulin-secreting $\beta$-cell line, INS-1. Endocrinology, 138(9):3735-40. 4.2.1 
Bonner-Weir, S., Deery, D., Leahy, J. L., and Weir, G. C. (1989). Compensatory growth of pancreatic $\beta$-cells in adult rats after short-term glucose infusion. Diabetes, 38(1):49-53. 4.2.2

Bonner-Weir, S., Trent, D. F., and Weir, G. C. (1983). Partial pancreatectomy in the rat and subsequent defect in glucose-induced insulin release. J Clin Invest, 71(6):1544-53. 4.1.2

Braun, M., Wendt, A., Birnir, B., Broman, J., Eliasson, L., Galvanovskis, J., Gromada, J., Mulder, H., and Rorsman, P. (2004). Regulated exocytosis of GABA-containing synaptic-like microvesicles in pancreatic $\beta$-cells. J Gen Physiol, 123(3):191-204. 3.1.3, 4.1 .2

Brenner, S. (1974). The genetics of Caenorhabditis elegans. Genetics, 77(1):71-94. 1.3 .3

Brown, H., Larsson, O., Branstrom, R., Yang, S. N., Leibiger, B., Leibiger, I., Fried, G., Moede, T., Deeney, J. T., Brown, G. R., Jacobsson, G., Rhodes, C. J., Braun, J. E., Scheller, R. H., Corkey, B. E., Berggren, P. O., and Meister, B. (1998). Cysteine string protein (CSP) is an insulin secretory granule-associated protein regulating $\beta$-cell exocytosis. Embo J, 17(17):5048-58. 1.1

Brown, H., Meister, B., Deeney, J., Corkey, B. E., Yang, S. N., Larsson, O., Rhodes, C. J., Seino, S., Berggren, P. O., and Fried, G. (2000). Synaptotagmin III isoform is compartmentalized in pancreatic $\beta$-cells and has a functional role in exocytosis.

Diabetes, 49(3):383-91. 1.3.3, 1.1, 4.2.3

Brown, H., Sanger, F., and Kitai, R. (1955). The structure of pig and sheep insulins. Biochem J, 60(4):556-65. 1.3.3

Burgoyne, R. D. (1995). Fast exocytosis and endocytosis triggered by depolarisation in single adrenal chromaffin cells before rapid Ca2+ current run-down. Pflugers Arch, 430(2):213-9.3.1.3

Burgoyne, R. D. and Morgan, A. (2003). Secretory granule exocytosis. Physiol Rev, 83(2):581-632. 1.3.3, 1.3.4

Carpenter, L., Mitchell, C. J., Xu, Z. Z., Poronnik, P., Both, G. W., and Biden, T. J. (2004). PKC alpha is activated but not required during glucose-induced insulin secretion from rat pancreatic islets. Diabetes, 53(1):53-60. 1.3.4, 4.2.3 
Caumo, A. and Luzi, L. (2004). First-phase insulin secretion: does it exist in real life? Considerations on shape and function. Am J Physiol Endocrinol Metab, 287(3):E371-85. 1.2

Cerasi, E. (1995). Insulin deficiency and insulin resistance in the pathogenesis of NIDDM: is a divorce possible? Diabetologia, 38(8):992-7. 1.4.2

Cerasi, E., Fick, G., and Rudemo, M. (1974). A mathematical model for the glucose induced insulin release in man. Eur J Clin Invest, 4(4):267-78. 1.3.5

Chan, C. B., MacPhail, R. M., Sheu, L., Wheeler, M. B., and Gaisano, H. Y. (1999). $\beta$-cell hypertrophy in $\mathrm{fa} / \mathrm{fa}$ rats is associated with basal glucose hypersensitivity and reduced SNARE protein expression. Diabetes, 48(5):997-1005. 4.2.1, 4.2.2

Chan, C. B., Saleh, M. C., Purje, A., and MacPhail, R. M. (2002). Glucose-inducible hypertrophy and suppression of anion efflux in rat $\beta$ cells. J Endocrinol, $173(1): 45-52.4 .2 .2$

Chen, D. and Wang, M. W. (2005). Development and application of rodent models for type 2 diabetes. Diabetes Obes Metab, 7(4):307-17. 1.5.1, 4.1

Chiasson, J. L. and Rabasa-Lhoret, R. (2004). Prevention of type 2 diabetes: insulin resistance and $\beta$-cell function. Diabetes, 53 Suppl 3:S34-8. 1.4.2

Ciufo, L. F., Barclay, J. W., Burgoyne, R. D., and Morgan, A. (2005). Munc18-1 regulates early and late stages of exocytosis via syntaxin-independent protein interactions. Mol Biol Cell, 16(2):470-82. 1.3.3

Clark, A., Jones, L. C., de Koning, E., Hansen, B. C., and Matthews, D. R. (2001). Decreased insulin secretion in type 2 diabetes: a problem of cellular mass or function? Diabetes, 50 Suppl 1:S169-71. 4.1.2

Cunningham, B. A., Deeney, J. T., Bliss, C. R., Corkey, B. E., and Tornheim, K. (1996). Glucose-induced oscillatory insulin secretion in perifused rat pancreatic islets and clonal $\beta$-cells (HIT). Am J Physiol, 271(4 Pt 1):E702-10. 4.1.1

Curry, D. L., Bennett, L. L., and Grodsky, G. M. (1968). Dynamics of insulin secretion by the perfused rat pancreas. Endocrinology, 83(3):572-84. 1.3.5

da Silva Xavier, G., Leclerc, I., Varadi, A., Tsuboi, T., Moule, S. K., and Rutter, G. A. (2003). Role for AMP-activated protein kinase in glucose-stimulated insulin secretion and preproinsulin gene expression. Biochem J, 371(Pt 3):761-74. 4.2.3 
Dachicourt, N., Serradas, D., Bailbe, D., and Portha, B. (1997). Abnormal cAMP content and insulin release in islets of spontaneously diabetic GK rats (Abstract). Diabetologia, 40(A114). 4.1.2

Daniel, S., Noda, M., Straub, S. G., and Sharp, G. W. (1999). Identification of the docked granule pool responsible for the first phase of glucose-stimulated insulin secretion. Diabetes, 48(9):1686-90. 1.3.5

Davies, S. P., Reddy, H., Caivano, M., and Cohen, P. (2000). Specificity and mechanism of action of some commonly used protein kinase inhibitors. Biochem $J$, 351(Pt 1):95-105. 4.2.3

Dean, P. M. and Matthews, E. K. (1968). Electrical activity in pancreatic islet cells. Nature, 219(5152):389-90. 1.3.1, 3.1.2

DeFronzo, R. A., Tobin, J. D., and Andres, R. (1979). Glucose clamp technique: a method for quantifying insulin secretion and resistance. Am J Physiol, 237(3):E214-23. 1.6

Dinkelacker, V., Voets, T., Neher, E., and Moser, T. (2000). The readily releasable pool of vesicles in chromaffin cells is replenished in a temperature-dependent manner and transiently overfills at 37 degrees C. J Neurosci, 20(22):8377-83. 2.5, 3.2.2

Elahi, D. (1996). In praise of the hyperglycemic clamp. A method for assessment of $\beta$-cell sensitivity and insulin resistance. Diabetes Care, 19(3):278-86. 1.5, 4.1

Eliasson, L., Ma, X., Renstrom, E., Barg, S., Berggren, P. O., Galvanovskis, J., Gromada, J., Jing, X., Lundquist, I., Salehi, A., Sewing, S., and Rorsman, P. (2003). SUR1 regulates PKA-independent cAMP-induced granule priming in mouse pancreatic B-cells. J Gen Physiol, 121(3):181-97. 1.3.4, 4.2.3

Engisch, K. L. and Nowycky, M. C. (1996). Calcium dependence of large dense-cored vesicle exocytosis evoked by calcium influx in bovine adrenal chromaffin cells. $J$ Neurosci, 16(4):1359-69. 3.1.3, 4.1.2

Fernandez-Chacon, R., Konigstorfer, A., Gerber, S. H., Garcia, J., Matos, M. F., Stevens, C. F., Brose, N., Rizo, J., Rosenmund, C., and Sudhof, T. C. (2001). Synaptotagmin I functions as a calcium regulator of release probability. Nature, 410(6824):41-9. 1.3.3

Filipsson, K., Kvist-Reimer, M., and Ahren, B. (2001). The neuropeptide pituitary adenylate cyclase-activating polypeptide and islet function. Diabetes, 50(9):1959-69. 1.3 .4 
Fisher, R. J., Pevsner, J., and Burgoyne, R. D. (2001). Control of fusion pore dynamics during exocytosis by Munc18. Science, 291(5505):875-8. 1.3.3

Franklin, I., Gromada, J., Gjinovci, A., Theander, S., and Wollheim, C. B. (2005). $\beta$-cell secretory products activate alpha-cell ATP-dependent potassium channels to inhibit glucagon release. Diabetes, 54(6):1808-15. 1.2

Gaisano, H. Y., Ostenson, C. G., Sheu, L., Wheeler, M. B., and Efendic, S. (2002). Abnormal expression of pancreatic islet exocytotic soluble $\mathrm{N}$-ethylmaleimide-sensitive factor attachment protein receptors in Goto-Kakizaki rats is partially restored by phlorizin treatment and accentuated by high glucose treatment. Endocrinology, 143(11):4218-26. 1.1, 4.2.1, 4.2.3

Galli, J., Fakhrai-Rad, H., Kamel, A., Marcus, C., Norgren, S., and Luthman, H. (1999). Pathophysiological and genetic characterization of the major diabetes locus in GK rats. Diabetes, 48(12):2463-70. 1.5.1

Gao, Z., Reavey-Cantwell, J., Young, R. A., Jegier, P., and Wolf, B. A. (2000). Synaptotagmin III/VII isoforms mediate Ca2+-induced insulin secretion in pancreatic islet $\beta$-cells. J Biol Chem, 275(46):36079-85. 1.3.3, 1.1

Gauguier, D., Froguel, P., Parent, V., Bernard, C., Bihoreau, M. T., Portha, B., James, M. R., Penicaud, L., Lathrop, M., and Ktorza, A. (1996). Chromosomal mapping of genetic loci associated with non-insulin dependent diabetes in the GK rat. Nat Genet, 12(1):38-43. 1.5.1

Gazdar, A. F., Chick, W. L., Oie, H. K., Sims, H. L., King, D. L., Weir, G. C., and Lauris, V. (1980). Continuous, clonal, insulin- and somatostatin-secreting cell lines established from a transplantable rat islet cell tumor. Proc Natl Acad Sci US A, 77(6):3519-23. 1.6

Gembal, M., Gilon, P., and Henquin, J. C. (1992). Evidence that glucose can control insulin release independently from its action on ATP-sensitive $\mathrm{K}+$ channels in mouse B cells. J Clin Invest, 89(4):1288-95. 1.3.2

Gerich, J. E. (1998). The genetic basis of type 2 diabetes mellitus: impaired insulin secretion versus impaired insulin sensitivity. Endocr Rev, 19(4):491-503. 1.4 .2

Gerich, J. E. (2000). Insulin resistance is not necessarily an essential component of type 2 diabetes. J Clin Endocrinol Metab, 85(6):2113-5. 1.4 .2 
Gerich, J. E. (2002). Is reduced first-phase insulin release the earliest detectable abnormality in individuals destined to develop type 2 diabetes? Diabetes, 51,Suppl $1:$ S117-21. 1.3.5, 1.4.2

Gerich, J. E., Charles, M. A., and Grodsky, G. M. (1974). Characterization of the effects of arginine and glucose on glucagon and insulin release from the perfused rat pancreas. J Clin Invest, 54(4):833-41. 1.5, 4.1

Gillis, K. D. (1995). Techniques for membrane capacitance measurements. In Sakmann, B. and Neher, E., editors, Single Channel Recording, pages 155-198. Plenum Press, New York. 2.5

Gillis, K. D., Gee, W. M., Hammoud, A., McDaniel, M. L., Falke, L. C., and Misler, S. (1989). Effects of sulfonamides on a metabolite-regulated ATPi-sensitive $\mathrm{K}+$ channel in rat pancreatic B-cells. Am J Physiol, 257(6 Pt 1):C1119-27. 3.1.2

Gillis, K. D. and Misler, S. (1992). Single cell assay of exocytosis from pancreatic islet B cells. Pflugers Arch, 420(1):121-3. 1.6, 3.1.3

Gillis, K. D., Mossner, R., and Neher, E. (1996). Protein kinase C enhances exocytosis from chromaffin cells by increasing the size of the readily releasable pool of secretory granules. Neuron, 16(6):1209-20. 3.2.2, 3.2.2, 4.2.3

Giordano, E., Cirulli, V., Bosco, D., Rouiller, D., Halban, P., and Meda, P. (1993). B-cell size influences glucose-stimulated insulin secretion. Am J Physiol, 265(2 Pt 1):C358-64. 3.2.2, 4.2.2

Giroix, M. H., Portha, B., Kergoat, M., Bailbe, D., and Picon, L. (1983). Glucose insensitivity and amino-acid hypersensitivity of insulin release in rats with non-insulin-dependent diabetes. A study with the perfused pancreas. Diabetes, $32(5): 445-51 \cdot 3.2 .2$

Gong, L. W., Di Paolo, G., Diaz, E., Cestra, G., Diaz, M. E., Lindau, M., De Camilli, P., and Toomre, D. (2005). Phosphatidylinositol phosphate kinase type I gamma regulates dynamics of large dense-core vesicle fusion. Proc Natl Acad Sci US A, 102(14):5204-9. 1.3 .3

Göpel, S., Kanno, T., Barg, S., Galvanovskis, J., and Rorsman, P. (1999). Voltage-gated and resting membrane currents recorded from $\beta$-cells in intact mouse pancreatic islets. J Physiol, 521 Pt 3:717-28. 1.6, 2.5, 3.1.2, 3.1.2, 3.1.2, 3.1.2, 3.1.3, 4.2.1 
Göpel, S., Zhang, Q., Eliasson, L., Ma, X. S., Galvanovskis, J., Kanno, T., Salehi, A., and Rorsman, P. (2004). Capacitance measurements of exocytosis in mouse pancreatic $\alpha$-, $\beta$ - and $\delta$-cells within intact islets of Langerhans. J Physiol, $556(\mathrm{Pt}$ 3):711-26. 1.6, 4.1.2

Göpel, S. O., Kanno, T., Barg, S., and Rorsman, P. (2000). Patch-clamp characterisation of somatostatin-secreting $\delta$-cells in intact mouse pancreatic islets. $J$ Physiol, 528(Pt 3):497-507. 1.3.1, 4.2.1

Goto, Y., Kakizaki, M., and Masaki, N. (1976). Production of spontaneous diabetic rats by repetition of selective breeding. Tohoku J Exp Med, 119(1):85-90. 1.5.1, 2.1

Goto, Y., Suzuki, K., Ono, T., Sasaki, M., and Toyota, T. (1988). Development of diabetes in the non-obese NIDDM rat (GK rat). Adv Exp Med Biol, 246:29-31. 3.2 .1

Grishanin, R. N., Kowalchyk, J. A., Klenchin, V. A., Ann, K., Earles, C. A., Chapman, E. R., Gerona, R. R., and Martin, T. F. (2004). CAPS acts at a prefusion step in dense-core vesicle exocytosis as a PIP2 binding protein. Neuron, 43(4):551-62. 1.3.3

Grodsky, G. M. (1972). A threshold distribution hypothesis for packet storage of insulin and its mathematical modeling. J Clin Invest, 51(8):2047-59. 1.3.5

Grodsky, G. M., Batts, A. A., Bennett, L. L., Vcella, C., McWilliams, N. B., and Smith, D. F. (1963). Effects of Carbohydrates on Secretion of Insulin from Isolated Rat Pancreas. Am J Physiol, 205:638-44. 1.6

Grodsky, G. M., Bennett, L. L., Smith, D. F., and Schmid, F. G. (1967). Effect of pulse administration of glucose or glucagon on insulin secretion in vitro. Metabolism, 16(3):222-33. 1.3 .5

Gromada, J., Hoy, M., Renstrom, E., Bokvist, K., Eliasson, L., Gopel, S., and Rorsman, P. (1999). CaM kinase II-dependent mobilization of secretory granules underlies acetylcholine-induced stimulation of exocytosis in mouse pancreatic B-cells. J Physiol, 518 ( Pt 3):745-59. 3.2.2

Grynkiewicz, G., Poenie, M., and Tsien, R. Y. (1985). A new generation of Ca2+ indicators with greatly improved fluorescence properties. J Biol Chem, 260(6):3440-50. 2.4.2

Guenif, A., Abdel-Halim, S. M., Hoog, A., Falkmer, S., and Ostenson, C. G. (1995). Preserved $\beta$-cell density in the endocrine pancreas of young, spontaneously diabetic Goto-Kakizaki (GK) rats. Pancreas, 10(2):148-53. 3.2.1, 4.2.3 
Gut, A., Kiraly, C. E., Fukuda, M., Mikoshiba, K., Wollheim, C. B., and Lang, J. (2001). Expression and localisation of synaptotagmin isoforms in endocrine $\beta$-cells: their function in insulin exocytosis. J Cell Sci, 114(Pt 9):1709-16. 1.3.3

Hales, C. N. and Randle, P. J. (1963). Immunoassay of insulin with insulin-antibody precipitate. Biochem J, 88:137-46. 1.6

Hay, J. C. and Martin, T. F. (1992). Resolution of regulated secretion into sequential MgATP-dependent and calcium-dependent stages mediated by distinct cytosolic proteins. J Cell Biol, 119(1):139-51. 1.3.3

Hayek, A. and Woodside, W. (1979). Correlation between morphology and function in isolated islets of the Zucker rat. Diabetes, 28(6):565-9. 4.2.2

Heidelberger, R., Heinemann, C., Neher, E., and Matthews, G. (1994). Calcium dependence of the rate of exocytosis in a synaptic terminal. Nature, 371(6497):513-5. 1.3.3

Heinemann, C., von Ruden, L., Chow, R. H., and Neher, E. (1993). A two-step model of secretion control in neuroendocrine cells. Pflugers Arch, 424(2):105-12. 1.3.3

Hellman, B., Gylfe, E., Grapengiesser, E., Lund, P. E., and Berts, A. (1992). Cytoplasmic $\mathrm{Ca}^{2+}$ oscillations in pancreatic $\beta$-cells. Biochim Biophys Acta, 1113(3-4):295-305. 1.3.5

Henquin, J. C. (1978). D-glucose inhibits potassium efflux from pancreatic islet cells. Nature, 271(5642):271-3. 4.1.1

Henquin, J. C. and Meissner, H. P. (1984). Significance of ionic fluxes and changes in membrane potential for stimulus-secretion coupling in pancreatic B-cells. Experientia, 40(10):1043-1052. 1.3.1, 4.1.1

Herman, W. H. and Engelgau, M. M. (2001). Postprandial Hyperglycemia: Actor or Understudy? Clin Diabetes, 19(3):126-. 1.1

Heuser, J. E. and Reese, T. S. (1973). Evidence for recycling of synaptic vesicle membrane during transmitter release at the frog neuromuscular junction. $J$ Cell Biol, 57(2):315-44. 1.3.3

Hiriart, M. and Matteson, D. R. (1988). Na channels and two types of Ca channels in rat pancreatic B cells identified with the reverse hemolytic plaque assay. J Gen Physiol, 91(5):617-39. 1.6, 3.1.2, 4.1.2 
Höög, A., Hu, W., Abdel-Halim, S. M., Falkmer, S., Qing, L., and Grimelius, L. (1997). Ultrastructural localization of insulin-like growth factor-2 (IGF-2) to the secretory granules of insulin cells: a study in normal and diabetic $(\mathrm{GK})$ rats. Ultrastruct Pathol, 21(5):457-66. 4.1.2, 4.2.3

Hori, T., Takai, Y., and Takahashi, T. (1999). Presynaptic mechanism for phorbol ester-induced synaptic potentiation. J Neurosci, 19(17):7262-7. 4.2.3

Horikawa, Y., Oda, N., Cox, N. J., Li, X., Orho-Melander, M., Hara, M., Hinokio, Y., Lindner, T. H., Mashima, H., Schwarz, P. E., del Bosque-Plata, L., Oda, Y., Yoshiuchi, I., Colilla, S., Polonsky, K. S., Wei, S., Concannon, P., Iwasaki, N., Schulze, J., Baier, L. J., Bogardus, C., Groop, L., Boerwinkle, E., Hanis, C. L., and Bell, G. I. (2000). Genetic variation in the gene encoding calpain-10 is associated with type 2 diabetes mellitus. Nat Genet, 26(2):163-75. 1.4.2

Horrigan, F. T. and Bookman, R. J. (1994). Releasable pools and the kinetics of exocytosis in adrenal chromaffin cells. Neuron, 13(5):1119-29. 1.3.3, 2.5, 3.2.2

Hsu, W. H., Xiang, H. D., Rajan, A. S., Kunze, D. L., and Boyd, A. E., r. (1991). Somatostatin inhibits insulin secretion by a G-protein-mediated decrease in $\mathrm{Ca} 2+$ entry through voltage-dependent $\mathrm{Ca} 2+$ channels in the $\beta$ cell. J Biol Chem, 266(2):837-43. 4.2.3

Hughes, H. (1956). An experimental study of regeneration in the islets of Langerhans with reference to the theory of balance. Acta Anat (Basel), 27(1-2):1-61. 4.1

Hughes, S. J., Faehling, M., Thorneley, C. W., Proks, P., Ashcroft, F. M., and Smith, P. A. (1998). Electrophysiological and metabolic characterization of single $\beta$-cells and islets from diabetic GK rats. Diabetes, 47(1):73-81. 1.5.1, 3.2.1, 4.1, 4.1.2, 4.2.2, 4.2 .3

Idris, I., Gray, S., and Donnelly, R. (2001). Protein kinase C activation: isozyme-specific effects on metabolism and cardiovascular complications in diabetes. Diabetologia, 44(6):659-73. 4.2.3

Iezzi, M., Kouri, G., Fukuda, M., and Wollheim, C. B. (2004). Synaptotagmin V and IX isoforms control Ca2+-dependent insulin exocytosis. J Cell Sci, 117(Pt 15):3119-27. 1.3.3, 1.1

Inagaki, N., Gonoi, T., Clement, J. P. t., Namba, N., Inazawa, J., Gonzalez, G., Aguilar-Bryan, L., Seino, S., and Bryan, J. (1995). Reconstitution of IKATP: an inward rectifier subunit plus the sulfonylurea receptor. Science, 270(5239):1166-70. 1.3.1 
Inoguchi, T., Battan, R., Handler, E., Sportsman, J. R., Heath, W., and King, G. L. (1992). Preferential elevation of protein kinase $C$ isoform $\beta$ II and diacylglycerol levels in the aorta and heart of diabetic rats: differential reversibility to glycemic control by islet cell transplantation. Proc Natl Acad Sci U S A, 89(22):11059-63. 4.2 .3

Ishihara, H., Maechler, P., Gjinovci, A., Herrera, P. L., and Wollheim, C. B. (2003). Islet $\beta$-cell secretion determines glucagon release from neighbouring alpha-cells. $N a t$ Cell Biol, 5(4):330-5. 1.2

Ishikawa, E. (1973). Enzyme immunoassay of insulin by fluorimetry of the insulin-glucoamylase complex. J Biochem (Tokyo), 73(6):1319-21. 1.6

Ishikawa, T., Iwasaki, E., Kanatani, K., Sugino, F., Kaneko, Y., Obara, K., and Nakayama, K. (2005). Involvement of novel protein kinase C isoforms in carbachol-stimulated insulin secretion from rat pancreatic islets. Life Sci, 77(4):462-9. 1.3.4

Jacobsson, G., Bean, A. J., Scheller, R. H., Juntti-Berggren, L., Deeney, J. T., Berggren, P. O., and Meister, B. (1994). Identification of synaptic proteins and their isoform mRNAs in compartments of pancreatic endocrine cells. Proc Natl Acad Sci US A, 91(26):12487-91. 1.1

Jahn, R., Lang, T., and Sudhof, T. C. (2003). Membrane fusion. Cell, 112(4):519-33. $1.3 .3,1.3 .3,1.3 .3$

Jahn, R. and Südhof, T. C. (1994). Synaptic vesicles and exocytosis. Annu Rev Neurosci, 17:219-46. 1.3.3

Jansson, L. (1994). The regulation of pancreatic islet blood flow. Diabetes Metab Rev, 10(4):407-16. 1.2

Jansson, L. and Hellerstrom, C. (1983). Stimulation by glucose of the blood flow to the pancreatic islets of the rat. Diabetologia, 25(1):45-50. 1.2

Jansson, L. and Hellerstrom, C. (1986). Glucose-induced changes in pancreatic islet blood flow mediated by central nervous system. Am J Physiol, 251(6 Pt 1):E644-7. 1.2

Jones, P. M., Fyles, J. M., and Howell, S. L. (1986). Regulation of insulin secretion by cAMP in rat islets of Langerhans permeabilised by high-voltage discharge. FEBS Lett, 205(2):205-9. 3.1.3 
Jones, P. M. and Persaud, S. J. (1998). Protein kinases, protein phosphorylation, and the regulation of insulin secretion from pancreatic $\beta$-cells. Endocr Rev, 19(4):429-61. $1.3 .4,1.3 .4$

Kahn, S. E. (2001). Clinical review 135: The importance of $\beta$-cell failure in the development and progression of type 2 diabetes. J Clin Endocrinol Metab, 86(9):4047-58. 1.4.2

Kanno, T., Ma, X., Barg, S., Eliasson, L., Galvanovskis, J., Göpel, S., Larsson, M., Renstrom, E., and Rorsman, P. (2004). Large dense-core vesicle exocytosis in pancreatic $\beta$-cells monitored by capacitance measurements. Methods, 33(4):302-11. $2.5,4.1 .2,4.2 .3$

Kasai, K., Ohara-Imaizumi, M., Takahashi, N., Mizutani, S., Zhao, S., Kikuta, T., Kasai, H., Nagamatsu, S., Gomi, H., and Izumi, T. (2005). Rab27a mediates the tight docking of insulin granules onto the plasma membrane during glucose stimulation. J Clin Invest, 115(2):388-96. 4.2.3

Kashima, Y., Miki, T., Shibasaki, T., Ozaki, N., Miyazaki, M., Yano, H., and Seino, S. (2001). Critical role of cAMP-GEFII-Rim2 complex in incretin-potentiated insulin secretion. J Biol Chem, 276(49):46046-53. 1.3.4

Katayama, N., Hughes, S. J., Persaud, S. J., Jones, P. M., and Howell, S. L. (1995). Insulin secretion from islets of GK rats is not impaired after energy generating steps. Mol Cell Endocrinol, 111(2):125-8. 4.2.3

Kato, S., Ishida, H., Tsuura, Y., Tsuji, K., Nishimura, M., Horie, M., Taminato, T., Ikehara, S., Odaka, H., Ikeda, I., Okada, Y., and Seino, Y. (1996). Alterations in basal and glucose-stimulated voltage-dependent $\mathrm{Ca} 2+$ channel activities in pancreatic $\beta$ cells of non-insulin-dependent diabetes mellitus GK rats. J Clin Invest, 97(11):2417-25. 3.2.1, 4.1, 4.2.1, 4.2.2, 4.2.3

Kee, Y., Yoo, J. S., Hazuka, C. D., Peterson, K. E., Hsu, S. C., and Scheller, R. H. (1997). Subunit structure of the mammalian exocyst complex. Proc Natl Acad Sci U $S$ A, 94(26):14438-43. 1.3.3

Kinasiewicz, A., Juszczak, M., Pachecka, J., and Fiedor, P. (2004). Pancreatic islets isolation using different protocols with in situ flushing and intraductal collagenase injection. Physiol Res, 53(3):327-33. 4.1

Kiraly-Borri, C. E., Morgan, A., Burgoyne, R. D., Weller, U., Wollheim, C. B., and Lang, J. (1996). Soluble N-ethylmaleimide-sensitive-factor attachment protein and 
$\mathrm{N}$-ethylmaleimide-insensitive factors are required for $\mathrm{Ca} 2+$-stimulated exocytosis of insulin. Biochem J, 314 ( Pt 1):199-203. 1.1

Kits, K. S. and Mansvelder, H. D. (2000). Regulation of exocytosis in neuroendocrine cells: spatial organization of channels and vesicles, stimulus-secretion coupling, calcium buffers and modulation. Brain Res Brain Res Rev, 33(1):78-94. 4.1.2

Klenchin, V. A. and Martin, T. F. (2000). Priming in exocytosis: attaining fusion-competence after vesicle docking. Biochimie, 82(5):399-407. 1.3.3

Knutson, K. L. and Hoenig, M. (1994). Identification and subcellular characterization of protein kinase-C isoforms in insulinoma $\beta$-cells and whole islets. Endocrinology, 135(3):881-6. 1.3.4

Kocmur, L. and Zorec, R. (1993). A new approach to separation of voltage-activated Ca currents in rat melanotrophs. Pflugers Arch, 425(1-2):172-4. 3.2.1

Komatsu, M., Schermerhorn, T., Aizawa, T., and Sharp, G. W. (1995). Glucose stimulation of insulin release in the absence of extracellular $\mathrm{Ca} 2+$ and in the absence of any increase in intracellular Ca2+ in rat pancreatic islets. Proc Natl Acad Sci US A, 92(23):10728-32. 1.3.4

Kruszynska, Y. T. (1997). Normal Metabolism: The Physiology of Fuel Homeostasis. In Pickup, J. and Williams, G., editors, Textbook of Diabetes. Oxford, UK. 1.3.1

Lacy, P. E. and Kostianovsky, M. (1967). Method for the isolation of intact islets of Langerhans from the rat pancreas. Diabetes, 16(1):35-9. 1.6, 4.1

Lang, J. (1999). Molecular mechanisms and regulation of insulin exocytosis as a paradigm of endocrine secretion. Eur J Biochem, 259(1-2):3-17. 1.3.3

Lang, J., Fukuda, M., Zhang, H., Mikoshiba, K., and Wollheim, C. B. (1997). The first C2 domain of synaptotagmin is required for exocytosis of insulin from pancreatic $\beta$-cells: action of synaptotagmin at low micromolar calcium. Embo J, 16(19):5837-46. 1.3.3, 1.1

Leahy, J. L., Bonner-Weir, S., and Weir, G. C. (1992). $\beta$-cell dysfunction induced by chronic hyperglycemia. Current ideas on mechanism of impaired glucose-induced insulin secretion. Diabetes Care, 15(3):442-55. 3.2.2

Lenzen, S. (1979). Insulin secretion by isolated perfused rat and mouse pancreas. Am J Physiol, 236(4):E391-400. 1.5, 4.1 
Lernmark, A. (1974). The preparation of, and studies on, free cell suspensions from mouse pancreatic islets. Diabetologia, 10(5):431-8. 1.6, 4.1

Leroith, D. and Gavrilova, O. (2005). Mouse models created to study the pathophysiology of Type 2 diabetes. Int J Biochem Cell Biol. 1.5.1

Leung, Y. M., Ahmed, I., Sheu, L., Tsushima, R. G., Diamant, N. E., Hara, M., and Gaisano, H. Y. (2005). Electrophysiological Characterization of Pancreatic Islet Cells in the MIP-GFP Mouse. Endocrinology. 3.2.2

Li, G., Rungger-Brandle, E., Just, I., Jonas, J. C., Aktories, K., and Wollheim, C. B. (1994). Effect of disruption of actin filaments by Clostridium botulinum C2 toxin on insulin secretion in HIT-T15 cells and pancreatic islets. Mol Biol Cell, 5(11):1199-213. 1.3.3

Lifson, N., Lassa, C. V., and Dixit, P. K. (1985). Relation between blood flow and morphology in islet organ of rat pancreas. Am J Physiol, 249(1 Pt 1):E43-8. 1.2, 4.1

Ling, Z. C., Efendic, S., Wibom, R., Abdel-Halim, S. M., Ostenson, C. G., Landau, B. R., and Khan, A. (1998). Glucose metabolism in Goto-Kakizaki rat islets. Endocrinology, 139(6):2670-5. 1.5.1

Littleton, J. T., Barnard, R. J., Titus, S. A., Slind, J., Chapman, E. R., and Ganetzky, B. (2001). SNARE-complex disassembly by NSF follows synaptic-vesicle fusion. Proc Natl Acad Sci U S A, 98(21):12233-8. 1.3.3

Liu, J. and Misler, S. (1998). alpha-Latrotoxin alters spontaneous and depolarization-evoked quantal release from rat adrenal chromaffin cells: evidence for multiple modes of action. J Neurosci, 18(16):6113-25. 3.2.1

Longo, E. A., Tornheim, K., Deeney, J. T., Varnum, B. A., Tillotson, D., Prentki, M., and Corkey, B. E. (1991). Oscillations in cytosolic free Ca2+, oxygen consumption, and insulin secretion in glucose-stimulated rat pancreatic islets. J Biol Chem, 266(14):9314-9. 4.1.1

Lou, X. L., Yu, X., Chen, X. K., Duan, K. L., He, L. M., Qu, A. L., Xu, T., and Zhou, Z. (2003). Na+ channel inactivation: a comparative study between pancreatic islet $\beta$-cells and adrenal chromaffin cells in rat. J Physiol, 548(Pt 1):191-202. 2.5, 3.1.2, $3.2 .1,3.2 .1$

Loyet, K. M., Kowalchyk, J. A., Chaudhary, A., Chen, J., Prestwich, G. D., and Martin, T. F. (1998). Specific binding of phosphatidylinositol 4,5-bisphosphate to 
calcium-dependent activator protein for secretion (CAPS), a potential phosphoinositide effector protein for regulated exocytosis. $J$ Biol Chem, 273(14):8337-43. 1.3.3

Ma, H., Fukiage, C., Kim, Y. H., Duncan, M. K., Reed, N. A., Shih, M., Azuma, M., and Shearer, T. R. (2001). Characterization and expression of calpain 10. A novel ubiquitous calpain with nuclear localization. J Biol Chem, 276(30):28525-31. 1.4.2

Ma, X., Zhang, Y., Gromada, J., Sewing, S., Berggren, P. O., Buschard, K., Salehi, A., Vikman, J., Rorsman, P., and Eliasson, L. (2005). Glucagon stimulates exocytosis in mouse and rat pancreatic alpha-cells by binding to glucagon receptors. $\mathrm{Mol}$

Endocrinol, 19(1):198-212. 1.2

Ma, Y. H., Wang, J., Rodd, G. G., Bolaffi, J. L., and Grodsky, G. M. (1995).

Differences in insulin secretion between the rat and mouse: role of cAMP. EurJ Endocrinol, 132(3):370-6. 1.5

MacDonald, P. E., Obermuller, S., Vikman, J., Galvanovskis, J., Rorsman, P., and Eliasson, L. (2005). Regulated exocytosis and kiss-and-run of synaptic-like microvesicles in INS-1 and primary rat $\beta$-cells. Diabetes, 54(3):736-43. 1.6, 2.5, $3.1 .3,3.2 .1,4.1 .2$

Magistretti, P., Pellerin, L., and Martin, J. (1995). Brain energy metabolism. An integrated cellular perspective. In Bloom, F. and Kupfer, D., editors, Psychopharmacology: The Fourth Generation of Progress., pages 657-670. Raven, New York. 1.1

Mansvelder, H. D. and Kits, K. S. (1998). The relation of exocytosis and rapid endocytosis to calcium entry evoked by short repetitive depolarizing pulses in rat melanotropic cells. J Neurosci, 18(1):81-92. 4.1.2

Marie, J. C., Bailbe, D., Gylfe, E., and Portha, B. (2001). Defective glucose-dependent cytosolic $\mathrm{Ca} 2+$ handling in islets of GK and $\mathrm{nSTZ}$ rat models of type 2 diabetes. $J$ Endocrinol, 169(1):169-76. 3.2.1, 4.1, 4.2.3

Marshall, C., Hitman, G. A., Partridge, C. J., Clark, A., Ma, H., Shearer, T. R., and Turner, M. D. (2005). Evidence that an isoform of calpain-10 is a regulator of exocytosis in pancreatic $\beta$-cells. Mol Endocrinol, 19(1):213-24. 1.4.2

Martin, F., Reig, J. A., and Soria, B. (1995). Secretagogue-induced [Ca2+]i changes in single rat pancreatic islets and correlation with simultaneously measured insulin release. J Mol Endocrinol, 15(2):177-85. 3.2.1, 4.1.1 
Martin, T. F. (1997). Phosphoinositides as spatial regulators of membrane traffic. Curr Opin Neurobiol, 7(3):331-8. 1.3.3, 1.3.3

Matos, M. F., Mukherjee, K., Chen, X., Rizo, J., and Sudhof, T. C. (2003). Evidence for SNARE zippering during Ca2+-triggered exocytosis in PC12 cells. Neuropharmacology, 45(6):777-86. 1.3.3

Mears, D., Sheppard, N. F., J., Atwater, I., and Rojas, E. (1995). Magnitude and modulation of pancreatic $\beta$-cell gap junction electrical conductance in situ. J Membr Biol, 146(2):163-76. 3.1.2

Meissner, H. P. (1976). Electrophysiological evidence for coupling between $\beta$ cells of pancreatic islets. Nature, 262(5568):502-4. 1.2

Mendez, C. F., Leibiger, I. B., Leibiger, B., Hoy, M., Gromada, J., Berggren, P. O., and Bertorello, A. M. (2003). Rapid association of protein kinase C-epsilon with insulin granules is essential for insulin exocytosis. J Biol Chem, 278(45):44753-7. 1.3.4

Meneghel-Rozzo, T., Rozzo, A., Poppi, L., and Rupnik, M. (2004). In vivo and in vitro development of mouse pancreatic $\beta$-cells in organotypic slices. Cell Tissue Res, 316(3):295-303. 1.6, 2.5

Metz, S. A., Meredith, M., Vadakekalam, J., Rabaglia, M. E., and Kowluru, A. (1999). A defect late in stimulus-secretion coupling impairs insulin secretion in Goto-Kakizaki diabetic rats. Diabetes, 48(9):1754-62. 1.5.1, 4.2.3

Michael, D. J., Geng, X., Cawley, N. X., Loh, Y. P., Rhodes, C. J., Drain, P., and Chow, R. H. (2004). Fluorescent cargo proteins in pancreatic $\beta$-cells: design determines secretion kinetics at exocytosis. Biophys J, 87(6):L03-5. 4.2 .3

Milosevic, I., Sorensen, J. B., Lang, T., Krauss, M., Nagy, G., Haucke, V., Jahn, R., and Neher, E. (2005). Plasmalemmal phosphatidylinositol-4,5-bisphosphate level regulates the releasable vesicle pool size in chromaffin cells. J Neurosci, 25(10):2557-65. 1.3.3, 1.3.3

Mirnics, K., Middleton, F. A., Marquez, A., Lewis, D. A., and Levitt, P. (2000). Molecular characterization of schizophrenia viewed by microarray analysis of gene expression in prefrontal cortex. Neuron, 28(1):53-67. 1.4.2

Misler, S., Barnett, D. W., Pressel, D. M., Gillis, K. D., Scharp, D. W., and Falke, L. C. (1992). Stimulus-secretion coupling in $\beta$-cells of transplantable human islets of Langerhans. Evidence for a critical role for Ca2+ entry. Diabetes, 41(6):662-70. 1.5, 4.1 
Miura, Y., Henquin, J. C., and Gilon, P. (1997). Emptying of intracellular Ca2+ stores stimulates $\mathrm{Ca} 2+$ entry in mouse pancreatic $\beta$-cells by both direct and indirect mechanisms. J Physiol, 503 ( Pt 2):387-98. 4.2.3

Miyaki, T., Nakama, K., Akimoto, T., Kitoh, J., and Ito, H. (1994). Gross morphology of the pancreas and distribution of pancreatic ducts in the rat. Jikken Dobutsu, 43(2):257-60. 1.2, 3.1.1

Moens, K., Berger, V., Ahn, J. M., Van Schravendijk, C., Hruby, V. J., Pipeleers, D., and Schuit, F. (2002). Assessment of the role of interstitial glucagon in the acute glucose secretory responsiveness of in situ pancreatic $\beta$-cells. Diabetes, 51(3):669-75. 1.2

Moser, T. and Neher, E. (1997). Rapid exocytosis in single chromaffin cells recorded from mouse adrenal slices. J Neurosci, 17(7):2314-23. 1.5.1, 3.2.2

Movassat, J., Saulnier, C., and Portha, B. (1995). $\beta$-cell mass depletion precedes the onset of hyperglycaemia in the GK rat, a genetic model of non-insulin-dependent diabetes mellitus. Diabete Metab, 21(5):365-70. 4.2.3

Nadal, A., Quesada, I., and Soria, B. (1999). Homologous and heterologous asynchronicity between identified alpha-, beta- and delta-cells within intact islets of Langerhans in the mouse. J Physiol, 517 ( Pt 1):85-93. 4.2.1

Nagamatsu, S., Nakamichi, Y., Yamamura, C., Matsushima, S., Watanabe, T., Ozawa, S., Furukawa, H., and Ishida, H. (1999a). Decreased expression of t-SNARE, syntaxin 1 , and SNAP-25 in pancreatic $\beta$-cells is involved in impaired insulin secretion from diabetic GK rat islets: restoration of decreased t-SNARE proteins improves impaired insulin secretion. Diabetes, 48(12):2367-73. 1.5.1, 1.1, 4.2.1

Nagamatsu, S., Watanabe, T., Nakamichi, Y., Yamamura, C., Tsuzuki, K., and Matsushima, S. (1999b). alpha-soluble N-ethylmaleimide-sensitive factor attachment protein is expressed in pancreatic $\beta$ cells and functions in insulin but not gamma-aminobutyric acid secretion. J Biol Chem, 274(12):8053-60. 1.1

Neher, E. (1998). Vesicle pools and Ca2+ microdomains: new tools for understanding their roles in neurotransmitter release. Neuron, 20(3):389-99. 3.2.2

Neher, E. and Marty, A. (1982). Discrete changes of cell membrane capacitance observed under conditions of enhanced secretion in bovine adrenal chromaffin cells. Proc Natl Acad Sci U S A, 79(21):6712-6. 1.6, 2.5 
Nesher, R. and Cerasi, E. (2002). Modeling phasic insulin release: immediate and time-dependent effects of glucose. Diabetes, 51 Suppl 1:S53-9. 1.3.5

Nobel-Foundation (1965). Nobel lectures including presentation speeches and laureates' biographies / publ. for the Nobel Foundation; 1922 - 1941. Elsevier, Amsterdam. 1

Novick, P. and Guo, W. (2002). Ras family therapy: Rab, Rho and Ral talk to the exocyst. Trends Cell Biol, 12(6):247-9. 1.3.3

Novick, P. and Schekman, R. (1979). Secretion and cell-surface growth are blocked in a temperature-sensitive mutant of Saccharomyces cerevisiae. Proc Natl Acad Sci U S A, 76(4):1858-62. 1.3.3

Ohara-Imaizumi, M., Nishiwaki, C., Kikuta, T., Nagai, S., Nakamichi, Y., and Nagamatsu, S. (2004a). TIRF imaging of docking and fusion of single insulin granule motion in primary rat pancreatic $\beta$-cells: different behaviour of granule motion between normal and Goto-Kakizaki diabetic rat $\beta$-cells. Biochem J, 381(Pt $1): 13-8.1 .5 .1,4.2 .3$

Ohara-Imaizumi, M., Nishiwaki, C., Nakamichi, Y., Kikuta, T., Nagai, S., and Nagamatsu, S. (2004b). Correlation of syntaxin-1 and SNAP-25 clusters with docking and fusion of insulin granules analysed by total internal reflection fluorescence microscopy. Diabetologia, 47(12):2200-7. 1.5.1

Olsen, H. L., Hoy, M., Zhang, W., Bertorello, A. M., Bokvist, K., Capito, K., Efanov, A. M., Meister, B., Thams, P., Yang, S. N., Rorsman, P., Berggren, P. O., and Gromada, J. (2003). Phosphatidylinositol 4-kinase serves as a metabolic sensor and regulates priming of secretory granules in pancreatic $\beta$ cells. Proc Natl Acad Sci US A, 100(9):5187-92. 1.3.3, 1.1

Orci, L., Gabbay, K. H., and Malaisse, W. J. (1972). Pancreatic $\beta$-cell web: its possible role in insulin secretion. Science, 175(26):1128-30. 1.3.3

Östenson, C.-G. (2000). The Goto-Kakizaki Rat. In Sima, A. A. F. and Shafrir, E., editors, Animal Models of Diabetes, pages 197-212. Taylor and Francis. 1.5.1, 1.5.1, $4.1,4.2 .1,4.2 .2$

Patton, C., Thompson, S., and Epel, D. (2004). Some precautions in using chelators to buffer metals in biological solutions. Cell Calcium, 35(5):427-31. 2.4 .2

Patton, G. S., Ipp, E., Dobbs, R. E., Orci, L., Vale, W., and Unger, R. H. (1977). Pancreatic immunoreactive somatostatin release. Proc Natl Acad Sci US A, $74(5): 2140-3.1 .2$ 
Peng, Y. Y. and Zucker, R. S. (1993). Release of LHRH is linearly related to the time integral of presynaptic $\mathrm{Ca} 2+$ elevation above a threshold level in bullfrog sympathetic ganglia. Neuron, 10(3):465-73. 3.2.2

Penner, R. and Neher, E. (1988). The role of calcium in stimulus-secretion coupling in excitable and non-excitable cells. J Exp Biol, 139:329-45. 1.6, 3.1.3

Pevsner, J., Hsu, S. C., and Scheller, R. H. (1994). n-Sec1: a neural-specific syntaxin-binding protein. Proc Natl Acad Sci U S A, 91(4):1445-9. 1.3.3

Pickup, J. C. and Williams, G. (2003). Textbook of diabetes. Blackwell Science, Malden, Mass., 3rd edition. 1.1, 1.4.1

Pipeleers, D., in't Veld, P. I., Maes, E., and Van De Winkel, M. (1982). Glucose-induced insulin release depends on functional cooperation between islet cells. Proc Natl Acad Sci U S A, 79(23):7322-5. 1.6, 4.1

Plant, T. D. (1988). Na+ currents in cultured mouse pancreatic B-cells. Pflugers Arch, 411(4):429-35. 3.1.2, 3.1.2

Portha, B. (2005). Programmed disorders of $\beta$-cell development and function as one cause for type 2 diabetes? The GK rat paradigm. Diabetes Metab Res Rev. 1.5.1, $1.5 .1,4.2 .3$

Portha, B., Giroix, M. H., Serradas, P., Gangnerau, M. N., Movassat, J., Rajas, F., Bailbe, D., Plachot, C., Mithieux, G., and Marie, J. C. (2001). $\beta$-cell function and viability in the spontaneously diabetic GK rat: information from the GK/Par colony. Diabetes, 50 Suppl 1:S89-93. 1.5.1, 4.2.2

Portha, B., Serradas, P., Bailbe, D., Suzuki, K., Goto, Y., and Giroix, M. H. (1991). $\beta$-cell insensitivity to glucose in the GK rat, a spontaneous nonobese model for type II diabetes. Diabetes, 40(4):486-91. 1.5.1

Prentki, M., Joly, E., El-Assaad, W., and Roduit, R. (2002). Malonyl-CoA signaling, lipid partitioning, and glucolipotoxicity: role in $\beta$-cell adaptation and failure in the etiology of diabetes. Diabetes, 51 Suppl 3:S405-13. 1.4.2

Pusch, M. and Neher, E. (1988). Rates of diffusional exchange between small cells and a measuring patch pipette. Pflugers Arch, 411(2):204-11. 3.1.2, 3.2.1, 4.1.2

Quesada, I., Nadal, A., and Soria, B. (1999). Different effects of tolbutamide and diazoxide in alpha, beta-, and delta-cells within intact islets of Langerhans. Diabetes, 48(12):2390-7. 4.2.1 
Quigley, R., Kennerly, D. A., Sheu, J. N., and Baum, M. (1995). Stimulation of proximal convoluted tubule phosphate transport by epidermal growth factor: signal transduction. Am J Physiol, 269(3 Pt 2):F339-44. 2.4.2

Rahier, J., Wallon, J., and Henquin, J. C. (1981). Cell populations in the endocrine pancreas of human neonates and infants. Diabetologia, 20(5):540-6. 1.2

Ravier, M. A. and Rutter, G. A. (2005). Glucose or insulin, but not zinc ions, inhibit glucagon secretion from mouse pancreatic alpha-cells. Diabetes, 54(6):1789-97. 1.2

Rees, D. A. and Alcolado, J. C. (2005). Animal models of diabetes mellitus. Diabet Med, 22(4):359-70. 4.1

Reetz, A., Solimena, M., Matteoli, M., Folli, F., Takei, K., and De Camilli, P. (1991). GABA and pancreatic $\beta$-cells: colocalization of glutamic acid decarboxylase (GAD) and GABA with synaptic-like microvesicles suggests their role in GABA storage and secretion. Embo J, 10(5):1275-84. 4.1.2

Renstrom, E., Eliasson, L., and Rorsman, P. (1997). Protein kinase A-dependent and -independent stimulation of exocytosis by cAMP in mouse pancreatic B-cells. $J$ Physiol, 502 ( Pt 1):105-18. 1.6, 3.1.3, 3.1.3

Rhodes, C. J. (2005). Type 2 diabetes-a matter of $\beta$-cell life and death? Science, 307(5708):380-4. 1.4.2

Rorsman, P. (1988). Two types of Ca2+ currents with different sensitivities to organic $\mathrm{Ca} 2+$ channel antagonists in guinea pig pancreatic alpha 2 cells. J Gen Physiol, $91(2): 243-54$. 1.3.1

Rorsman, P., Berggren, P. O., Bokvist, K., Ericson, H., Mohler, H., Ostenson, C. G., and Smith, P. A. (1989). Glucose-inhibition of glucagon secretion involves activation of GABAA-receptor chloride channels. Nature, 341(6239):233-6. 1.2

Rorsman, P., Eliasson, L., Renstrom, E., Gromada, J., Barg, S., and Göpel, S. (2000). The Cell Physiology of Biphasic Insulin Secretion. News Physiol Sci, 15:72-77. 1.3.5, 4.2.3

Rorsman, P. and Hellman, B. (1988). Voltage-activated currents in guinea pig pancreatic alpha 2 cells. Evidence for $\mathrm{Ca} 2+$-dependent action potentials. J Gen Physiol, 91(2):223-42. 1.3.1

Rorsman, P. and Renstrom, E. (2003). Insulin granule dynamics in pancreatic $\beta$ cells. Diabetologia, 46(8):1029-45. 1.3.5 
Rouiller, D., Schusdziarra, V., and Unger, R. H. (1981). Insulin inhibits somatostatin-like immunoreactivity release stimulated by intragastric $\mathrm{HCl}$. Diabetes, 30(9):735-8. 1.2

Sakaba, T., Stein, A., Jahn, R., and Neher, E. (2005). Distinct kinetic changes in neurotransmitter release after SNARE protein cleavage. Science, 309(5733):491-4. 4.2.3

Salomon, D. and Meda, P. (1986). Heterogeneity and contact-dependent regulation of hormone secretion by individual B cells. Exp Cell Res, 162(2):507-20. 1.6

Samols, E., Marri, G., and Marks, V. (1966). Interrelationship of glucagon, insulin and glucose. The insulinogenic effect of glucagon. Diabetes, 15(12):855-66. 1.2

Samols, E. and Stagner, J. I. (1988). Intra-islet regulation. Am J Med, 85(5A):31-5. $1.2,4.2 .3$

Santos, R. M., Rosario, L. M., Nadal, A., Garcia-Sancho, J., Soria, B., and Valdeolmillos, M. (1991). Widespread synchronous [Ca2+]i oscillations due to bursting electrical activity in single pancreatic islets. Pflugers Arch, 418(4):417-22. $1.2,4.1 .1$

Sato, Y., Aizawa, T., Komatsu, M., Okada, N., and Yamada, T. (1992). Dual functional role of membrane depolarization/Ca2 + influx in rat pancreatic B-cell. Diabetes, 41(4):438-43. 1.3.2

Sedej, S., Rose, T., and Rupnik, M. (2005). cAMP increases Ca2+-dependent exocytosis through both PKA and Epac2 in mouse melanotrophs from pituitary tissue slices. J Physiol, 567(Pt 3):799-813. 1.5.1

Sedej, S., Tsujimoto, T., Zorec, R., and Rupnik, M. (2004). Voltage-activated Ca(2+) channels and their role in the endocrine function of the pituitary gland in newborn and adult mice. J Physiol, 555(Pt 3):769-82. 3.2.1

Serre-Beinier, V., Le Gurun, S., Belluardo, N., Trovato-Salinaro, A., Charollais, A., Haefliger, J. A., Condorelli, D. F., and Meda, P. (2000). Cx36 preferentially connects $\beta$-cells within pancreatic islets. Diabetes, 49(5):727-34. 1.2

Seward, E. P. and Nowycky, M. C. (1996). Kinetics of stimulus-coupled secretion in dialyzed bovine chromaffin cells in response to trains of depolarizing pulses. $J$ Neurosci, 16(2):553-62. 4.2.3 
Sherman, A., Rinzel, J., and Keizer, J. (1988). Emergence of organized bursting in clusters of pancreatic beta-cells by channel sharing. Biophys J, 54(3):411-25. 4.1.1

Sheu, L., Pasyk, E. A., Ji, J., Huang, X., Gao, X., Varoqueaux, F., Brose, N., and Gaisano, H. Y. (2003). Regulation of insulin exocytosis by Munc13-1. J Biol Chem, 278(30):27556-63. 1.3.3, 1.5.1, 1.1, 4.2.3

Sieradzki, J., Schatz, H., Nierle, C., and Pfeiffer, E. F. (1975). Somatostatin-induced inhibition of insulin secretion from isolated islets of rat pancreas in presence of glucagon. Horm Metab Res, 7(4):284-7. 4.2.3

Sima, A. A. F. and Shafrir, E., editors (2000). Animal Models of Diabetes. Taylor and Francis Routledge, Amsterdam. 4.1

Slack, J. M. (1995). Developmental biology of the pancreas. Development, 121(6):1569-80. 1.2

Smith, C. (1999). A persistent activity-dependent facilitation in chromaffin cells is caused by Ca2+ activation of protein kinase C. J Neurosci, 19(2):589-98. 3.2.2

Smith, C., Moser, T., Xu, T., and Neher, E. (1998). Cytosolic Ca2+ acts by two separate pathways to modulate the supply of release-competent vesicles in chromaffin cells. Neuron, 20(6):1243-53. 1.3.3

Smith, C. and Neher, E. (1997). Multiple forms of endocytosis in bovine adrenal chromaffin cells. J Cell Biol, 139(4):885-94. 3.1.3, 4.1.2

Smith, P. A., Proks, P., and Ashcroft, F. M. (1999). Quantal analysis of 5-hydroxytryptamine release from mouse pancreatic beta-cells. J Physiol, $521 \mathrm{Pt}$ 3:651-64. 4.1.2

Smolen, P., Rinzel, J., and Sherman, A. (1993). Why pancreatic islets burst but single $\beta$ cells do not. The heterogeneity hypothesis. Biophys J, 64(6):1668-80. 4.1.1

Sø rensen, J. B. (2004). Formation, stabilisation and fusion of the readily releasable pool of secretory vesicles. Pfugers Arch, 448(4):347-62. 4.2.3

Sø rensen, J. B., Matti, U., Wei, S. H., Nehring, R. B., Voets, T., Ashery, U., Binz, T., Neher, E., and Rettig, J. (2002). The SNARE protein SNAP-25 is linked to fast calcium triggering of exocytosis. Proc Natl Acad Sci U S A, 99(3):1627-32. 4.2.3 
Sollner, T., Bennett, M. K., Whiteheart, S. W., Scheller, R. H., and Rothman, J. E. (1993a). A protein assembly-disassembly pathway in vitro that may correspond to sequential steps of synaptic vesicle docking, activation, and fusion. Cell, 75(3):409-18. 1.3.3

Sollner, T., Whiteheart, S. W., Brunner, M., Erdjument-Bromage, H., Geromanos, S., Tempst, P., and Rothman, J. E. (1993b). SNAP receptors implicated in vesicle targeting and fusion. Nature, 362(6418):318-24. 1.3.3

Sondergaard, L. G., Stoltenberg, M., Flyvbjerg, A., Brock, B., Schmitz, O., Danscher, G., and Rungby, J. (2003). Zinc ions in $\beta$-cells of obese, insulin-resistant, and type 2 diabetic rats traced by autometallography. Apmis, 111(12):1147-54. 4.1.2

Song, J. C., Rangachari, P. K., and Matthews, J. B. (2002). Opposing effects of PKCalpha and PKCepsilon on basolateral membrane dynamics in intestinal epithelia. Am J Physiol Cell Physiol, 283(5):C1548-56. 4.2.3

Speidel, D., Bruederle, C. E., Enk, C., Voets, T., Varoqueaux, F., Reim, K., Becherer, U., Fornai, F., Ruggieri, S., Holighaus, Y., Weihe, E., Bruns, D., Brose, N., and Rettig, J. (2005). CAPS1 regulates catecholamine loading of large dense-core vesicles. Neuron, 46(1):75-88. 1.3.3

Speier, S. and Rupnik, M. (2003). A novel approach to in situ characterization of pancreatic $\beta$-cells. Pflugers Arch, 446(5):553-8. 1.6, 2.5, 3.1.1, 3.1.2, 3.1.3, 4.1, 4.1 .1

Speier, S., Yang, S. B., Sroka, K., Rose, T., and Rupnik, M. (2005). KATP-channels in $\beta$-cells in tissue slices are directly modulated by millimolar ATP. Mol Cell Endocrinol, 230(1-2):51-8. 3.1.2, 3.1.2, 4.1.1, 4.2.2

Spurlin, B. A. and Thurmond, D. C. (2005). Syntaxin 4 Facilitates Biphasic Glucose-Stimulated Insulin Secretion From Pancreatic $\beta$-Cells. Mol Endocrinol. 1.1

Srinivas, M., Rozental, R., Kojima, T., Dermietzel, R., Mehler, M., Condorelli, D. F., Kessler, J. A., and Spray, D. C. (1999). Functional properties of channels formed by the neuronal gap junction protein connexin36. J Neurosci, 19(22):9848-55. 1.2

Stagner, J. I., Samols, E., Koerker, D. J., and Goodner, C. J. (1992). Perfusion with anti-insulin gamma globulin indicates a $\mathrm{B}$ to $\mathrm{A}$ to $\mathrm{D}$ cellular perfusion sequence in the pancreas of the rhesus monkey, Macaca mulatta. Pancreas, 7(1):26-9. 1.2

Stefan, Y., Meda, P., Neufeld, M., and Orci, L. (1987). Stimulation of insulin secretion reveals heterogeneity of pancreatic B cells in vivo. J Clin Invest, 80(1):175-83. 4.1 
Straub, S. G., Cosgrove, K. E., Ammala, C., Shepherd, R. M., O’Brien, R. E., Barnes, P. D., Kuchinski, N., Chapman, J. C., Schaeppi, M., Glaser, B., Lindley, K. J., Sharp, G. W., Aynsley-Green, A., and Dunne, M. J. (2001). Hyperinsulinism of infancy: the regulated release of insulin by KATP channel-independent pathways. Diabetes, 50(2):329-39. 1.3.2

Straub, S. G., Shanmugam, G., and Sharp, G. W. (2004). Stimulation of insulin release by glucose is associated with an increase in the number of docked granules in the $\beta$-cells of rat pancreatic islets. Diabetes, 53(12):3179-83. 1.3.3, 1.3.3, 1.3.5, 3.1.3, 4.2.2

Straub, S. G. and Sharp, G. W. (2002). Glucose-stimulated signaling pathways in biphasic insulin secretion. Diabetes Metab Res Rev, 18(6):451-63. 1.3.5

Straub, S. G. and Sharp, G. W. (2004). Hypothesis: one rate-limiting step controls the magnitude of both phases of glucose-stimulated insulin secretion. Am J Physiol Cell Physiol, 287(3):C565-71. 4.1.2

Strowski, M. Z., Parmar, R. M., Blake, A. D., and Schaeffer, J. M. (2000).

Somatostatin inhibits insulin and glucagon secretion via two receptors subtypes: an in vitro study of pancreatic islets from somatostatin receptor 2 knockout mice. Endocrinology, 141(1):111-7. 1.2

Strubbe, J. H. and Steffens, A. B. (1975). Rapid insulin release after ingestion of a meal in the unanesthetized rat. Am J Physiol, 229(4):1019-22. 1.2

Sugita, S., Shin, O. H., Han, W., Lao, Y., and Sudhof, T. C. (2002). Synaptotagmins form a hierarchy of exocytotic $\mathrm{Ca}(2+)$ sensors with distinct $\mathrm{Ca}(2+)$ affinities. Embo J, 21(3):270-80. 1.3.3

Sussman, K. E., Vaughan, G. D., and Timmer, R. F. (1966). An in vitro method for studying insulin secretion in the perfused isolated rat pancreas. Metabolism, 15(5):466-76. 1.6

Svensson, A. M., Ostenson, C. G., Bodin, B., and Jansson, L. (2005). Lack of compensatory increase in islet blood flow and islet mass in GK rats following 60\% partial pancreatectomy. J Endocrinol, 184(2):319-27. 3.1.1, 4.2.3

Svensson, A. M., Ostenson, C. G., and Jansson, L. (2000). Age-induced changes in pancreatic islet blood flow: evidence for an impaired regulation in diabetic GK rats. Am J Physiol Endocrinol Metab, 279(5):E1139-44. 3.2.1 
Taguchi, N., Aizawa, T., Sato, Y., Ishihara, F., and Hashizume, K. (1995). Mechanism of glucose-induced biphasic insulin release: physiological role of adenosine triphosphate-sensitive $\mathrm{K}+$ channel-independent glucose action. Endocrinology, 136(9):3942-8. 1.3.5

Takahashi, N., Kadowaki, T., Yazaki, Y., Miyashita, Y., and Kasai, H. (1997). Multiple exocytotic pathways in pancreatic $\beta$ cells. J Cell Biol, 138(1):55-64. 1.3.3, 4.1.2

TerBush, D. R., Maurice, T., Roth, D., and Novick, P. (1996). The Exocyst is a multiprotein complex required for exocytosis in Saccharomyces cerevisiae. Embo J, 15(23):6483-94. 1.3.3

Theis, M., Mas, C., Doring, B., Degen, J., Brink, C., Caille, D., Charollais, A., Kruger, O., Plum, A., Nepote, V., Herrera, P., Meda, P., and Willecke, K. (2004).

Replacement by a lac $Z$ reporter gene assigns mouse connexin36, 45 and 43 to distinct cell types in pancreatic islets. Exp Cell Res, 294(1):18-29. 1.2

Thomas-Reetz, A. C. and De Camilli, P. (1994). A role for synaptic vesicles in non-neuronal cells: clues from pancreatic $\beta$ cells and from chromaffin cells. Faseb J, 8(2):209-16. 4.1.2

Tokuyama, T., Yagui, K., Yamaguchi, T., Huang, C. I., Kuramoto, N., Shimada, F., Miyazaki, J., Horie, H., Saito, Y., Makino, H., and Kanatsuka, A. (1997). Expression of human islet amyloid polypeptide/amylin impairs insulin secretion in mouse pancreatic $\beta$ cells. Metabolism, 46(9):1044-51. 1.2

Toullec, D., Pianetti, P., Coste, H., Bellevergue, P., Grand-Perret, T., Ajakane, M., Baudet, V., Boissin, P., Boursier, E., Loriolle, F., and et al. (1991). The bisindolylmaleimide GF $109203 \mathrm{X}$ is a potent and selective inhibitor of protein kinase C. J Biol Chem, 266(24):15771-81. 3.2.2

Tourrel, C., Bailbe, D., Lacorne, M., Meile, M. J., Kergoat, M., and Portha, B. (2002). Persistent improvement of type 2 diabetes in the Goto-Kakizaki rat model by expansion of the $\beta$-cell mass during the prediabetic period with glucagon-like peptide-1 or exendin-4. Diabetes, 51(5):1443-52. 4.2.2

Trimble, E. R., Halban, P. A., Wollheim, C. B., and Renold, A. E. (1982). Functional differences between rat islets of ventral and dorsal pancreatic origin. J Clin Invest, 69(2):405-13. 4.1

Tsuboi, T., McMahon, H. T., and Rutter, G. A. (2004). Mechanisms of dense core vesicle recapture following "kiss and run" ("cavicapture") exocytosis in insulin-secreting cells. J Biol Chem, 279(45):47115-24. 1.3.3 
Tsuboi, T., Ravier, M. A., Xie, H., Ewart, M. A., Gould, G. W., Baldwin, S. A., and Rutter, G. A. (2005). Mammalian exocyst complex is required for the docking step of insulin vesicle exocytosis. J Biol Chem, 280(27):25565-70. 1.3.3

Tsuboi, T. and Rutter, G. A. (2003). Insulin secretion by 'kiss-and-run' exocytosis in clonal pancreatic islet $\beta$-cells. Biochem Soc Trans, 31(Pt 4):833-6. 1.3.3

Tsunoda, K., Sanke, T., Nakagawa, T., Furuta, H., and Nanjo, K. (2001). Single nucleotide polymorphism (D68D, T to C) in the syntaxin $1 \mathrm{~A}$ gene correlates to age at onset and insulin requirement in Type II diabetic patients. Diabetologia, 44(11):2092-7. 1.4.2

Tucker, W. C. and Chapman, E. R. (2002). Role of synaptotagmin in Ca2+-triggered exocytosis. Biochem J, 366(Pt 1):1-13. 1.3.3

UKPDS (1998). Intensive blood-glucose control with sulphonylureas or insulin compared with conventional treatment and risk of complications in patients with type 2 diabetes (UKPDS 33). UK Prospective Diabetes Study (UKPDS) Group. Lancet, 352(9131):837-53. 1.4.2

Vaag, A., Henriksen, J. E., Madsbad, S., Holm, N., and Beck-Nielsen, H. (1995). Insulin secretion, insulin action, and hepatic glucose production in identical twins discordant for non-insulin-dependent diabetes mellitus. J Clin Invest, 95(2):690-8. 1.4 .2

van Haeften, T. W., Dubbeldam, S., Zonderland, M. L., and Erkelens, D. W. (1998). Insulin secretion in normal glucose-tolerant relatives of type 2 diabetic subjects. Assessments using hyperglycemic glucose clamps and oral glucose tolerance tests. Diabetes Care, 21(2):278-82. 1.4.2

Vikman, J., Ma, X., Tagaya, M., and Eliasson, L. (2003). Requirement for N-ethylmaleimide-sensitive factor for exocytosis of insulin-containing secretory granules in pancreatic $\beta$-cells. Biochem Soc Trans, 31(Pt 4):842-7. 1.1

Voets, T., Neher, E., and Moser, T. (1999). Mechanisms underlying phasic and sustained secretion in chromaffin cells from mouse adrenal slices. Neuron, 23(3):607-15. 1.3.3, 3.2.2

Von Mering, J. and Minkowski, O. (1890). Diabetes mellitus nach Pankreasextirpation. Arch Exper Path Pharm Leipzig, 26:371-387. 1.2, 1.5 
Wallace, K. J., Wallis, R. H., Collins, S. C., Argoud, K., Kaisaki, P. J., Ktorza, A., Woon, P. Y., Bihoreau, M. T., and Gauguier, D. (2004). Quantitative trait locus dissection in congenic strains of the Goto-Kakizaki rat identifies a region conserved with diabetes loci in human chromosome 1q. Physiol Genomics, 19(1):1-10. 1.5.1

Wan, Q. F., Dong, Y., Yang, H., Lou, X., Ding, J., and Xu, T. (2004). Protein kinase activation increases insulin secretion by sensitizing the secretory machinery to $\mathrm{Ca} 2+$. J Gen Physiol, 124(6):653-62. 1.3.3, 4.2.3

Wang, L., Bhattacharjee, A., Fu, J., and Li, M. (1996). Abnormally expressed low-voltage-activated calcium channels in $\beta$-cells from NOD mice and a related clonal cell line. Diabetes, 45(12):1678-83. 4.2.1

Waselle, L., Gerona, R. R., Vitale, N., Martin, T. F., Bader, M. F., and Regazzi, R. (2005). Role of phosphoinositide signaling in the control of insulin exocytosis. Mol Endocrinol. 1.3.3

Weber, T., Zemelman, B. V., McNew, J. A., Westermann, B., Gmachl, M., Parlati, F., Sollner, T. H., and Rothman, J. E. (1998). SNAREpins: minimal machinery for membrane fusion. Cell, 92(6):759-72. 1.3.3

Westerlund, J. and Bergsten, P. (2001). Glucose metabolism and pulsatile insulin release from isolated islets. Diabetes, 50(8):1785-90. 1.6

Wheeler, M. B., Sheu, L., Ghai, M., Bouquillon, A., Grondin, G., Weller, U., Beaudoin, A. R., Bennett, M. K., Trimble, W. S., and Gaisano, H. Y. (1996). Characterization of SNARE protein expression in $\beta$ cell lines and pancreatic islets. Endocrinology, 137(4):1340-8. 1.1

Wiser, O., Bennett, M. K., and Atlas, D. (1996). Functional interaction of syntaxin and SNAP-25 with voltage-sensitive L- and N-type Ca2+ channels. Embo J, 15(16):4100-10. 4.2.1

Wong, A. H., Trakalo, J., Likhodi, O., Yusuf, M., Macedo, A., Azevedo, M. H., Klempan, T., Pato, M. T., Honer, W. G., Pato, C. N., Van Tol, H. H., and Kennedy, J. L. (2004). Association between schizophrenia and the syntaxin 1A gene. Biol Psychiatry, 56(1):24-9. 1.4.2

Wu, X. S. and Wu, L. G. (2001). Protein kinase c increases the apparent affinity of the release machinery to $\mathrm{Ca} 2+$ by enhancing the release machinery downstream of the Ca2+ sensor. J Neurosci, 21(20):7928-36. 4.2.3 
Xu, T., Ashery, U., Burgoyne, R. D., and Neher, E. (1999). Early requirement for alpha-SNAP and NSF in the secretory cascade in chromaffin cells. Embo J, 18(12):3293-304. 1.3.3

Yalow, R. S. and Berson, S. A. (1959). Assay of plasma insulin in human subjects by immunological methods. Nature, 184 (Suppl 21):1648-9. 1.6

Yang, S. B., Proks, P., Ashcroft, F. M., and Rupnik, M. (2004). Inhibition of ATP-sensitive potassium channels by haloperidol. Br J Pharmacol, 143(8):960-7. 3.1 .2

Yang, S. N. and Berggren, P. O. (2005). $\beta$-cell CaV channel regulation in physiology and pathophysiology. Am J Physiol Endocrinol Metab, 288(1):E16-28. 1.3.1

Yang, Y. and Gillis, K. D. (2004). A highly Ca2+-sensitive pool of granules is regulated by glucose and protein kinases in insulin-secreting INS-1 cells. J Gen Physiol, 124(6):641-51. 1.3.3, 4.2.3

Yang, Y., Udayasankar, S., Dunning, J., Chen, P., and Gillis, K. D. (2002). A highly $\mathrm{Ca} 2+-$ sensitive pool of vesicles is regulated by protein kinase $\mathrm{C}$ in adrenal chromaffin cells. Proc Natl Acad Sci U S A, 99(26):17060-5. 1.3.3

Yedovitzky, M., Mochly-Rosen, D., Johnson, J. A., Gray, M. O., Ron, D., Abramovitch, E., Cerasi, E., and Nesher, R. (1997). Translocation inhibitors define specificity of protein kinase $\mathrm{C}$ isoenzymes in pancreatic $\beta$-cells. J Biol Chem, 272(3):1417-20. 1.3.4

Yeoman, M. S., Brezden, B. L., and Benjamin, P. R. (1999). LVA and HVA Ca(2+) currents in ventricular muscle cells of the Lymnaea heart. J Neurophysiol, 82(5):2428-40. 3.2.1

Zaitsev, S., Efanova, I., Ostenson, C. G., Efendic, S., and Berggren, P. O. (1997). Delayed Ca2+ response to glucose in diabetic GK rat. Biochem Biophys Res Commun, 239(1):129-33. 3.2.1, 4.1, 4.2.3

Zawalich, W. S., Bonnet-Eymard, M., Zawalich, K. C., and Yaney, G. C. (1998). Chronic exposure to TPA depletes PKCalpha and augments Ca-dependent insulin secretion from cultured rat islets. Am J Physiol Cell Physiol, 274(5):C1388-1396. 1.6, 4.2 .3

Zawalich, W. S. and Zawalich, K. C. (1996a). Regulation of insulin secretion by phospholipase C. Am J Physiol, 271(3 Pt 1):409-16. 1.3.4, 1.5 
Zawalich, W. S. and Zawalich, K. C. (1996b). Species differences in the induction of time-dependent potentiation of insulin secretion. Endocrinology, 137(5):1664-9. 1.5

Zawalich, W. S. and Zawalich, K. C. (2001). Effects of protein kinase C inhibitors on insulin secretory responses from rodent pancreatic islets. Mol Cell Endocrinol, 177(1-2):95-105. 1.3.4, 4.2.3

Zhang, H., Nagasawa, M., Yamada, S., Mogami, H., Suzuki, Y., and Kojima, I. (2004). Bimodal role of conventional protein kinase $\mathrm{C}$ in insulin secretion from rat pancreatic $\beta$ cells. J Physiol, 561(Pt 1):133-47. 1.3.4, 3.2.2, 4.2.3

Zhang, M., Goforth, P., Bertram, R., Sherman, A., and Satin, L. (2003). The Ca2+ dynamics of isolated mouse $\beta$-cells and islets: implications for mathematical models. Biophys J, 84(5):2852-70. 1.6, 4.1.1

Zhang, W., Khan, A., Ostenson, C. G., Berggren, P. O., Efendic, S., and Meister, B. (2002). Down-regulated expression of exocytotic proteins in pancreatic islets of diabetic GK rats. Biochem Biophys Res Commun, 291(4):1038-44. 1.5.1, 1.1, 4.2.1, 4.2 .3

Zorec, R., Sikdar, S. K., and Mason, W. T. (1991). Increased cytosolic calcium stimulates exocytosis in bovine lactotrophs. Direct evidence from changes in membrane capacitance. J Gen Physiol, 97(3):473-97. 3.2.1 


\section{Curriculum Vitae}

\section{Personal details}

Name

Nationality

Date and place of birth

\section{School education}

August 1982-June 1986

August 1986-June 1995

\section{University education}

October 1995-June 2002

November 2002-January 2006

\section{Honors / Awards}

February 1994

July 2003-November 2005

\section{Further scientific training}

June-August 2005
Tobias Rose

German

05.07.1976, Warburg, Germany

Katholische Grundschule Borgholz, Germany

Städt. Gymnasium Beverungen, Germany

Biologie / Germanistik (Sekundarstufe II)

Georg-August-Universität Göttingen, Germany

Examination thesis:

Zoological Institute, Göttingen, Germany

Department of Cell Biology, Prof. Dr. Michael Hörner "Electrophysiological and pharmacological studies on the excitability-control of spontaneously active neurons of the medicinal leech Hirudo medicinalis"

$\mathrm{PhD}$ student

European Neuroscience Institute, Göttingen, Germany Neuroendocrinology group, Prof. Dr. Marjan Rupnik "Stimulus-secretion coupling in pancreatic $\beta$-cells of healthy and diabetic rats in tissue slice preparation"

Biology award of the German young researchers competition (regional level)

PhD scholarship of the Boehringer Ingelheim Fonds

Summer course "Neurobiology", Woods Hole, USA 


\section{Publications}

Speier S, Yang S, Sroka T, Rose T, Rupnik M (2005): $\mathrm{K}_{\mathrm{ATP}}$-Channels in $\beta$-cells in tissue slices are directly modulated by millimolar ATP. Mol. Cell. Endocrinol., 230(1-2):51-58

Sedej S, Rose T, Rupnik M (2005): cAMP increases $\mathrm{Ca}^{2+}$-dependent exocytosis through both PKA and Epac2 in mouse melanotrophs from pituitary tissue slices. J Physiol., 567(3):799-813

Rose T, Rupnik M: $\mathrm{Ca}^{2+}$-secretion coupling of pancreatic $\beta$-cells is impaired in diabetic Goto Kakizaki rats. submitted

Rose T, Rupnik, M: Electrophysiological characterization of rat pancreatic $\beta$-cells in tissue slice preparation. in preparation

Rose T, Hörner M: Activity-dependent suppression of spontaneous spike generation in the Retzius neurons of the leech Hirudo medicinalis. to be submitted

\section{Poster presentations}

Rose T, Rupnik M (2005): $\mathrm{Ca}^{2+}$-secretion coupling in $\beta$-cells of healthy and diabetic rats. Biophys J, 88(1), print suppl. annual meeting abstracts:111a Biophysical Society Meeting, Long Beach, USA, February 2005

Rose T, Rupnik M (2005): $\mathrm{Ca}^{2+}$-secretion coupling in $\beta$-cells of healthy and diabetic rats. Proc. 30th Göttingen Neurobiol. Conf., Spektrum-Verlag, Goettingen, p. 1166.

Göttingen Neurobiology Conference, Göttingen, Germany, March 2005

Rose T, Rupnik M (2005): $\mathrm{Ca}^{2+}$-secretion coupling in $\beta$-cells of healthy and diabetic rats. Neurizons, Göttingen, Germany, November 2004

Rose T, Hörner M (2003): Activity-dependent suppression of spontaneous spike generation in the Retzius neurons of the leech Hirudo medicinalis. Proc. 29th Göttingen Neurobiol. Conf., Thieme, Stuttgart, New York, 765:798-799

Göttingen Neurobiology Conference, Göttingen, Germany, June 2003

\section{Oral presentations}

Rose T, Rupnik M (2005): $\mathrm{Ca}^{2+}$-secretion coupling in $\beta$-cells of healthy and diabetic rats. $12^{\text {th }}$ Young Neuroscientists Meeting, Lipica, Slovenia, May 2005

Rose T, Rupnik M (2005): $\mathrm{Ca}^{2+}{ }_{-}$-secretion coupling in $\beta$-cells of healthy and diabetic rats. $8^{\text {th }}$ Islet Workshop, Goslar, Germany, April 2005

Rose T, Rupnik M (2005): $\mathrm{Ca}^{2+}$-secretion coupling in $\beta$-cells of healthy and diabetic rats. Growbeta Final Meeting, Göttingen, Germany, November 2004 


\section{Acknowledgements}

I would like to thank Prof. Dr. Marjan Rupnik for his encouragement, constant support and for giving me the opportunity to learn as much as I did during my time in his group.

I am also much obliged to Prof. Erwin Neher, Prof. Michael Hörner and Dr. Jakob Sørensen for their support as my thesis committee. I am especially indebted to Prof. Neher for his assistance and seminal advice.

Furthermore, I would like to thank everybody from the neuroendocrinology group in special and from the old ENI in general — it was great for as long as it lasted! Especially Stephan, Simon and Robert need to be mentioned separately for being supportive in professional as well as recreational ways ...

Special thanks also goes to Marion and Heiko—-the best TAs far and wide!

Finally, I would like to thank the Boehringer Ingelheim Fonds for supporting me throughout my time as a $\mathrm{PhD}$ student.

This dissertation is dedicated to Andrea. 